\title{
Cyclic Dipeptide-Guided Aggregation-Induced Emission of Naphthalimide and Its Application for the Detection of Phenolic Drugs
}

Chenikkayala Balachandra and Thimmaiah Govindaraju*

Bioorganic Chemistry Laboratory, New Chemistry Unit and The School of Advanced Materials (SAMat), Jawaharlal Nehru Centre for Advanced Scientific Research, Jakkur P.O., Bengaluru-560064, Karnataka, India.

\section{Contents}

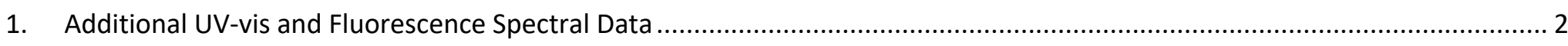

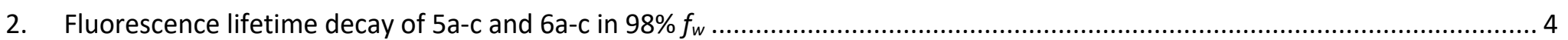

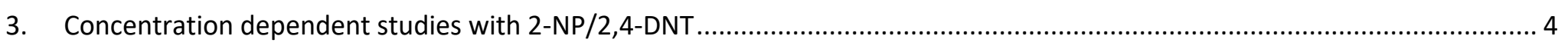

4. Fluorescence response of 4 a against commercially available drugs in water and concentration dependent studies ................. 5

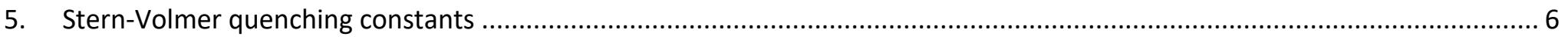

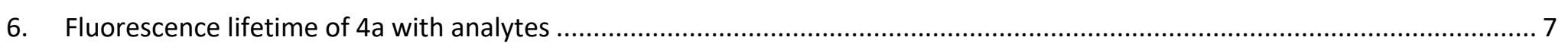

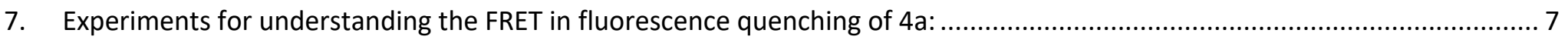

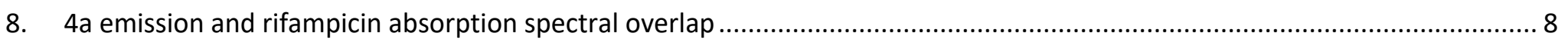

9. Time dependent fluorescence studies of 4 a aggregates towards 2,4-DNT, 2-NP and PA: ................................................. 8

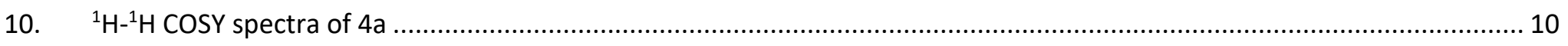

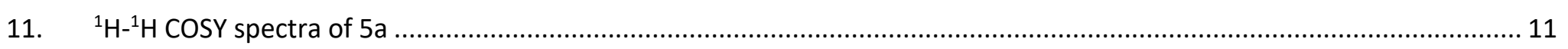

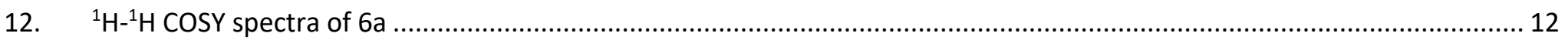

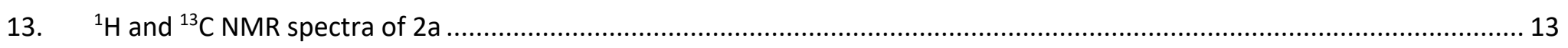

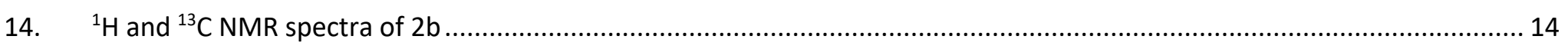

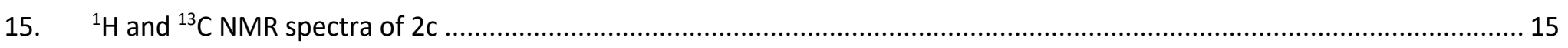

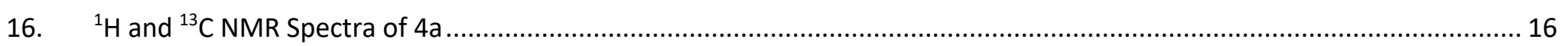

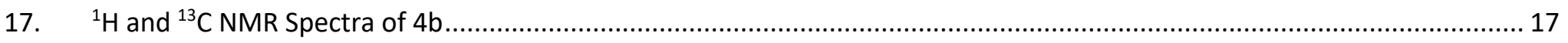

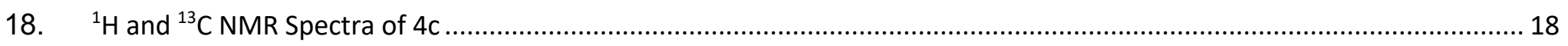

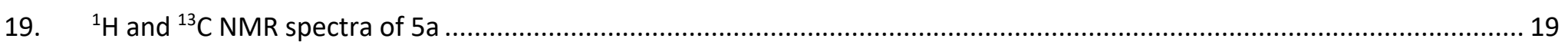

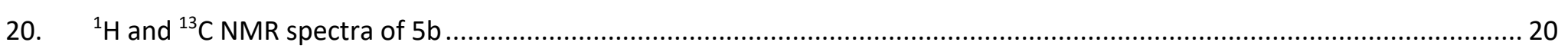

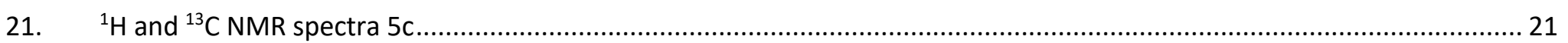

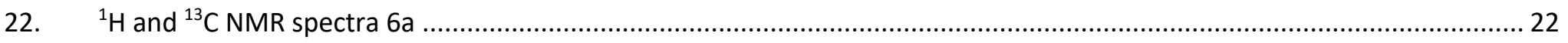

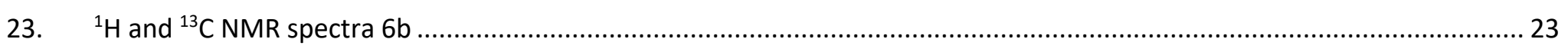

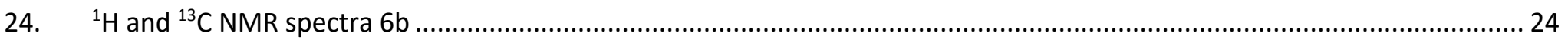

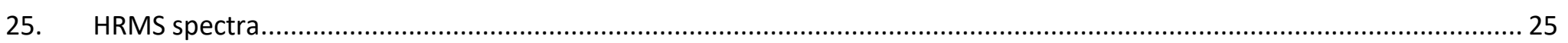




\section{Additional UV-vis and Fluorescence Spectral Data}

A

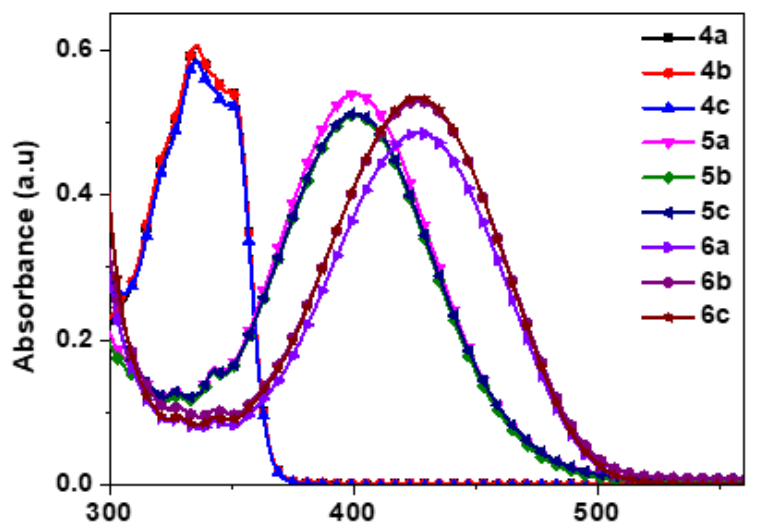

C

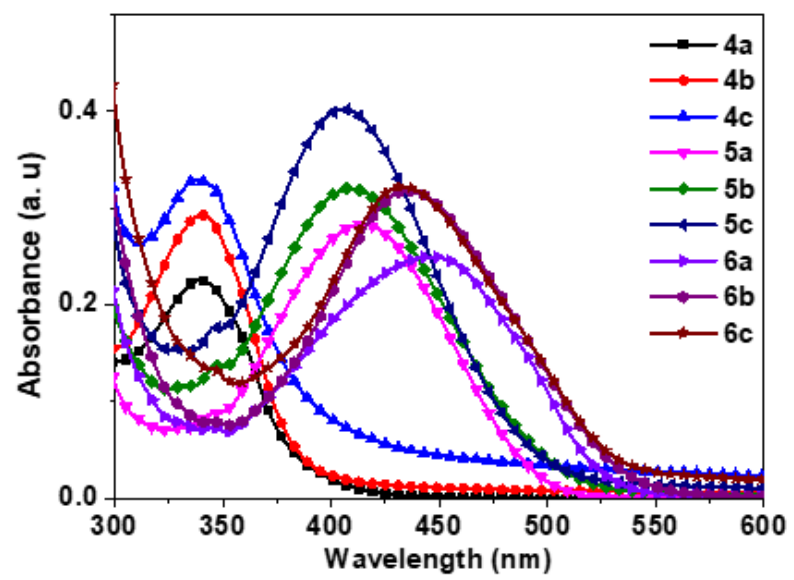

B
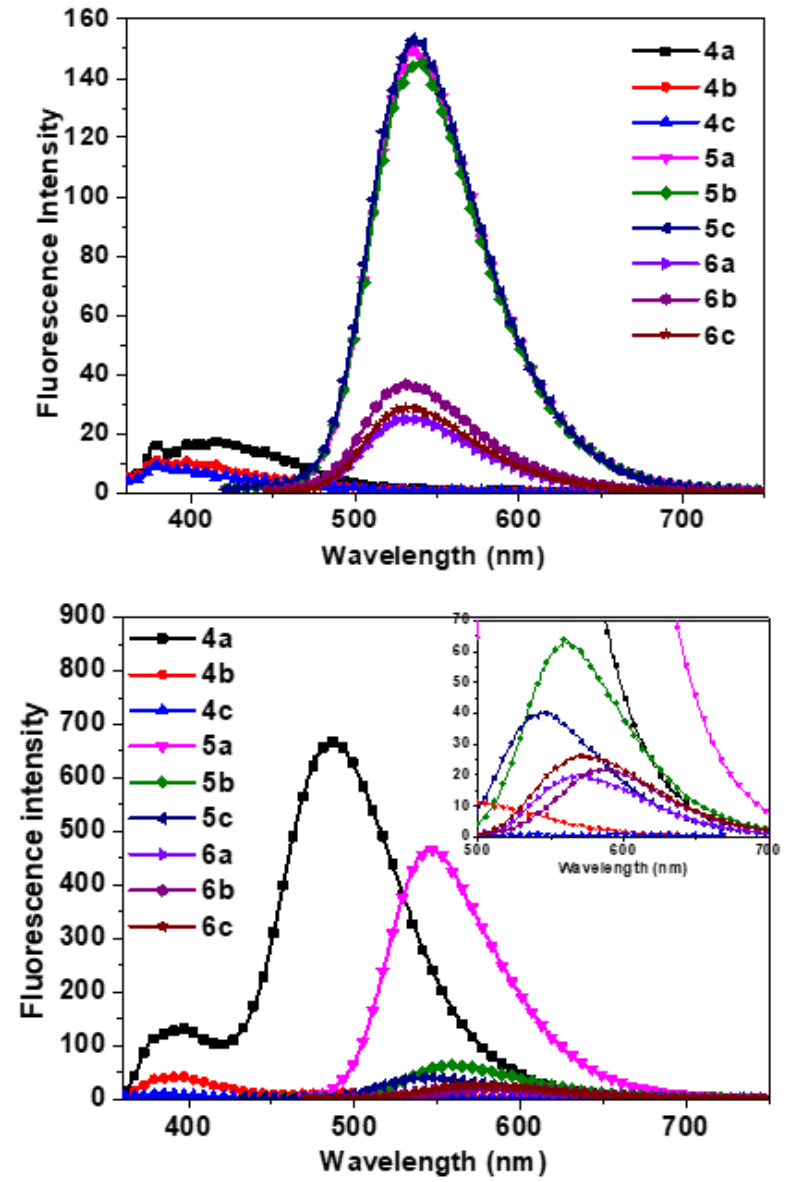

Figure S1. A\&B) Absorption and emission spectra of CDP- NI $(50 \mu \mathrm{M})$ derivatives in DMSO. C\&D) Absorption and emission spectra of CDP-NI $(50 \mu \mathrm{M})$ derivatives in $98 f_{w}(98: 2$; water:DMSO (v/v)).

A

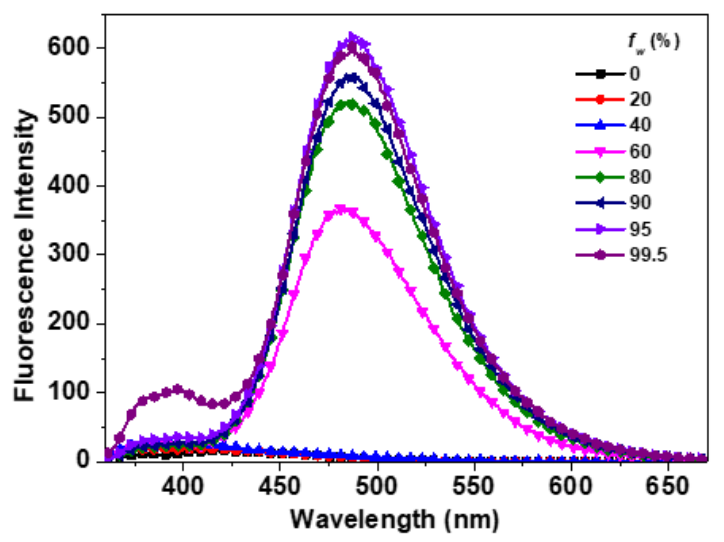

B

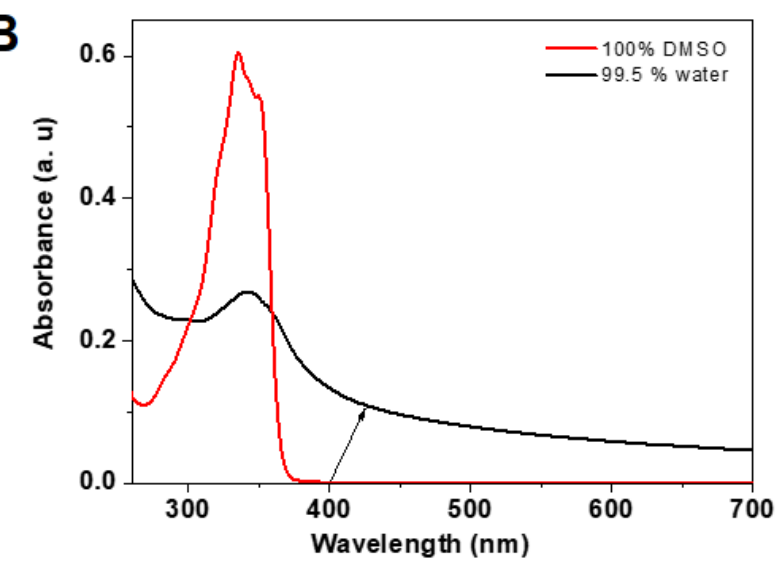

Figure S2. A) Emission spectra of $4 \mathbf{a}$ at different water fractions (0-99.5\%) at $50 \mu \mathrm{M}$ in phosphate buffered saline (PBS, $10 \mathrm{mM}, \mathrm{pH} 7.4)$. B) Absorbance spectra of $4 \mathbf{a}$ in DMSO (100\%) and in $99.5 \% f_{w}$. 
A

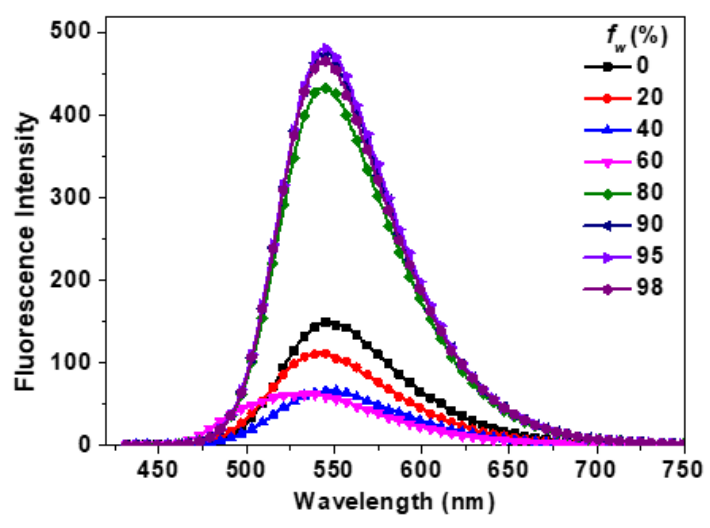

B

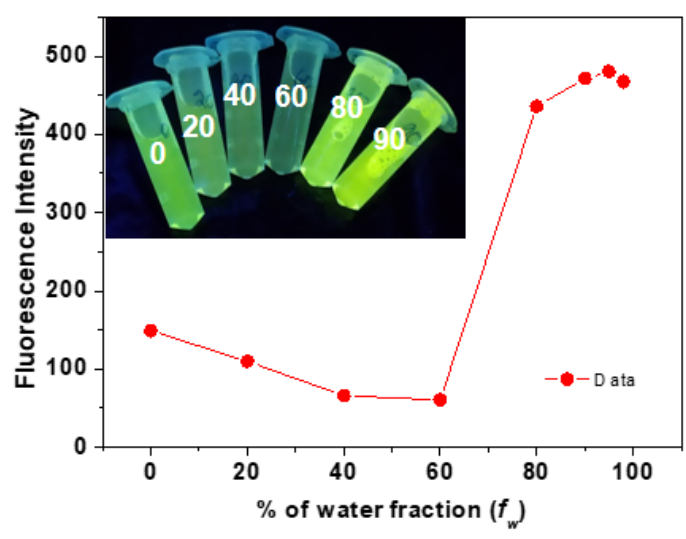

Figure S3. A) Emission spectra of 5a at different water fractions (0-98\%) at $50 \mu \mathrm{M}$ in water. B) Plot of fluorescence intensity vs water fraction $\left(0-98 \% f_{w}\right)$ inset: digital photograph under hand held UV lamp (365 $\left.\mathrm{nm}\right)$.

\begin{tabular}{|c|c|c|c|c|c|c|c|}
\hline & $\begin{array}{c}\lambda_{\text {abs.max }}(\mathrm{nm}) \\
(\mathrm{DMSO})\end{array}$ & $\begin{array}{l}\text { Molar extinction } \\
\text { co-efficient in } \\
\text { DMSO } \\
\varepsilon\left(1 \mathrm{M}^{-1} \mathrm{~cm}^{-1}\right)^{\mathrm{a}} \\
\end{array}$ & $\begin{array}{c}\lambda_{\text {em.max }} \\
(\mathrm{DMSO})\end{array}$ & $\begin{array}{c}\lambda_{\text {abs.max }}(\mathrm{nm}) \\
\left(98 \% f_{w}\right)\end{array}$ & $\begin{array}{c}\lambda_{\text {em.max }} \\
\left(98 \% f_{w}\right)\end{array}$ & $\tau(\mathrm{ns})^{\mathrm{c}}$ & $\varphi_{\mathrm{f}}$ \\
\hline $4 a$ & 335,350 & 11680 & $413^{b}$ & 341 & 486 & $29.1^{d}$ & $13 \%$ \\
\hline $4 b$ & 335,350 & 12100 & $396^{b}$ & 341 & $393^{b}$ & nd & - \\
\hline $4 c$ & 335,350 & 11680 & $396^{b}$ & 341 & $393^{b}$ & nd & - \\
\hline $5 \mathbf{a}$ & 400 & 10740 & 535 & 413 & 545 & 9.3 & $17 \%$ \\
\hline $5 \mathbf{b}$ & 400 & 10180 & 535 & 406 & 558 & 3.03 & - \\
\hline $5 c$ & 400 & 10180 & 535 & 405 & $543^{b}$ & 1.80 & - \\
\hline $6 \mathbf{a}$ & 426 & 9700 & $530^{\mathrm{b}}$ & 446 & $570^{\mathrm{b}}$ & 1.84 & - \\
\hline $6 \mathbf{b}$ & 426 & 10620 & $530^{\mathrm{b}}$ & 431 & $587^{\mathrm{b}}$ & 2.10 & - \\
\hline $6 c$ & 426 & 10620 & $530^{\mathrm{b}}$ & 431 & $575^{b}$ & 2.77 & - \\
\hline
\end{tabular}

Table S1. Absorption and emission spectral parameters of 4a-c, 5a-c and 6a-c in DMSO and $98 \% f_{w}$. ${ }^{\text {aCalculated at }}$ absorption maxima. ${ }^{b}$ Weak fluorescence. ${ }^{c}$ In case of bi- and tri-exponential lifetimes, an average lifetime was calculated. $\mathrm{d} \mathbf{4 a}$ aggregates lifetime was recorded in $99.5 \%$ water (excited at $340 \mathrm{~nm}$ and counts at $486 \mathrm{~nm}$ ). 5a-c and 6a-c lifetime decays were recorded in $98 \% f_{w}$ (excited at $405 \mathrm{~nm}$ and counts at their emission maxima). Quantum yield of 4a was calculated relative to quinine sulphate standard in $0.5 \mathrm{M} \mathrm{H}_{2} \mathrm{SO}_{4}(0.54$; excitation of sample and reference $=341 \mathrm{~nm})$ and 5a quantum yield was calculated relative to fluorescein in $0.1 \mathrm{~N} \mathrm{NaOH}(0.79$; excitation of sample and reference $=450$ $\mathrm{nm}$ ) by following standard procedures and applying obtained vales in the formulae given below. ${ }^{1,2}$

$$
\begin{aligned}
& \Phi_{\mathrm{s}}=\varphi_{\mathrm{r}} \times \mathrm{f}_{\mathrm{r}} / \mathrm{f}_{\mathrm{s}} \times \mathrm{E}_{\mathrm{s}} / \mathrm{E}_{\mathrm{r}} \times\left(\eta_{\mathrm{s}} / \eta_{\mathrm{r}}\right)^{2} \\
& \mathrm{f}_{\mathrm{r}}=1-10^{-\mathrm{Ar}} ; \mathrm{f}_{\mathrm{s}}=1-10^{-\mathrm{As}}
\end{aligned}
$$

Obtained fluorescence lifetime data was processed using Fluoracle software. The quality of the fit was judged by $\chi^{2}$ (Chisquare) value. Data was plotted using origin 8.5 software.

4a and 5a have shown good fitting with single exponential decay function. While 5b-c and $\mathbf{6 a - c}$ have shown good fitting with triexponential decay function.

The average lifetime in case of bi- and tri-exponential decay patterns was calculated by following given formulas.

1. $\left\langle\tau>=\mathrm{B}_{1} \tau_{1}+\mathrm{B}_{2} \tau_{2} / \mathrm{B}_{1}+\mathrm{B}_{2} \quad\right.$ (equation for calculating average $<\tau>$ for biexponential decay patterns)

2. $\left\langle\tau>=\mathrm{B}_{1} \tau_{1}+\mathrm{B}_{2} \tau_{2}+\mathrm{B}_{3} \tau_{3} / \mathrm{B}_{1}+\mathrm{B}_{2}+\mathrm{B}_{3} \quad\right.$ (equation for calculating average $<\tau>$ for triexponential decay patterns)

\section{References}

(1) Kellogg, R. E.; Bennett, R. G. Radiationless Intermolecular Energy Transfer. III. Determination of Phosphorescence Efficiencies. J. Chem. Phys. 1964, 41, 3042-3045.

(2) Brouwer, A. M. Standards for Photoluminescence Quantum Yield Measurements in Solution (IUPAC Technical Report). Pure Appl. Chem. 2011, 83, 2213-2228. 
2. Fluorescence lifetime decay of $5 \mathrm{a}-\mathrm{c}$ and $6 \mathrm{a}-\mathrm{c}$ in $98 \% \mathrm{f}_{w}$

A

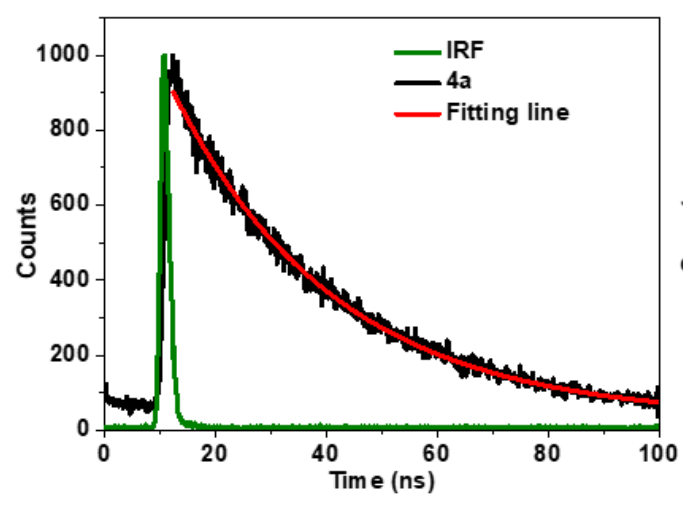

B

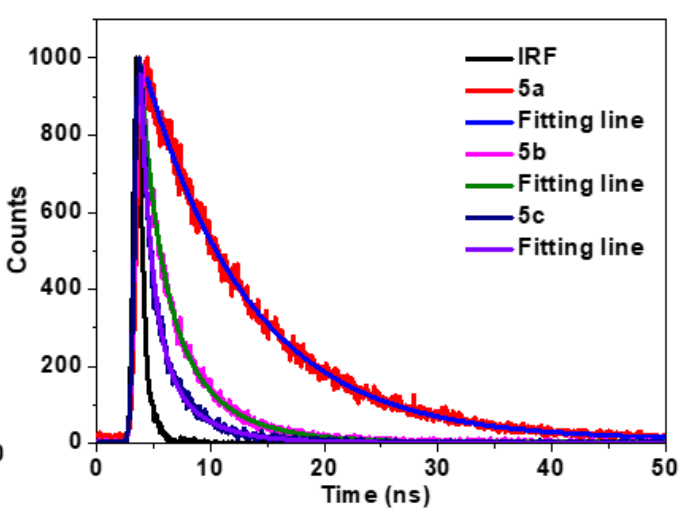

C

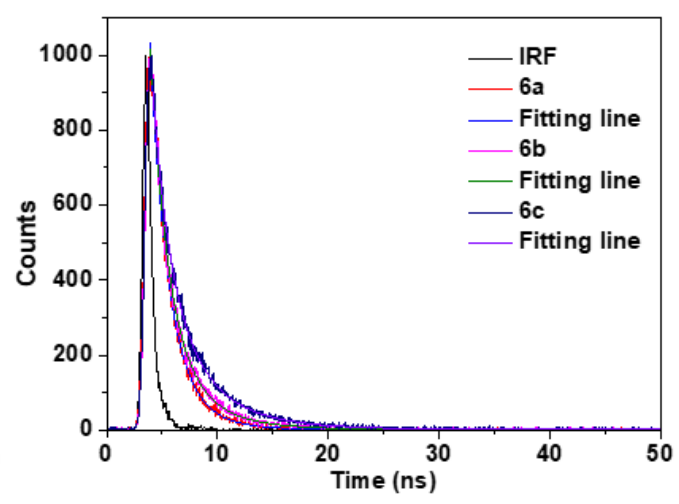

Figure S4. A) Fluorescence lifetime decay pattern of $4 \mathbf{a}$ in $99.5 \% f_{w}$. B) Fluorescence lifetime decay patterns of 5a-c in $98 \% f_{w}$. C) Fluorescence lifetime decay patterns of $\mathbf{6 a - c}$ in $98 \% f_{w}$.

\section{Concentration dependent studies with $2-\mathrm{NP} / 2,4-\mathrm{DNT}$}

A

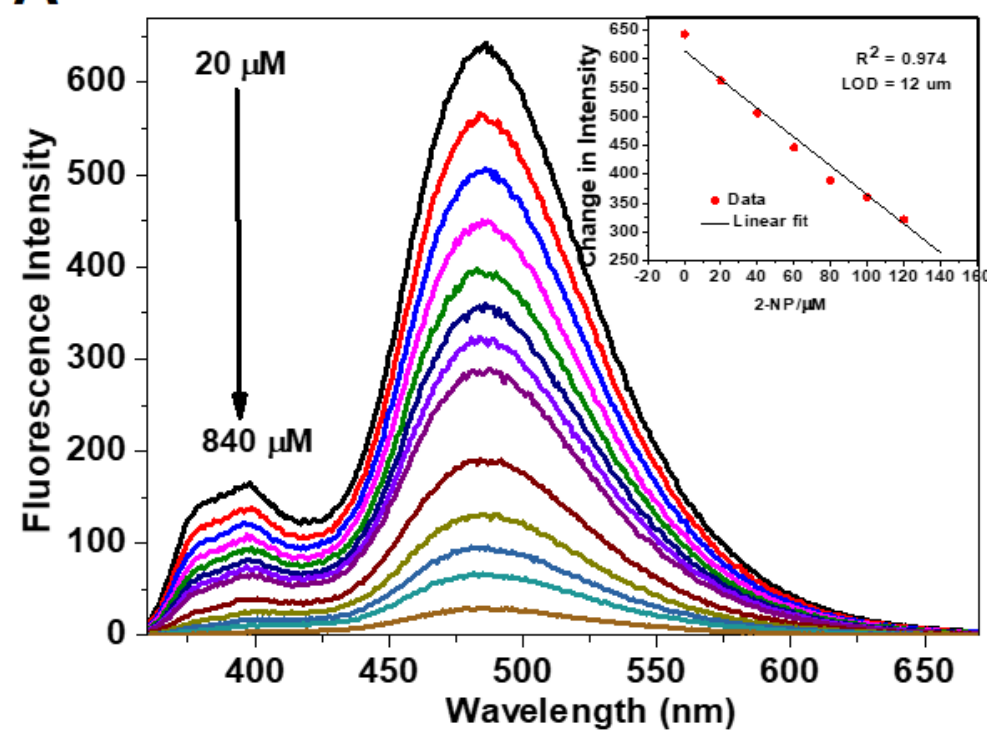

B

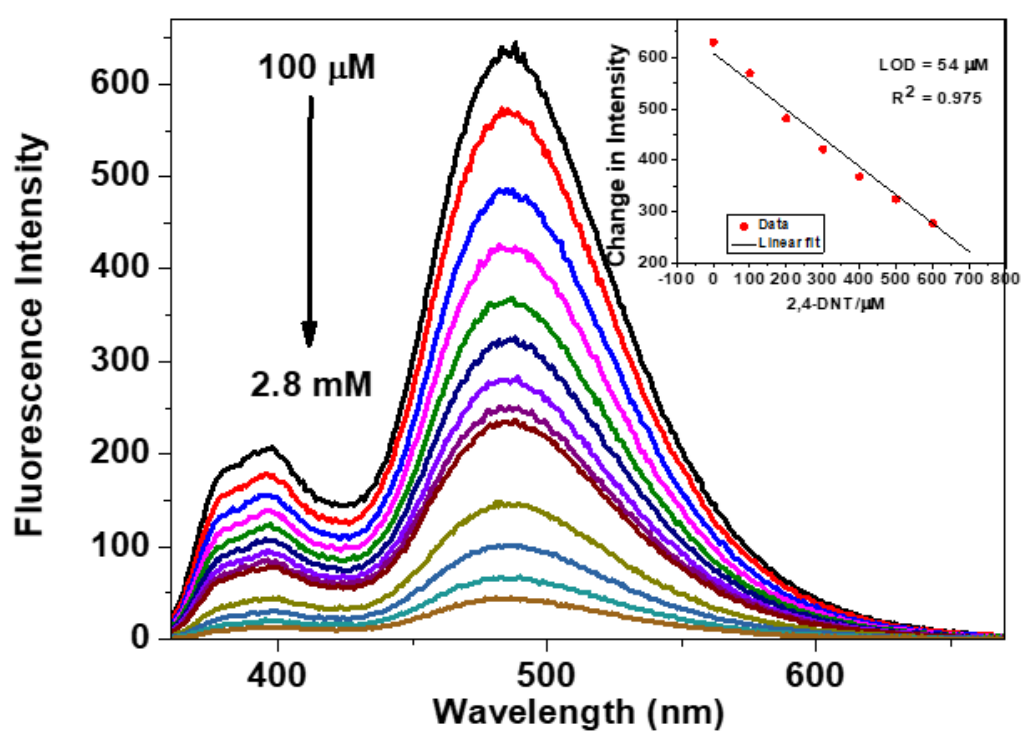

Figure S5. Concentration dependent experiments with 2-nitrophenol (2-NP) (A) and 2,4-dinitrotoluene (2,4-DNT) (B). 


\section{Fluorescence response of 4 a against commercially available drugs in water and concentration dependent studies}

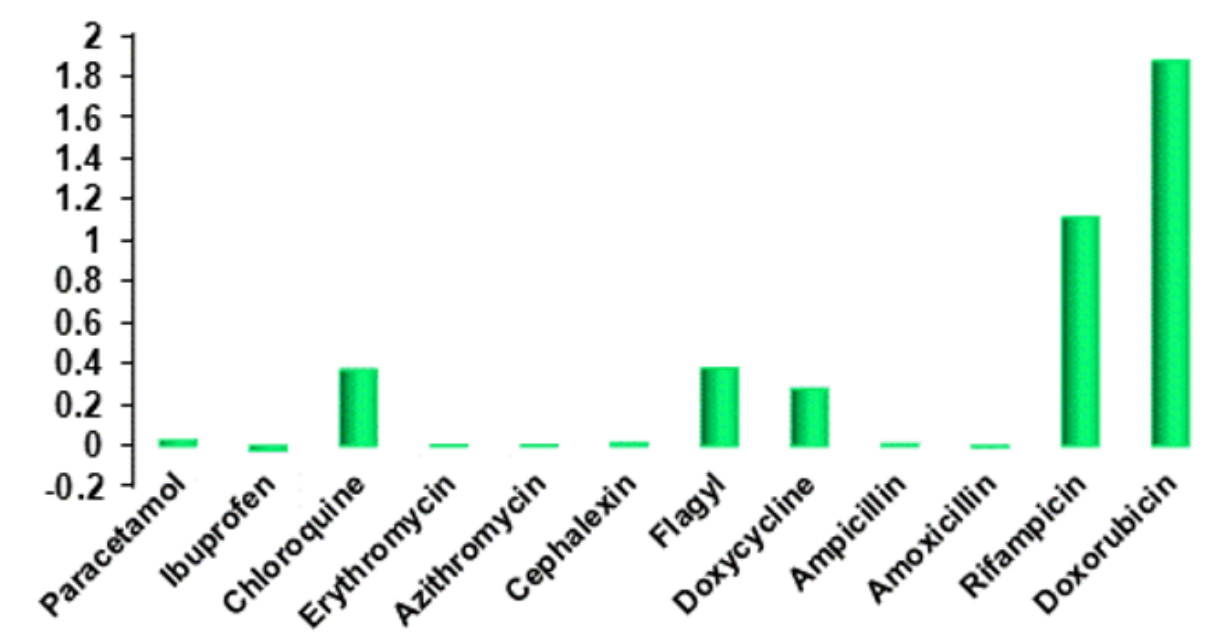

Figure S6. The change in fluorescence intensity of $4 \mathbf{a}(50 \mu \mathrm{M})$ in water after adding the corresponding organic analytes (50 $\mu \mathrm{M})$; A) Bar diagrams depicting the fluorescence response of $\mathbf{4 a}$ to tested analytes.

A

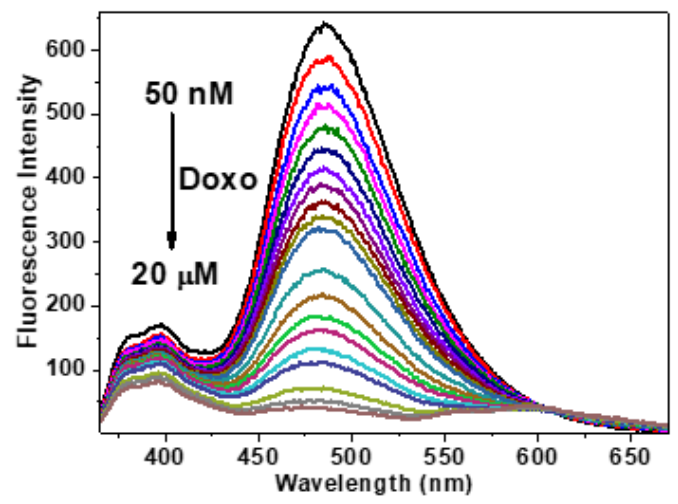

B

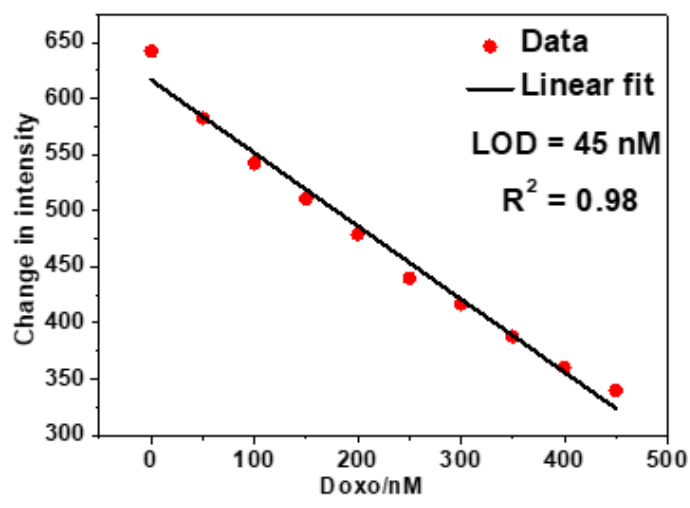

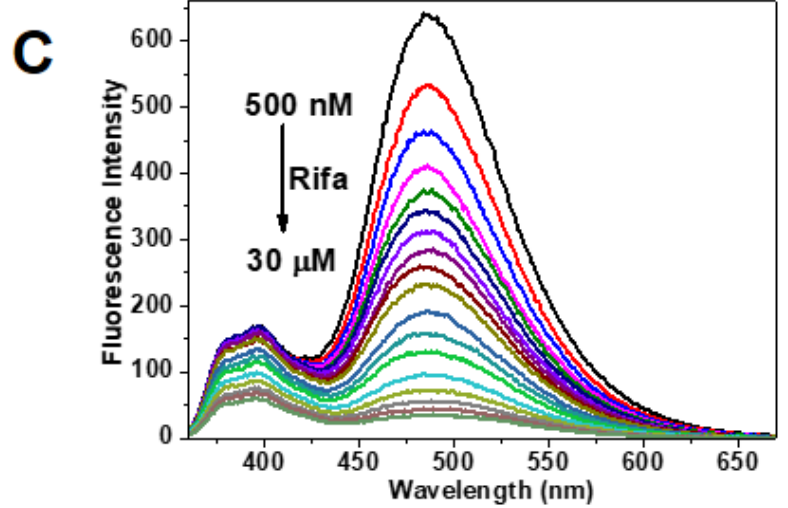

D

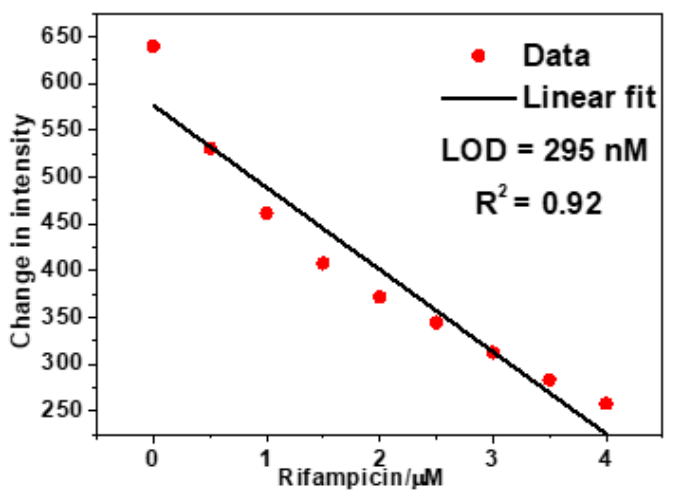

Figure S7. A) Fluorescence response of $4 a$ with increasing concentration of doxorubicin (Doxo) in water $(50 \mathrm{nM}-20 \mu \mathrm{M})$; B) Plot of fluorescence intensity vs conc. of Doxo fitted to linear regression (inset LOD). C) Fluorescence response of 4a with increasing concentration of rifampicin (Rifa) in water (500 $\mathrm{nM}-30 \mu \mathrm{M})$; D) Plot of fluorescence intensity vs conc. of Rifa fitted to linear regression (inset: LOD calculated from the data following $\mathbf{3 \sigma} / \mathbf{K}$ ). 


\section{Stern-Volmer quenching constants}
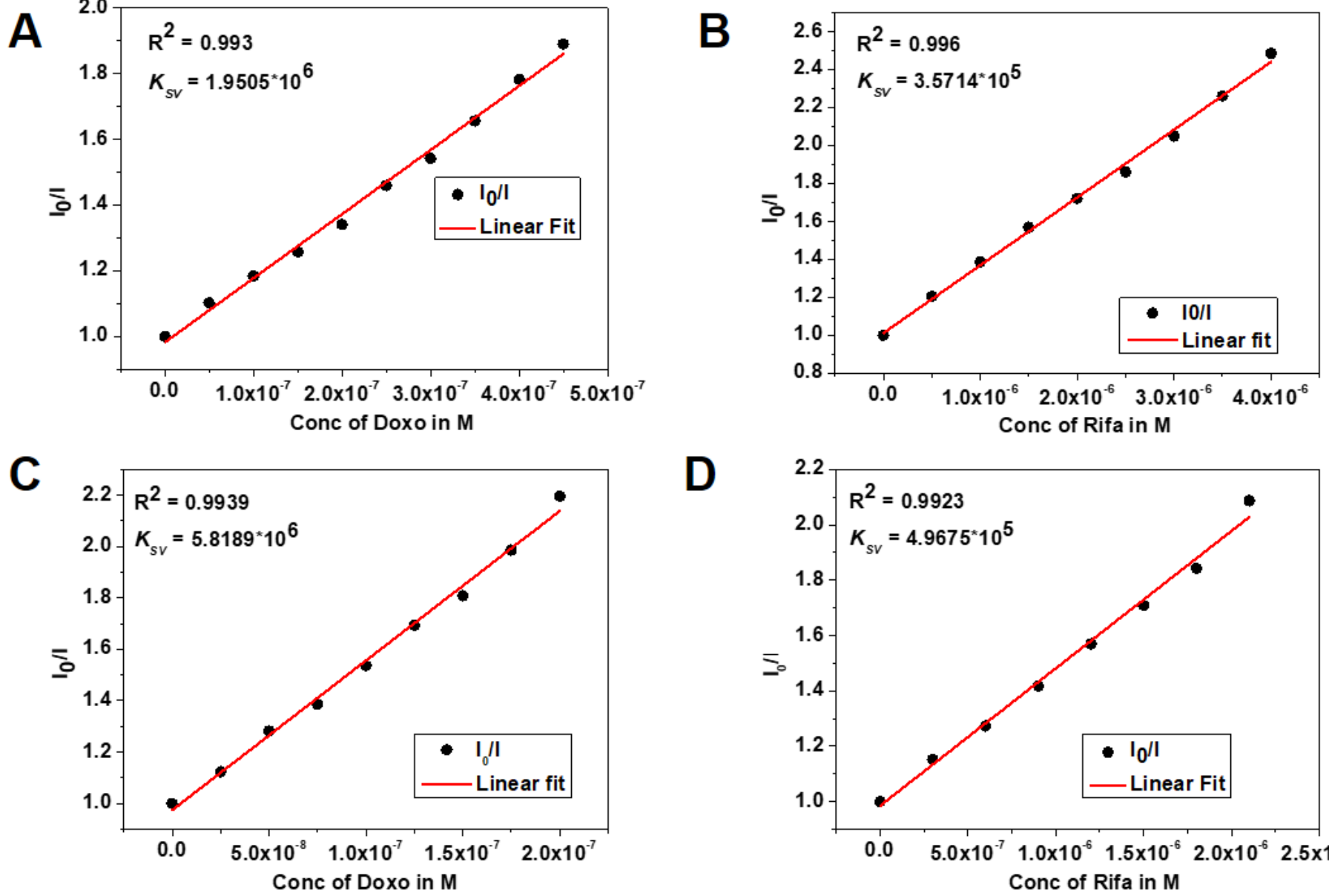

D
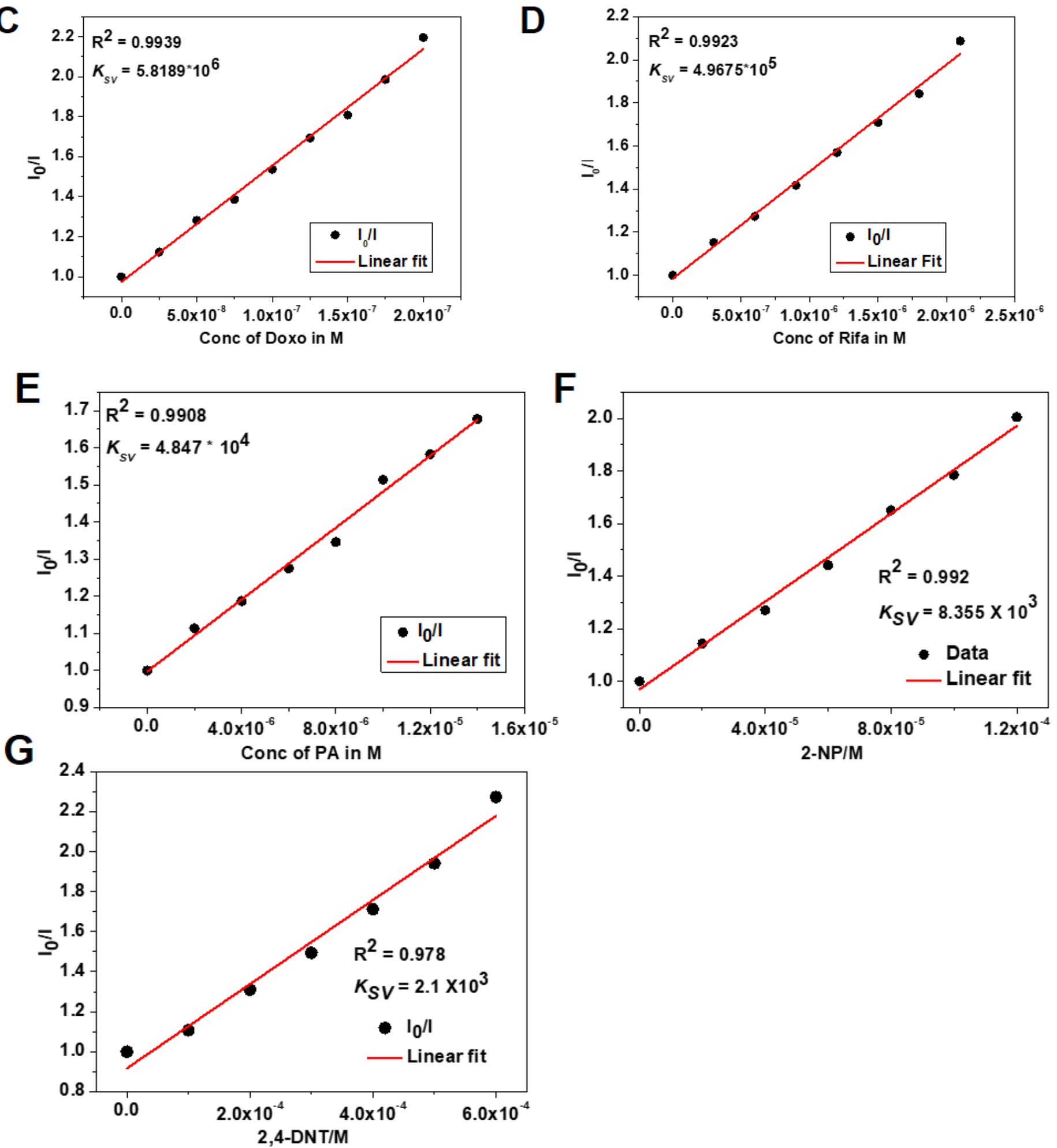

Figure S8. A\&B) Stern-Volmer plots to determine Stern-Volmer $\left(K_{S V}\right)$ quenching constants in water in presence of corresponding analytes. C\&D) Stern-Volmer plots to determine Stern-Volmer $\left(K_{S V}\right)$ quenching constants in PBS (10 mM, $\mathrm{pH}=7.4)$ in presence of corresponding analytes. E-G) Stern-Volmer plots to determine Stern-Volmer $\left(K_{S V}\right)$ quenching constants of PA, 2-NP, 2,4-DNT in water. 


\section{Fluorescence lifetime of 4 a with analytes}

A

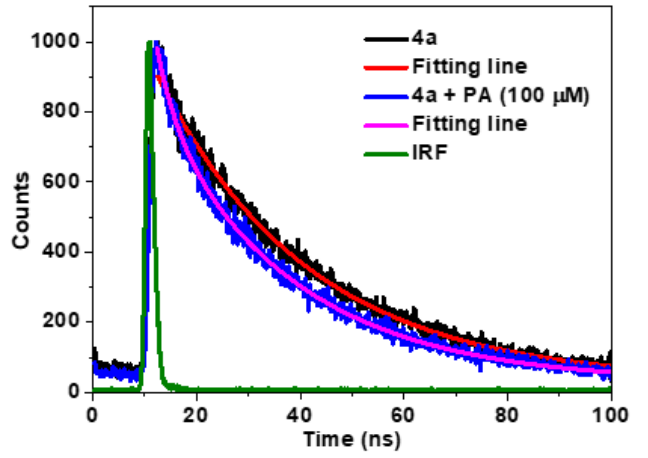

B

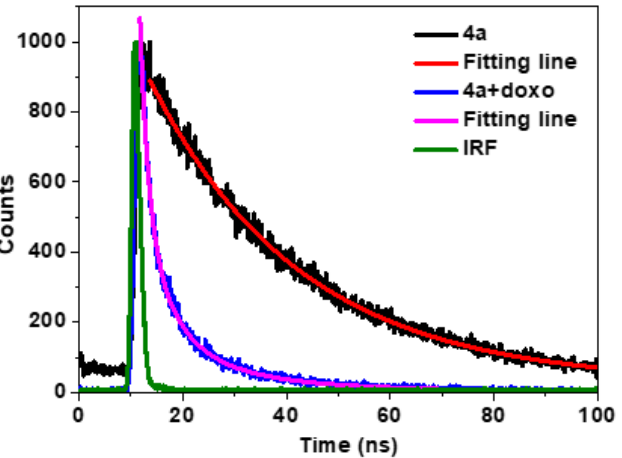

E
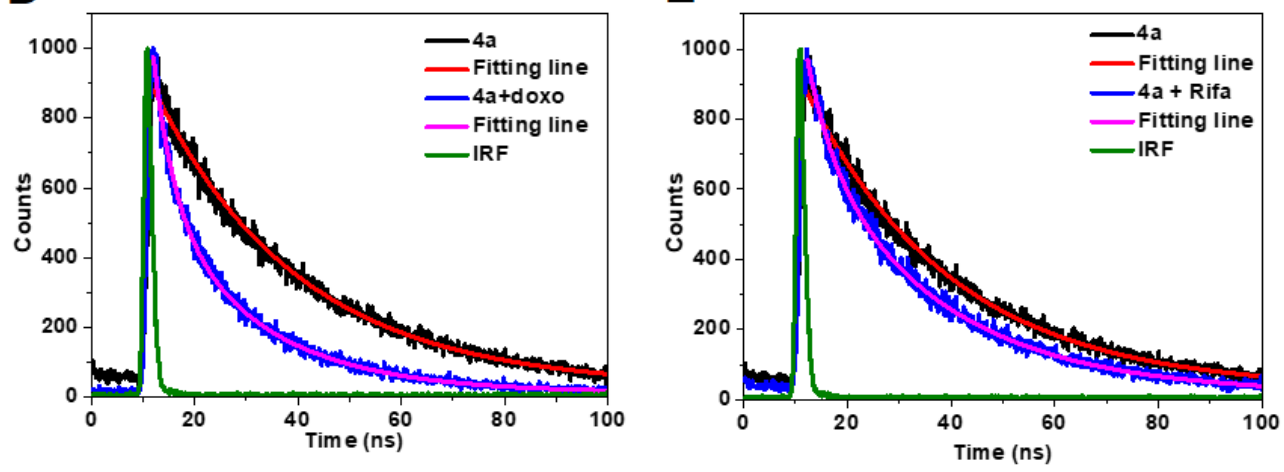

C

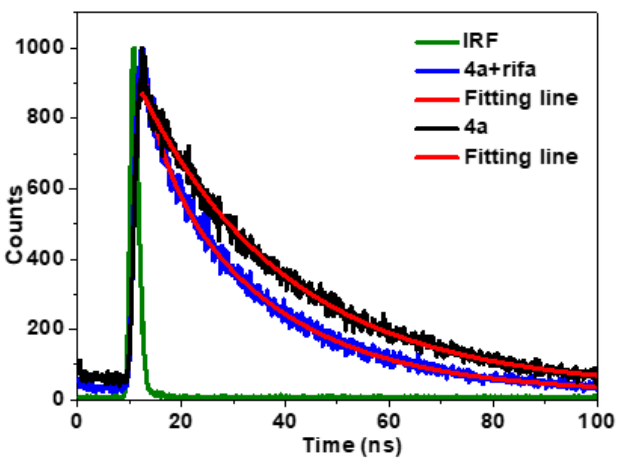

Figure S9. A) Fluorescence lifetime decay patterns of $4 \mathbf{a}(50 \mu \mathrm{M})$ and $\mathbf{4 a}+\mathbf{P A}(100 \mu \mathrm{M})$ in water. B) Fluorescence lifetime decay patterns of $\mathbf{4 a}(50 \mu \mathrm{M})$ and $\mathbf{4 a}+\mathbf{d o x o}(5.0 \mu \mathrm{M})$ in PBS. C) Fluorescence lifetime decay patterns of $\mathbf{4 a}(50 \mu \mathrm{M})$ and 4a+rifa $(5.0 \mu \mathrm{M})$ in PBS. D) Fluorescence lifetime decay patterns of $\mathbf{4 a}(50 \mu \mathrm{M})$ and $\mathbf{4 a}+\mathbf{d o x}(5.0 \mu \mathrm{M})$ in water. E) Fluorescence lifetime decay patterns of $\mathbf{4 a}$ and $\mathbf{4 a}+\mathbf{r i f a}(5.0 \mu \mathrm{M})$ in water.

\section{Experiments for understanding the FRET in fluorescence quenching of 4a:}

A

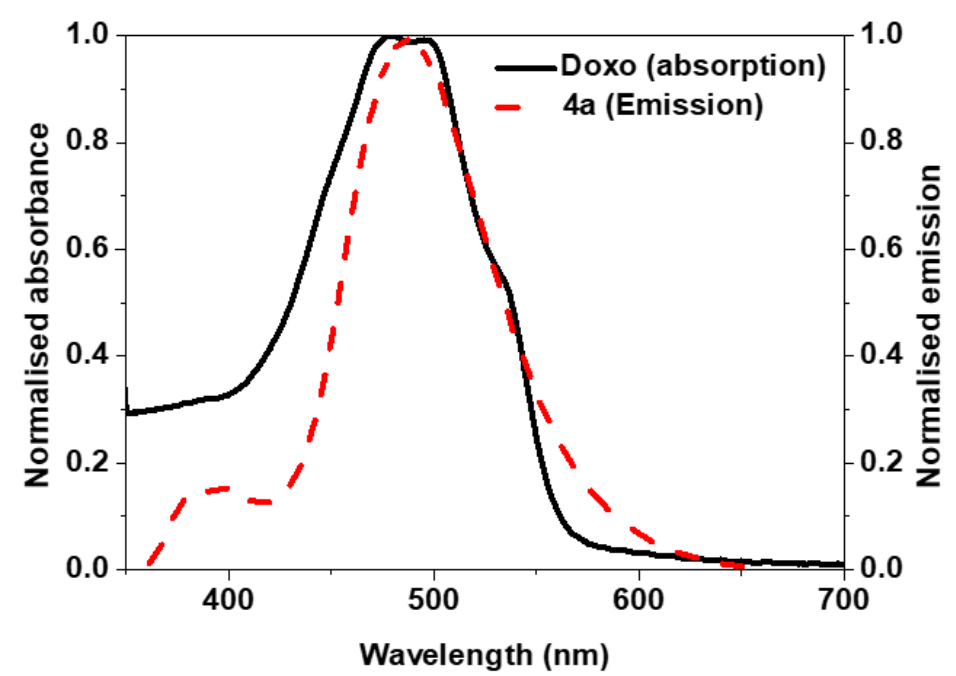

B

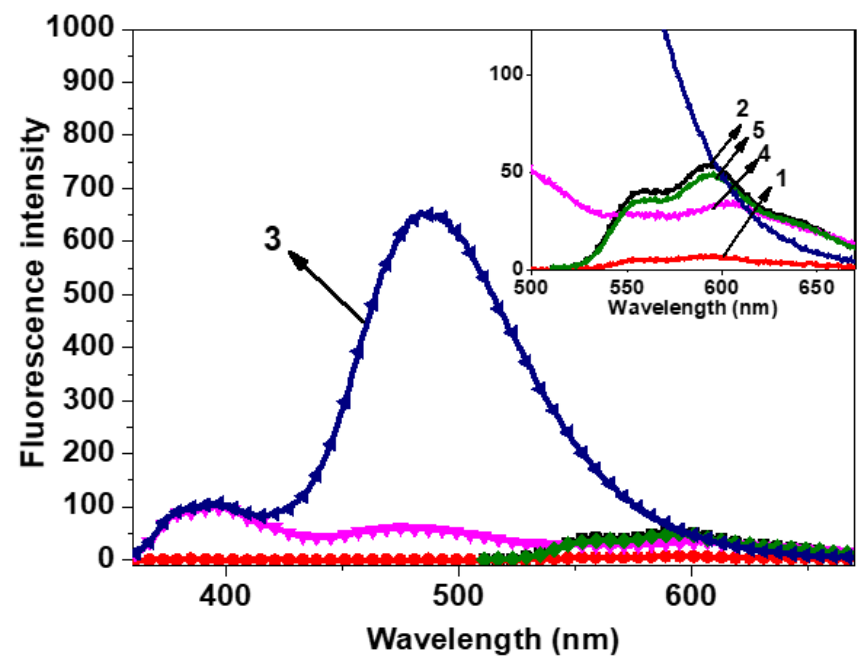

Figure S10. A) Normalised absorbance of doxorubicin and normalised emission of 4a in PBS which show the spectral overlap. B) Fluorescence experiments for understanding the possible FRET mechanism in sensing of doxorubicin (in PBS, $10 \mathrm{mM}$; pH 7.4), doxorubicin: $5 \mu \mathrm{M}$ and 4a: $50 \mu \mathrm{M}$. inset: expanded region from $500-670 \mathrm{~nm}$. 1: doxorubicin $\left(\lambda_{\mathrm{ex}}=341\right.$ $\mathrm{nm}), 2:$ doxorubicin $\left(\lambda_{\mathrm{ex}}=490 \mathrm{~nm}\right), 3: \mathbf{4 a}\left(\lambda_{\mathrm{ex}}=341 \mathrm{~nm}\right), 4: \mathbf{4 a}+\operatorname{dox}$ orubicin $\left(\lambda_{\mathrm{ex}}=341 \mathrm{~nm}\right), 5: \mathbf{4 a}+\operatorname{doxorubicin}\left(\lambda_{\mathrm{ex}}=\right.$ $490 \mathrm{~nm})$.

- Initially, fluorescence of doxorubicin was recorded by exciting at $341 \mathrm{~nm}$ (spectra 1, excitation wavelength of 4a) and $490 \mathrm{~nm}$ (spectra 2, excitation wavelength of doxorubicin). The fluorescence spectra recorded by exciting at $341 \mathrm{~nm}$ has showed weak emission, while fluorescence recorded by exciting at $490 \mathrm{~nm}$ has showed considerable emission.

- Similar experiments were performed in presence of $4 \mathbf{a}$ (spectra 4 and 5). The fluorescence spectra obtained in presence of $4 \mathbf{a}$ by exciting at $341 \mathrm{~nm}$ showed enhanced emission of doxorubicin at its emission maxima (spectra 4). This suggest the involvement of FRET (fluorescence resonance energy transfer) in fluorescence quenching of AIEgen 4a in presence of doxorubicin. Fluorescence of same sample was recorded by exciting at $490 \mathrm{~nm}$ (spectra 5), which showed spectra similar to (2).

- Overall, these experiments supported the involvement of FRET in fluorescence quenching of 4a. 


\section{4a emission and rifampicin absorption spectral overlap}

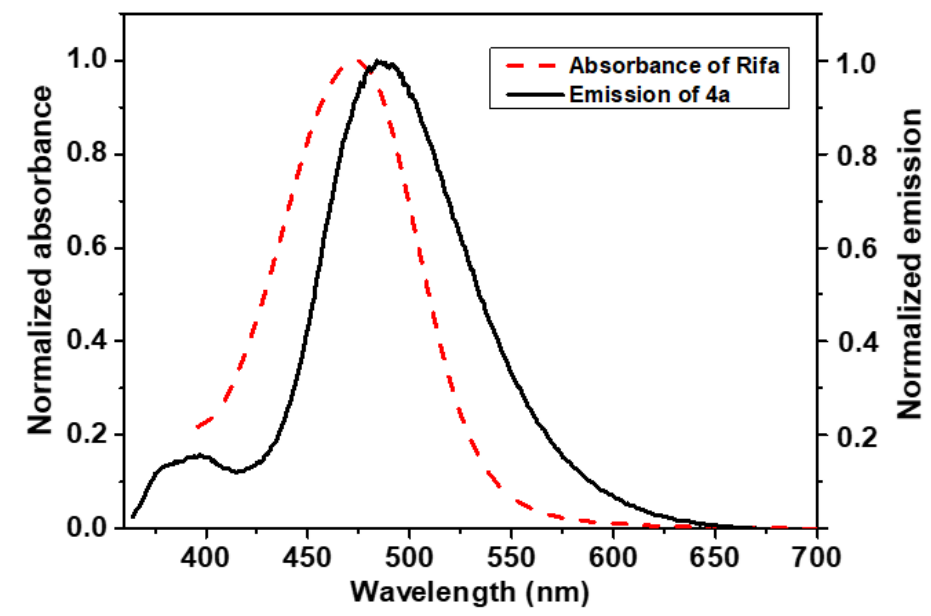

Figure S11. A) Normalised absorbance of rifampicin and normalised emission of $4 \mathbf{a}$ in PBS which show the spectral overlap.

\section{Time dependent fluorescence studies of 4a aggregates towards 2,4-DNT, 2-NP and PA:}
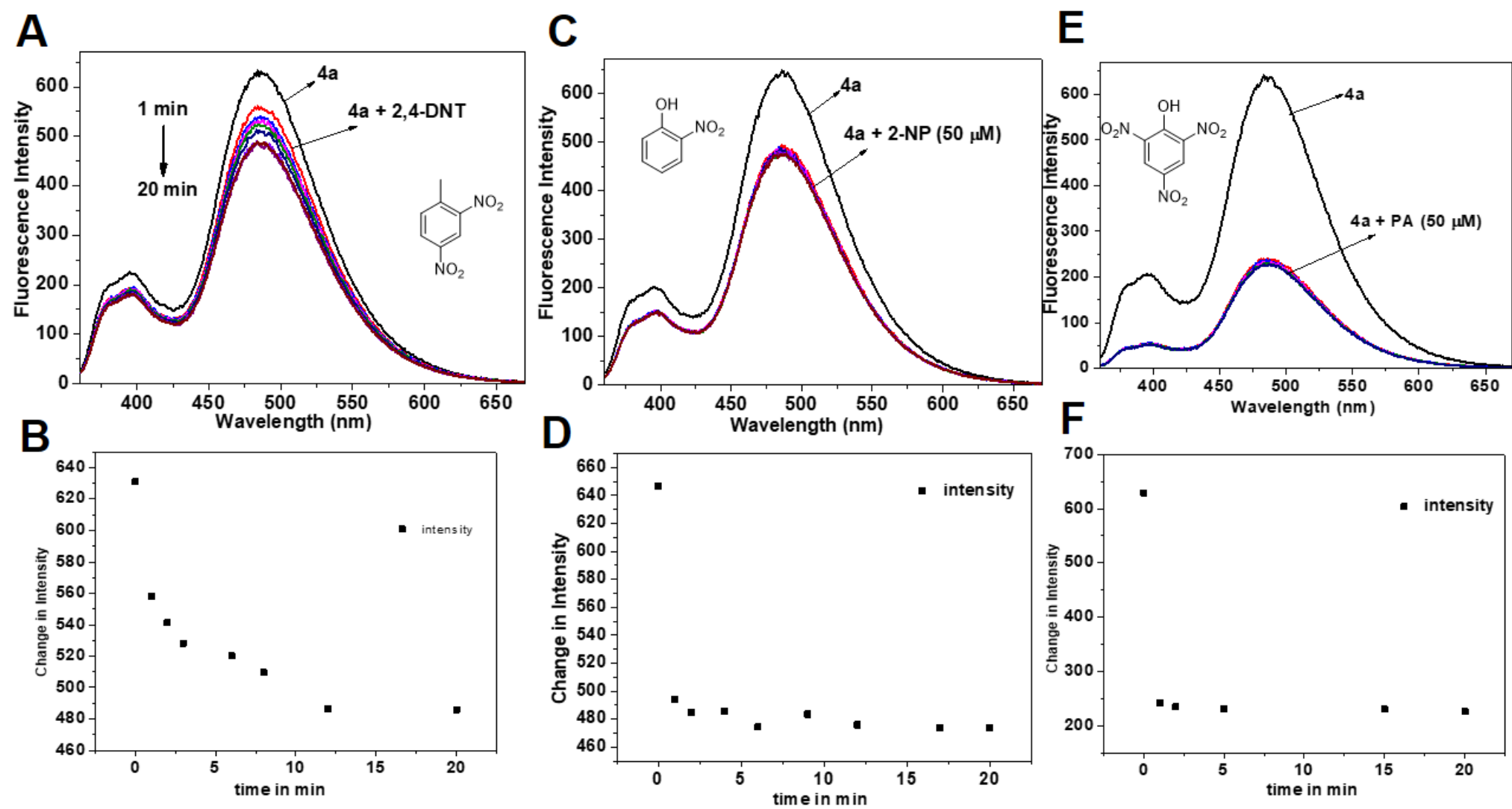

Figure S12. A\&B) Time dependent fluorescence response of AIEgen 4a in water towards 2,4-DNT and plot of change in intensity vs time, respectively. C\&D) Time dependent fluorescence response of AIEgen 4a in water towards 2-NP and plot of change in intensity vs time, respectively. E\&F) Time dependent fluorescence response of AIEgen 4a in water towards $\mathrm{PA}$ and plot of change in intensity vs time, respectively. 

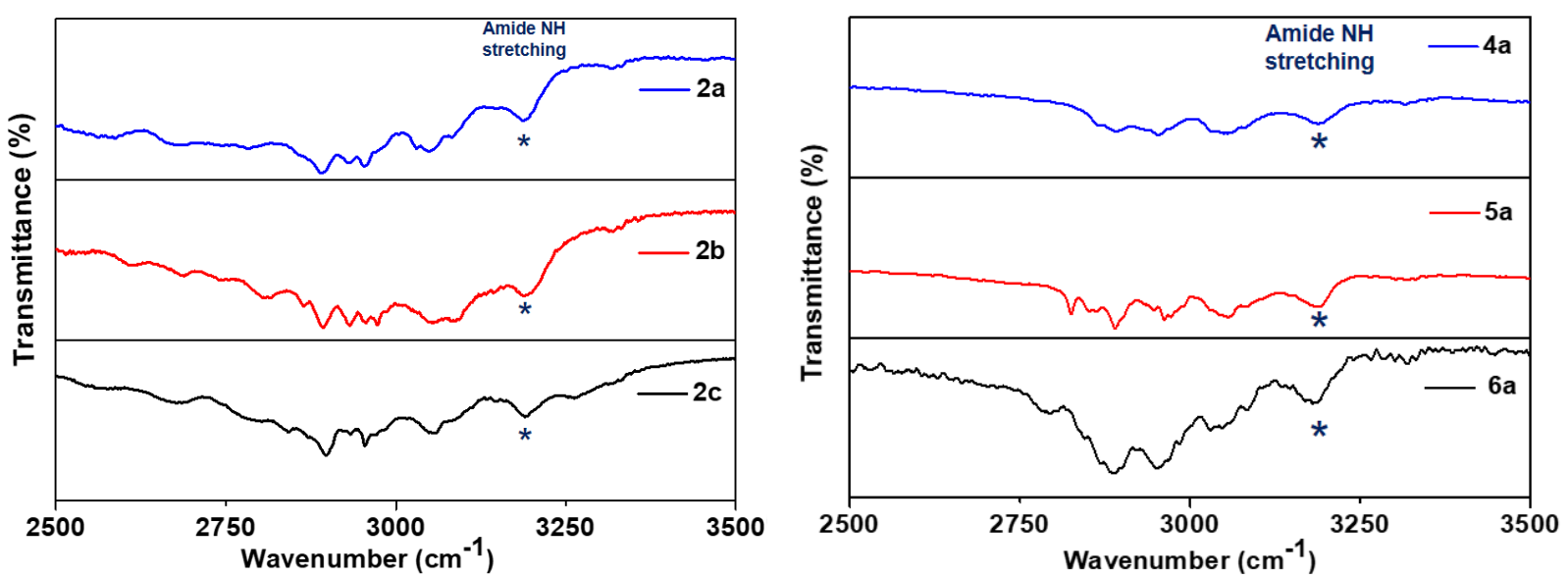

Figure S13. A) Partial FT-IR (ATR-IR) spectra of $\mathbf{2 a - c}$ and $\mathbf{4 a} / \mathbf{5 a} / \mathbf{6 a}$ showing amide NH stretching frequency $(* v N H=$ $\left.3189 \mathrm{~cm}^{-1}\right)$.

Table S2. Summary of Stern-Volmer quenching constants $\left(K_{S V}\right)$, Limit of Detection (LOD) of analytes and fluorescence lifetimes $(\tau)$ of AIEgen 4a in presence of various analytes.

\begin{tabular}{|c|c|c|c|}
\hline $\begin{array}{c}\text { Analyte } \\
(\text { medium})\end{array}$ & $\begin{array}{c}\text { Stern-Volmer quenching } \\
\text { constant }(K s v) \mathrm{M}^{-1}\end{array}$ & $\begin{array}{c}\text { Limit of detection } \\
(\mathrm{LOD})\end{array}$ & $\begin{array}{c}\text { fluorescence lifetime after addition of analyte }\left(\tau_{0}=\right. \\
\left.29.1 \mathrm{~ns}(\text { water }) \text { and } \tau_{0}=28.7 \mathrm{~ns}(\mathrm{PBS})\right)\end{array}$ \\
\hline PA (water) & $4.8 \times 10^{4}$ & $1.7 \mu \mathrm{M}$ & $\mathbf{2 2 . 4}[\mathbf{3 . 9 5}(3.50 \%) ; \mathbf{2 6 . 9 8}(96.50 \%)]$ \\
\hline Doxo (water) & $1.95 \times 10^{6}$ & $45 \mathrm{nM}$ & $\mathbf{1 3 . 0 5}[\mathbf{4 . 1 2}(13.73 \%) ; \mathbf{1 9 . 9 6}(86.27 \%)]$ \\
\hline Rifa (water) & $3.57 \times 10^{5}$ & $295 \mathrm{nM}$ & $\mathbf{2 0 . 3 2}[\mathbf{5 . 2 1}(6.75 \%) ; \mathbf{2 5 . 7 2}(93.25 \%)]$ \\
\hline Doxo (PBS) & $5.8 \times 10^{6}$ & $18 \mathrm{nM}$ & $\mathbf{5 . 3 4}[\mathbf{1 . 6 8}(16.64 \%) ; \mathbf{6 . 0 5}(40.15 \%) ; \mathbf{2 0 . 0 5}(43.22 \%)]$ \\
\hline Rifa (PBS) & $4.96 \times 10^{5}$ & $202 \mathrm{nM}$ & $\mathbf{1 9 . 3 0}[\mathbf{4 . 1 0}(4.63 \%) ; \mathbf{2 3 . 5 4}(95.37 \%)]$ \\
\hline 2-NP & $8.355 \times 10^{3}$ & $12 \mu \mathrm{M}$ & \\
\hline 2,4-DNT & $2.1 \times 10^{3}$ & $54 \mu \mathrm{M}$ & \\
\hline
\end{tabular}




\section{0. ${ }^{1} \mathrm{H}-{ }^{1} \mathrm{H}$ COSY spectra of $4 \mathrm{a}$}

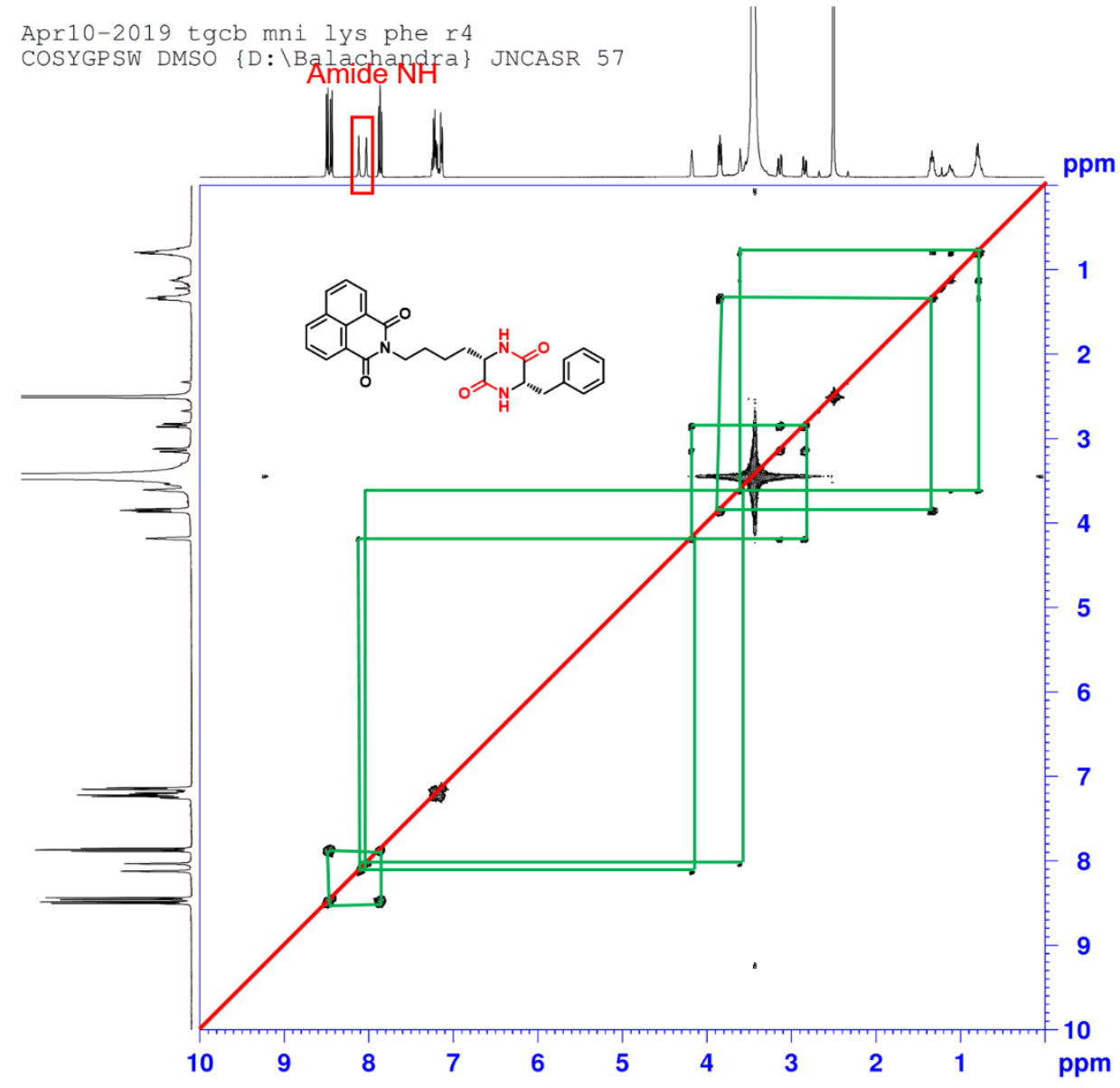

Figure S14. ${ }^{1} \mathrm{H}-{ }^{-1} \mathrm{H}$ COSY spectra of $4 \mathrm{a}$ in DMSO-D6 $(400 \mathrm{MHz})$.

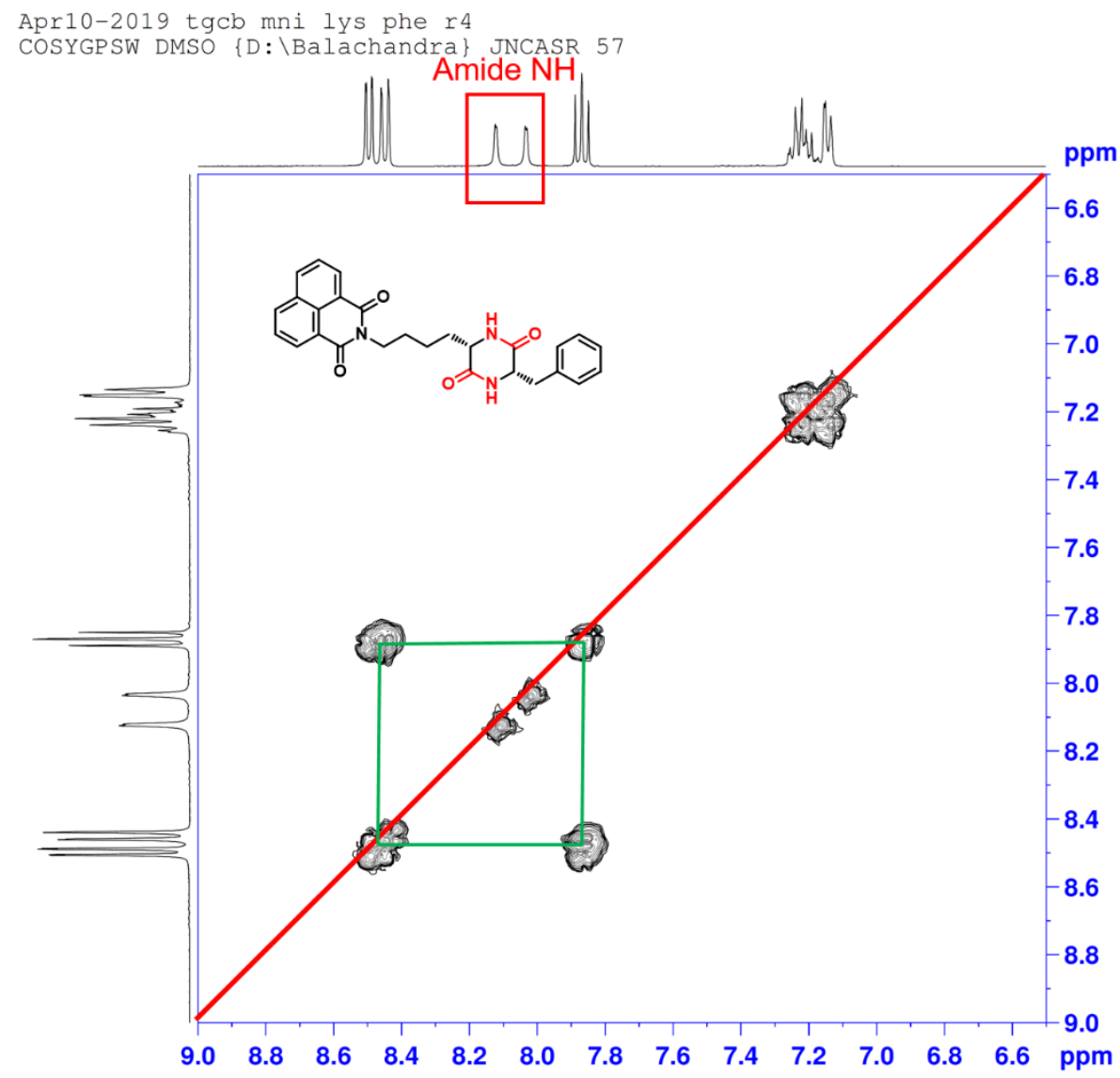

Figure S15. Partial ${ }^{1} \mathrm{H}-{ }^{1} \mathrm{H}$ COSY spectra of $4 a$ in DMSO-D6 (400 MHz). 


\section{1. ${ }^{1} \mathrm{H}-{ }^{1} \mathrm{H}$ COSY spectra of $5 \mathrm{a}$}

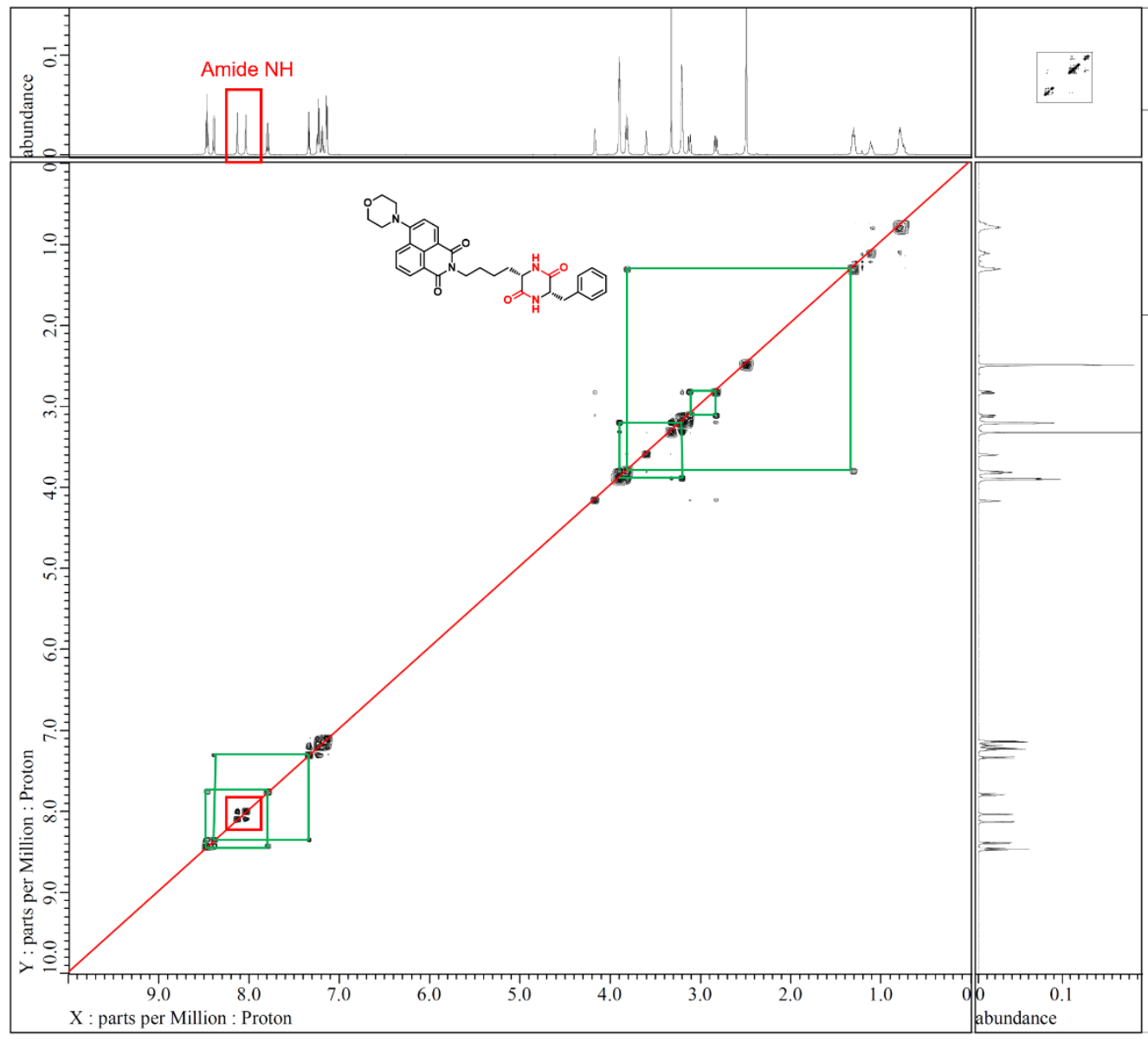

Figure S16. ${ }^{1} \mathrm{H}-{ }^{1} \mathrm{H}$ COSY spectra of $5 \mathrm{a}$ in DMSO-D6.

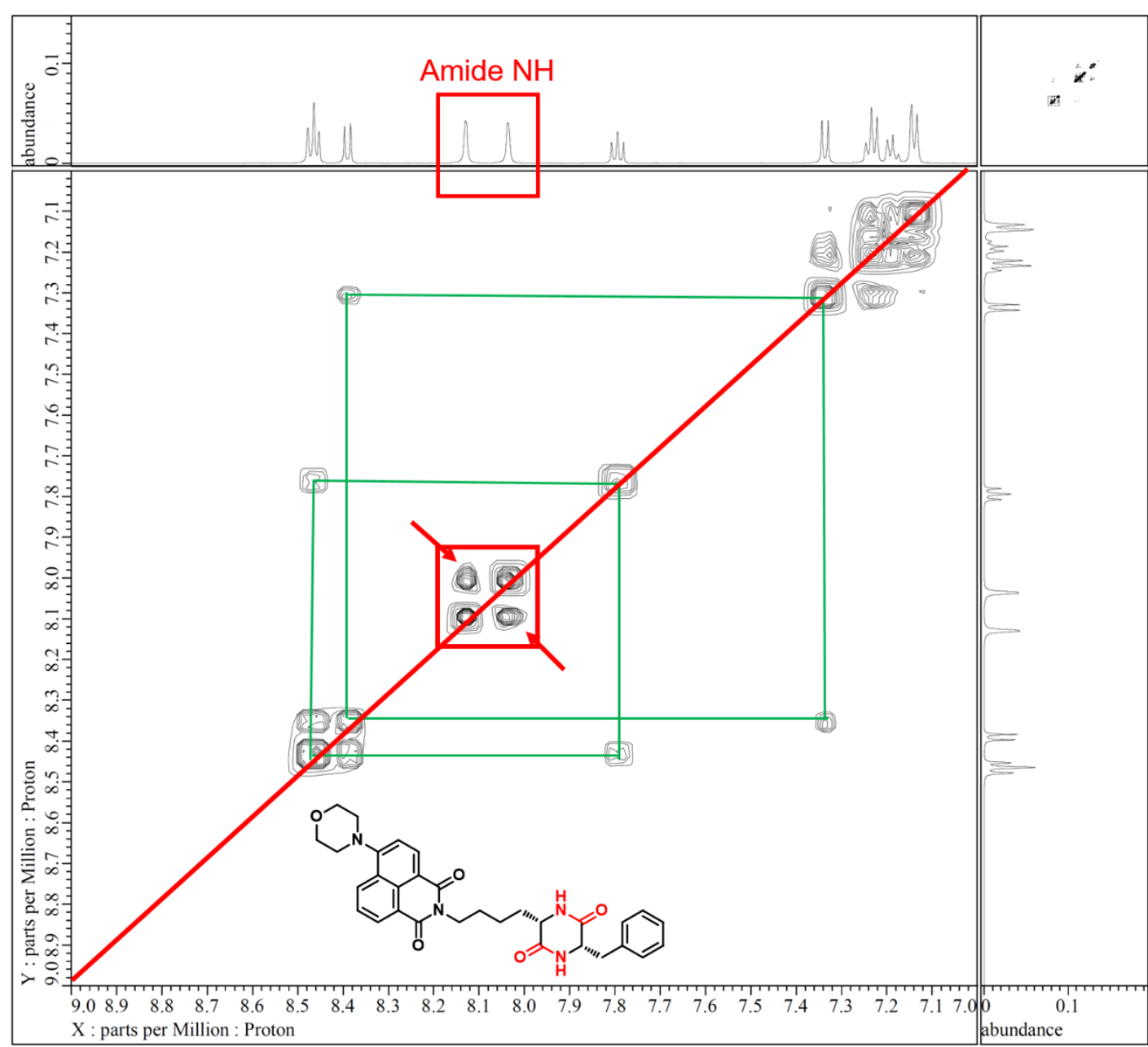

Figure S17. Partial ${ }^{1} \mathrm{H}-{ }^{1} \mathrm{H}$ COSY spectra of 5a in DMSO-D6 (Highlighted in red box and indicated with the arrow are correlation between the two amide $\mathrm{NH}$ protons, $(600 \mathrm{MHz}))$. 
12. ${ }^{1} \mathrm{H}-{ }^{1} \mathrm{H}$ COSY spectra of $6 \mathrm{a}$

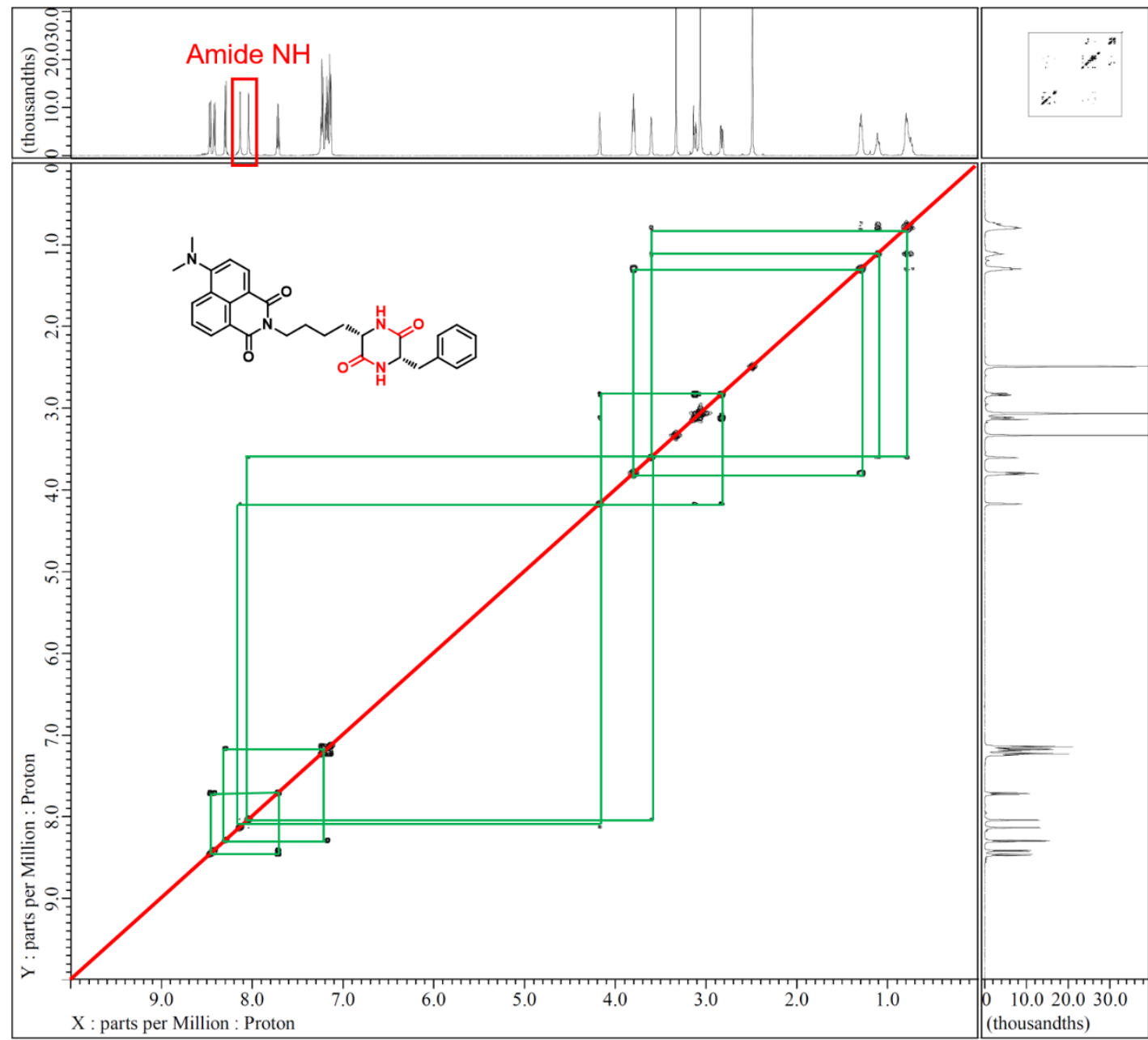

Figure $\mathbf{S 1 8} .{ }^{1} \mathrm{H}-{ }^{1} \mathrm{H}$ COSY spectra of $6 \mathbf{a}$ in DMSO-d6.

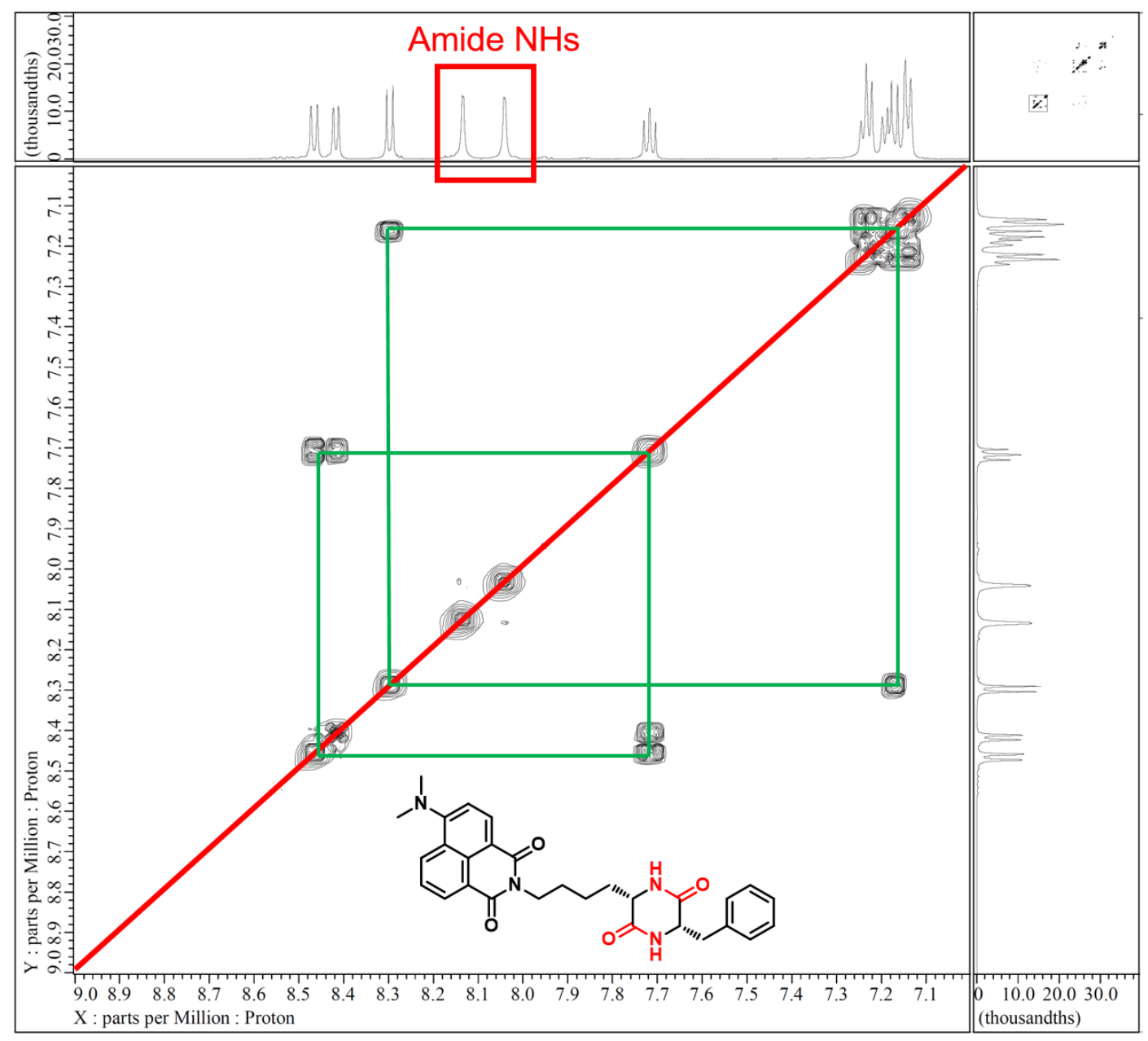

Figure S19. Partial ${ }^{1} \mathrm{H}-{ }^{1} \mathrm{H}$ COSY spectra of $6 a$ in DMSO-D6 $(600 \mathrm{MHz})$. 
13. ${ }^{1} \mathrm{H}$ and ${ }^{13} \mathrm{C}$ NMR spectra of $2 \mathrm{a}$

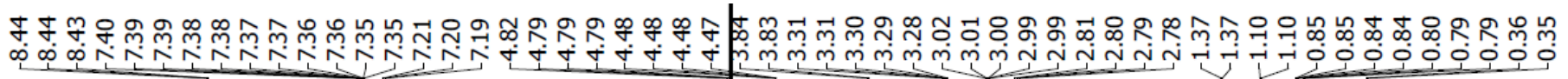

$\mathrm{HCO}_{2} \mathrm{H}$<smiles>NCCCCC[C@H]1NC(=O)[C@H](Cc2ccccc2)NC1=O</smiles>

$2 a$

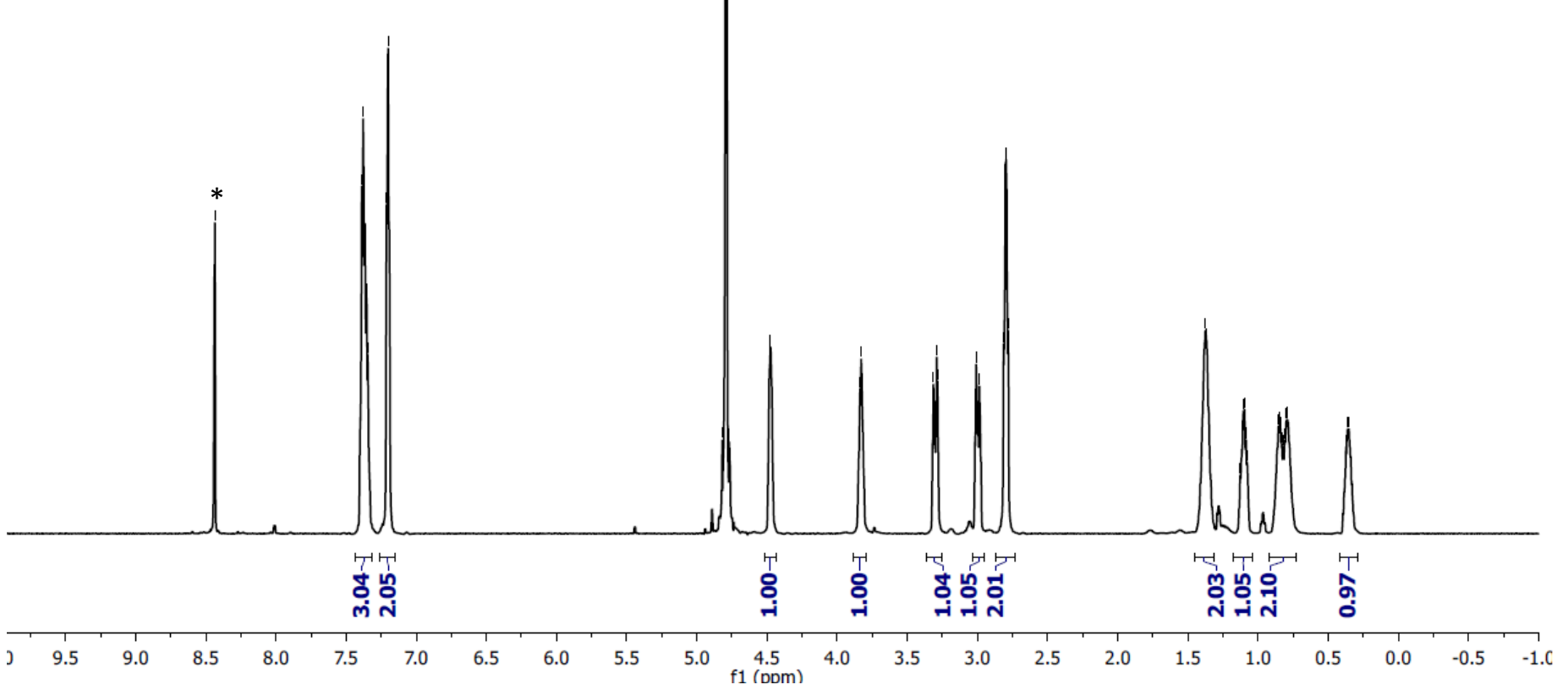

( ${ }^{*} \mathrm{HCO}_{2}^{-}$proton).

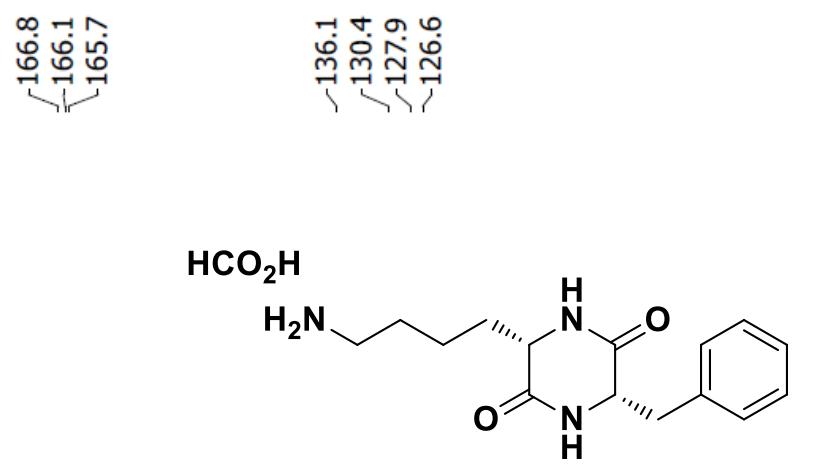

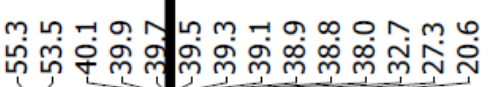

$2 a$
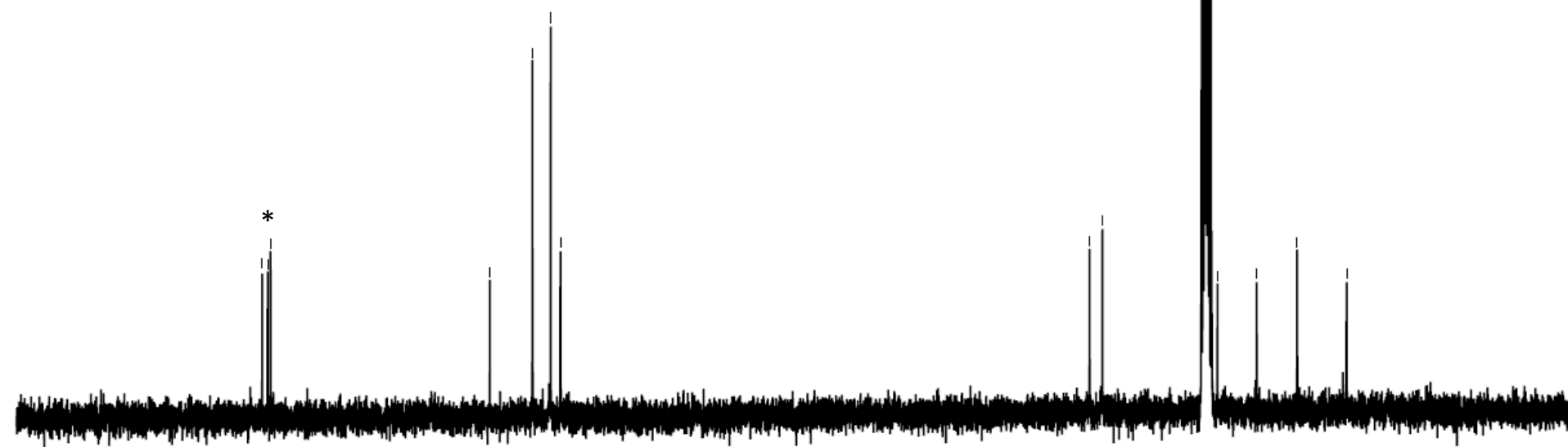

200

$\begin{array}{lllllllllll}190 & 180 & 170 & 160 & 150 & 140 & 130 & 120 & 110 & \begin{array}{c}100 \\ \mathrm{f} 1(\mathrm{ppm})\end{array}\end{array}$

$\begin{array}{llllllllll}80 & 70 & 60 & 50 & 40 & 30 & 20 & 10 & 0 & -10\end{array}$

( ${ }^{*} \mathrm{HCO}_{2}{ }^{-}$carbon). 


\section{4. ${ }^{1} \mathrm{H}$ and ${ }^{13} \mathrm{C}$ NMR spectra of $2 \mathrm{~b}$}

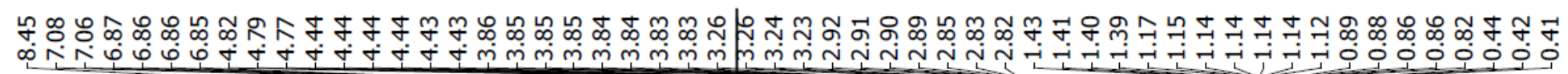<smiles>NCCCC[C@H]1NC(=O)[C@H](Cc2ccc(O)cc2)NC1=O</smiles>

2b
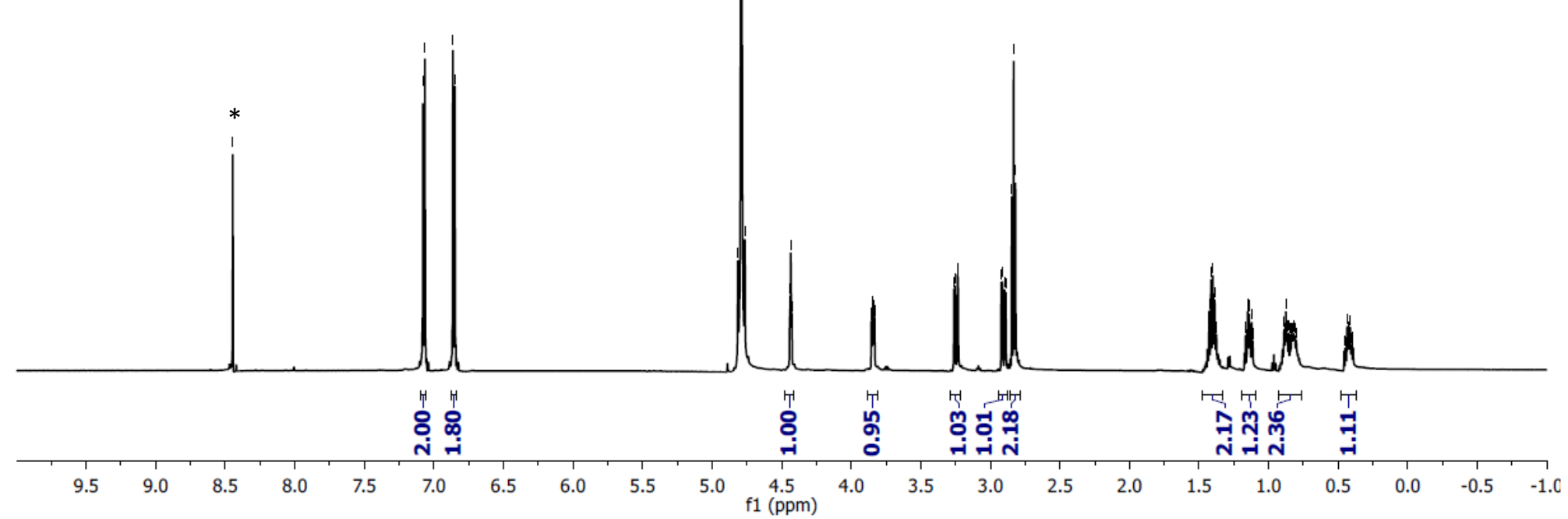

( ${ }^{*} \mathrm{HCO}_{2}{ }^{-}$proton).

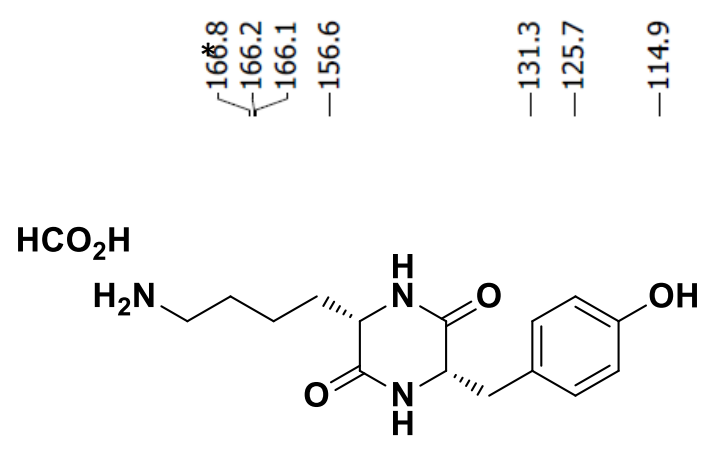

2b

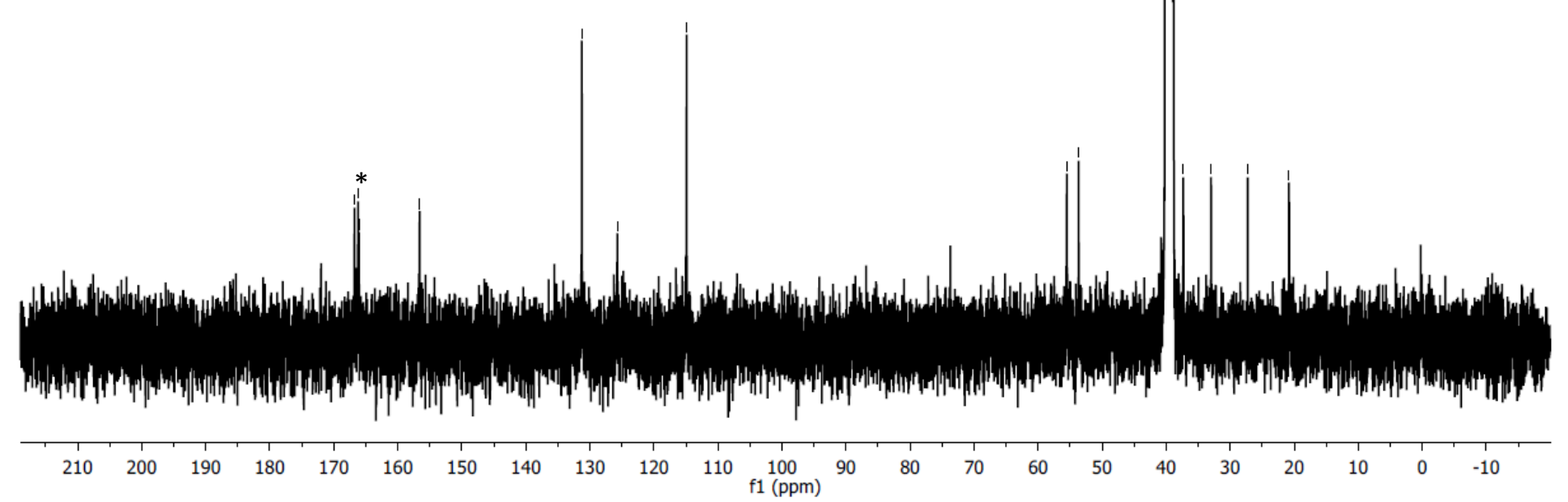

( ${ }^{*} \mathrm{HCO}_{2}{ }^{-}$carbon). 


\section{5. ${ }^{1} \mathrm{H}$ and ${ }^{13} \mathrm{C}$ NMR spectra of $2 \mathrm{c}$}

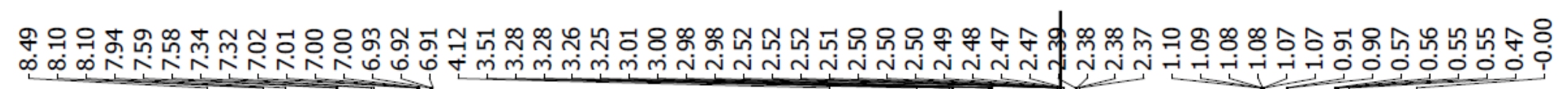
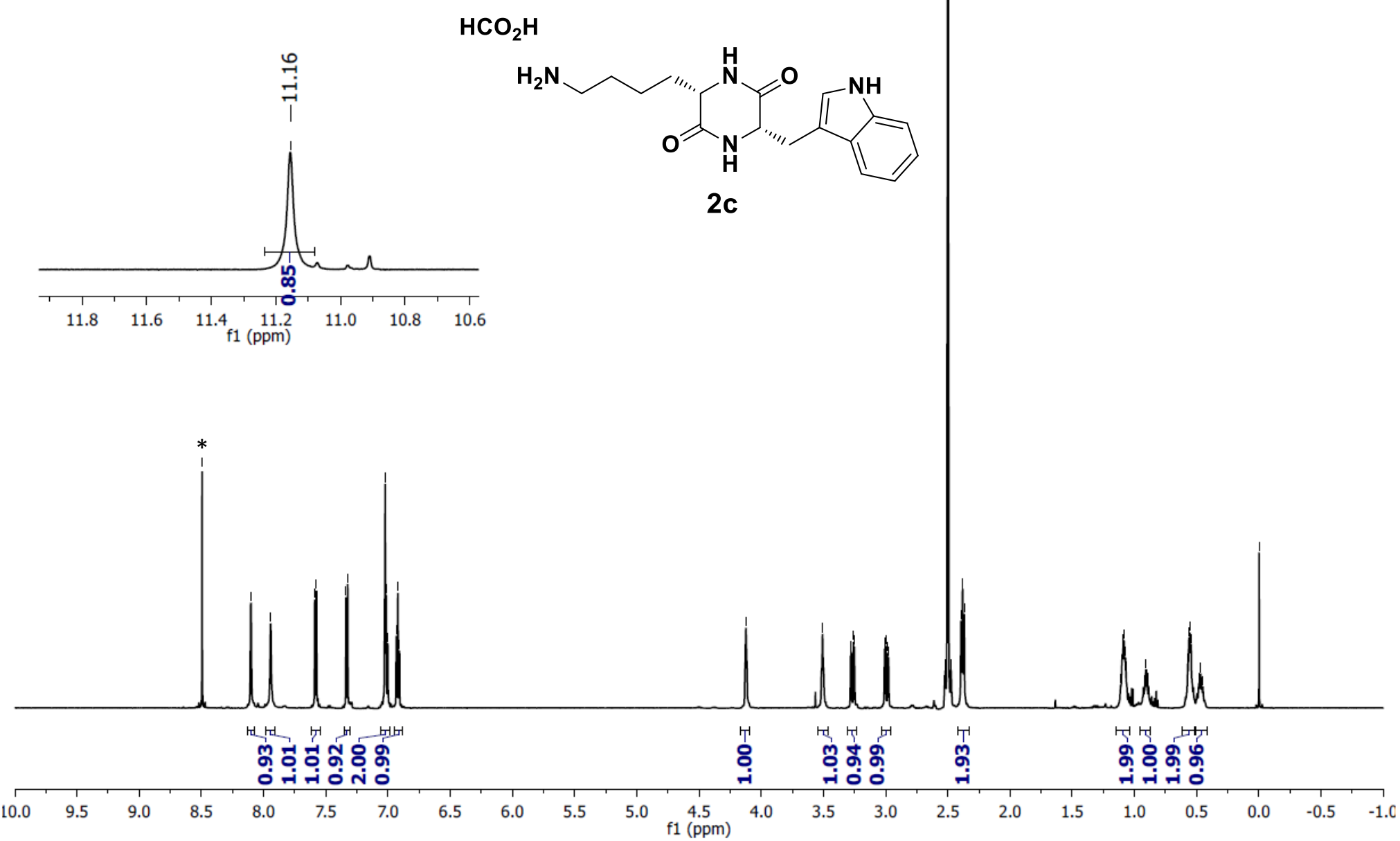

( ${ }^{*} \mathrm{HCO}_{2}^{-}$proton).
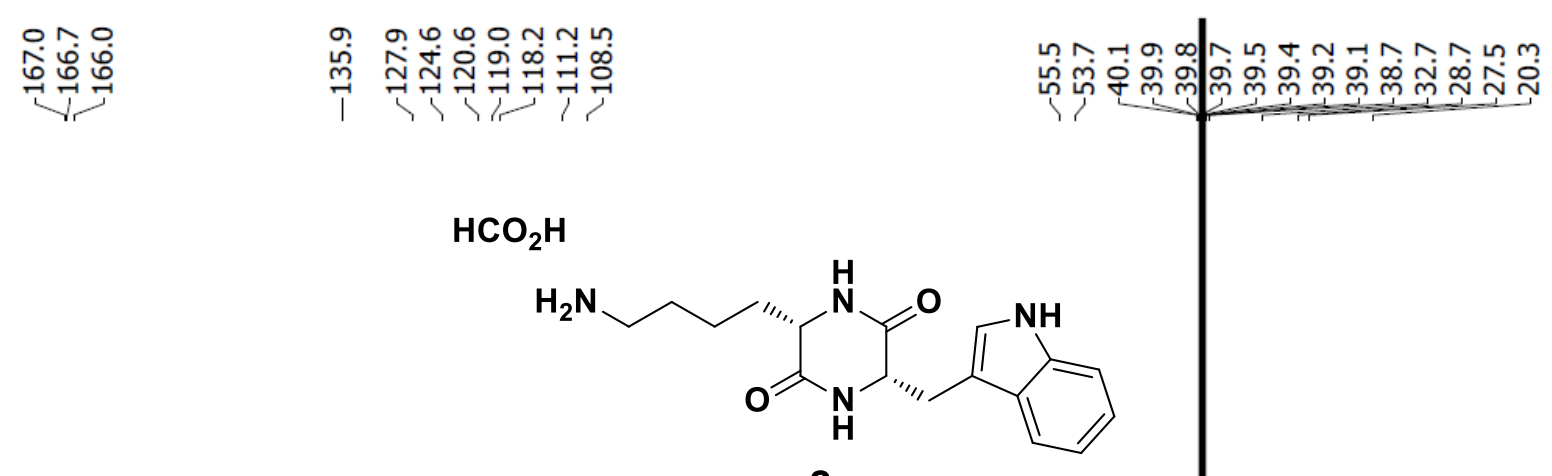

2c

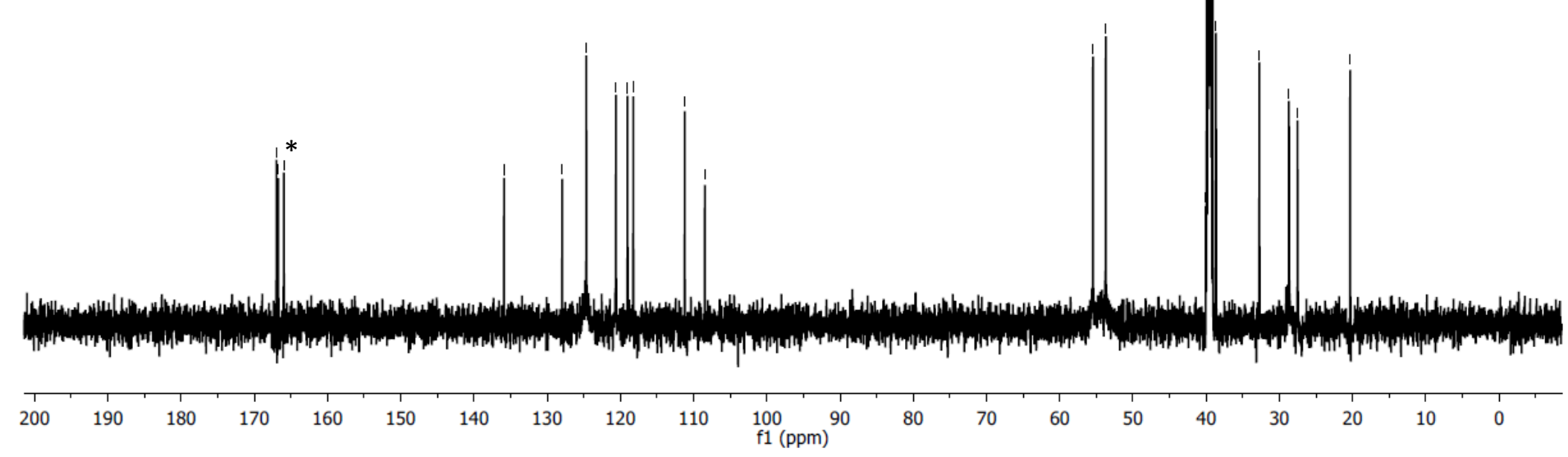

( ${ }^{*} \mathrm{HCO}_{2}{ }^{-}$carbon). 


\section{6. ${ }^{1} \mathrm{H}$ and ${ }^{13} \mathrm{C}$ NMR Spectra of $4 \mathrm{a}$}

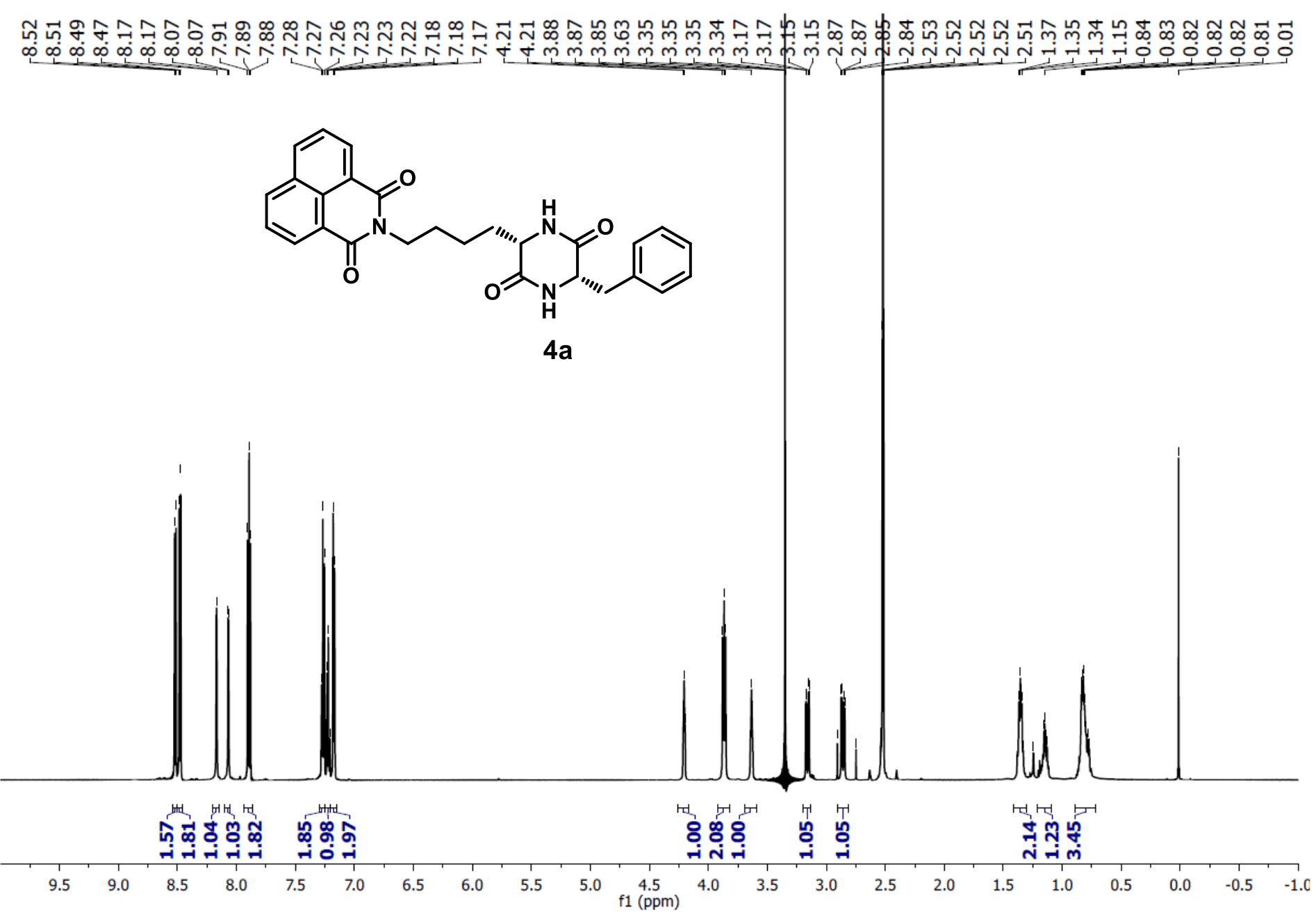

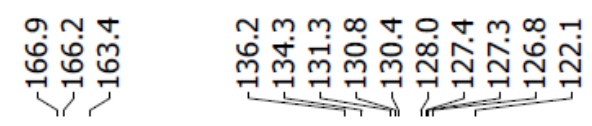
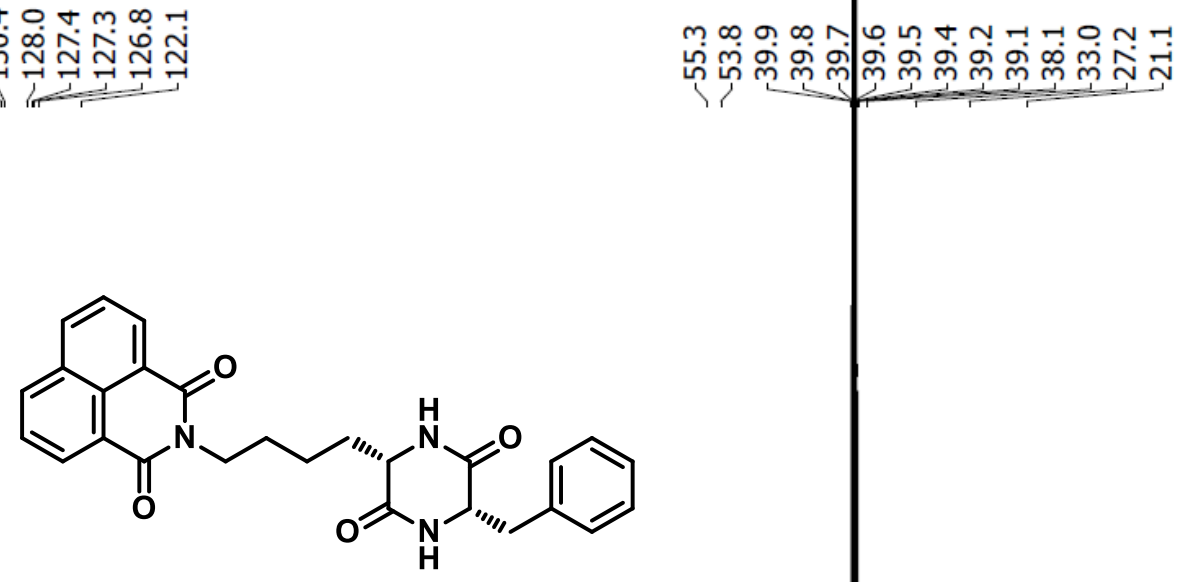

$4 a$

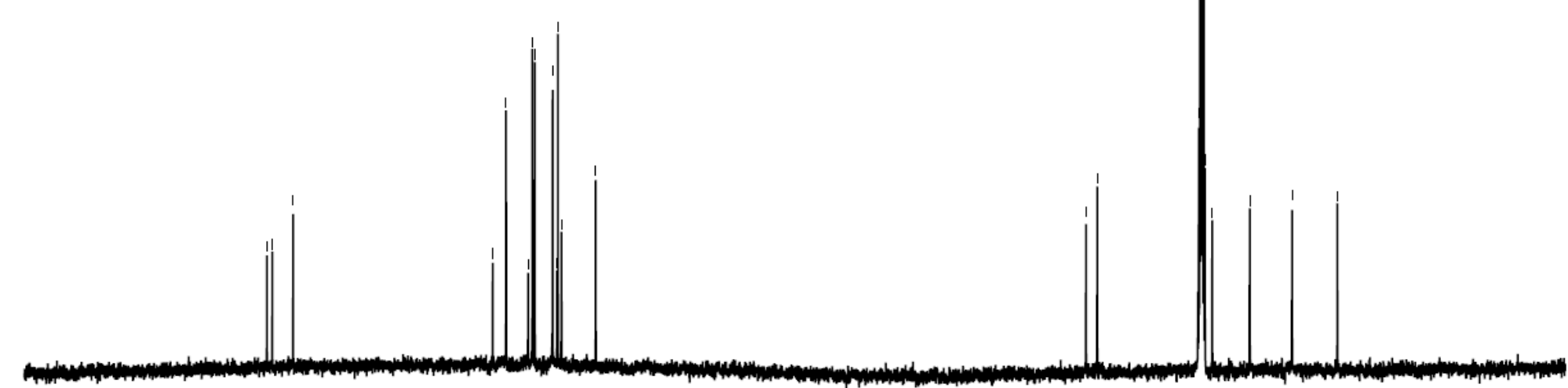

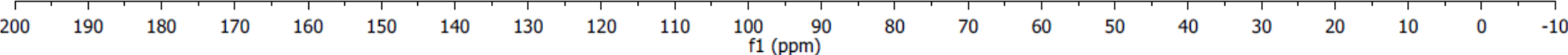


17. ${ }^{1} \mathrm{H}$ and ${ }^{13} \mathrm{C}$ NMR Spectra of $4 \mathrm{~b}$

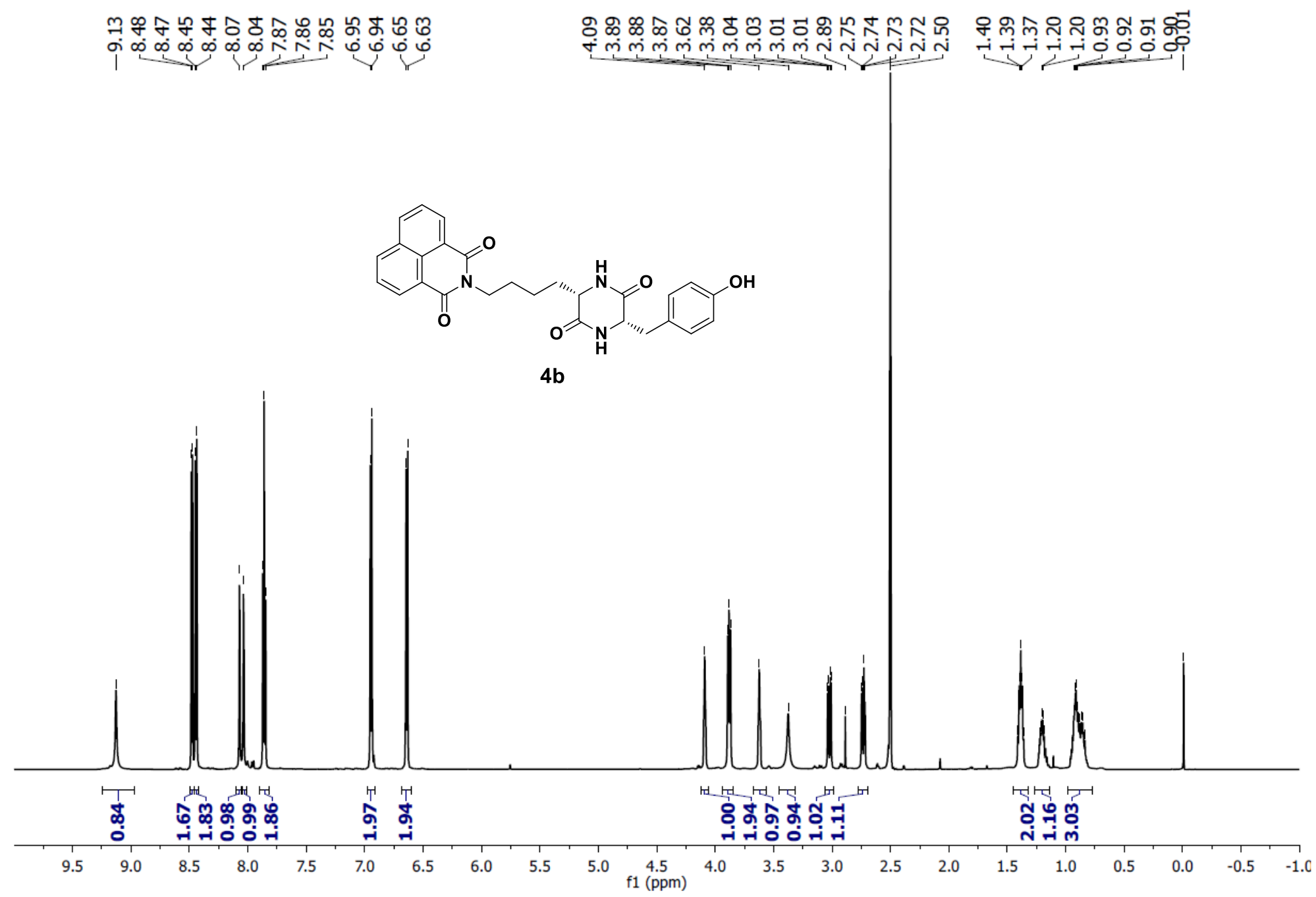

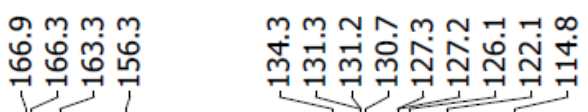
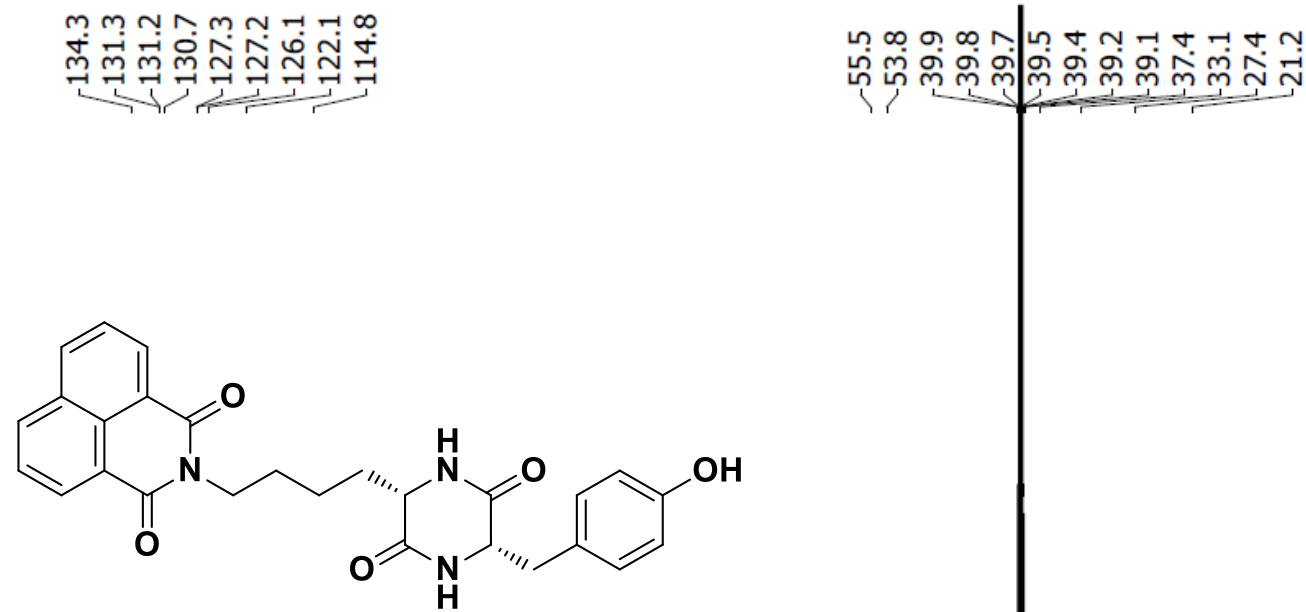

4b

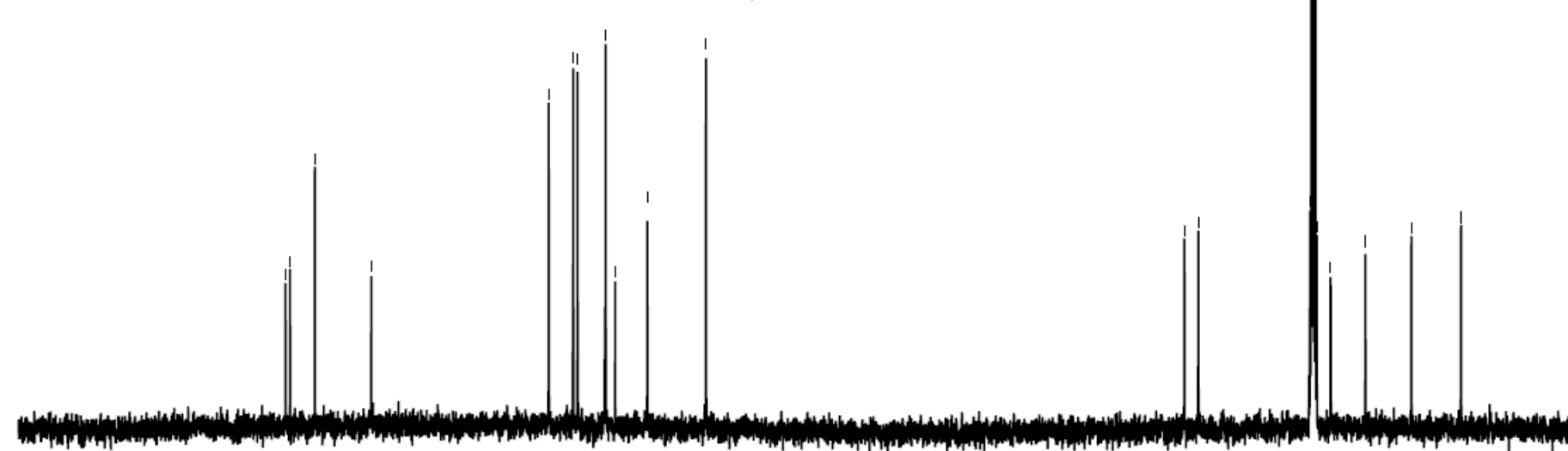

$\begin{array}{llllllllll}190 & 180 & 170 & 160 & 150 & 140 & 130 & 120 & 110 & 100 \\ & & & & & & & & & 90\end{array}$

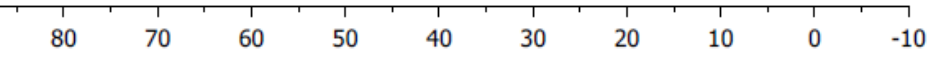


18. ${ }^{1} \mathrm{H}$ and ${ }^{13} \mathrm{C}$ NMR Spectra of $4 \mathrm{c}$

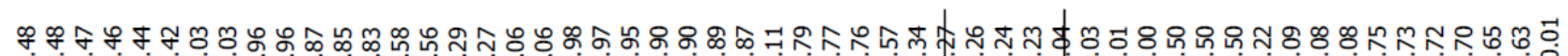

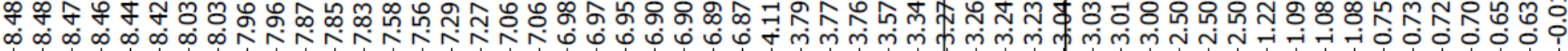
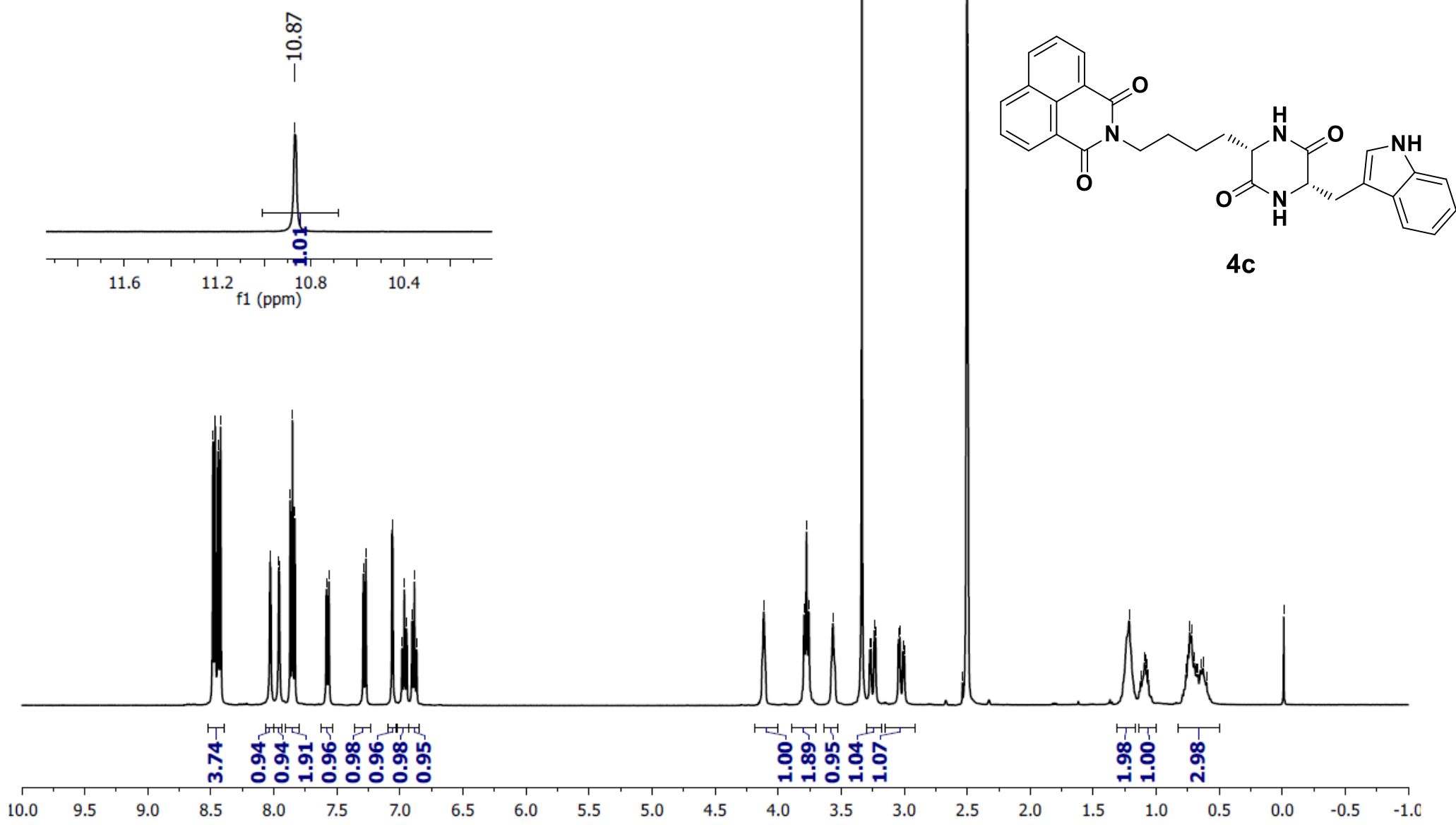

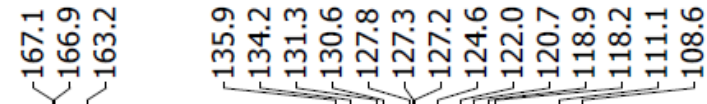

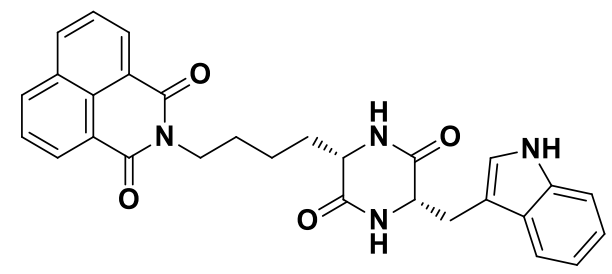

4c

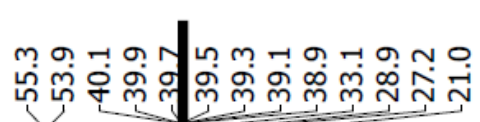

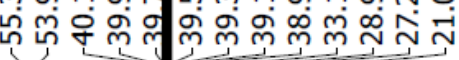

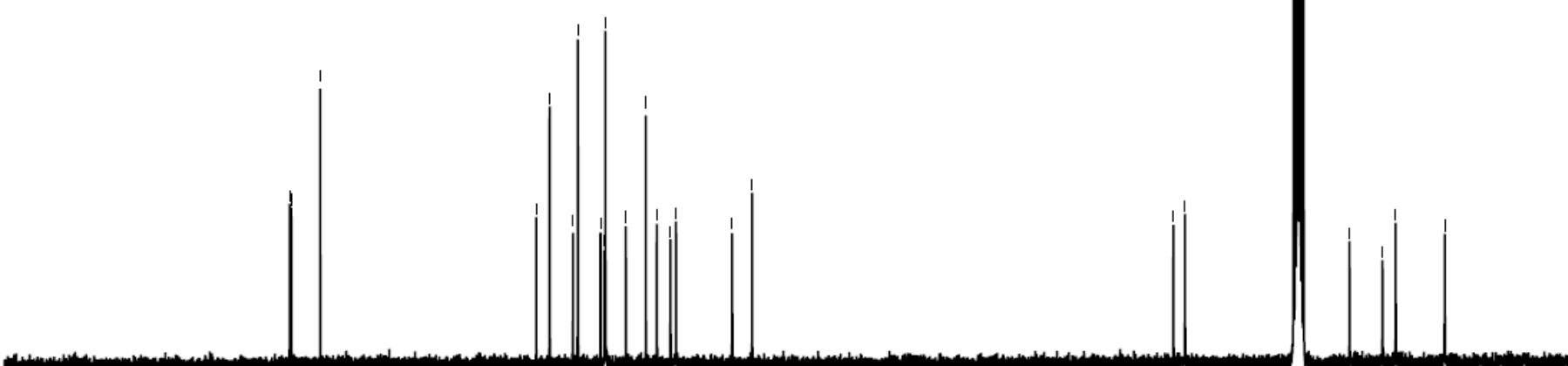


19. ${ }^{1} \mathrm{H}$ and ${ }^{13} \mathrm{C}$ NMR spectra of $5 \mathrm{a}$

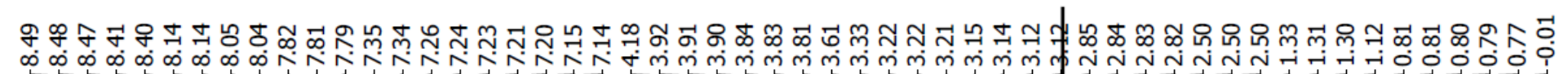<smiles>O=C1NC(Cc2ccccc2)C(=O)NC1CCCCN1C(=O)c2cccc3c(N4CCOCC4)ccc(c23)C1=O</smiles>

$5 a$

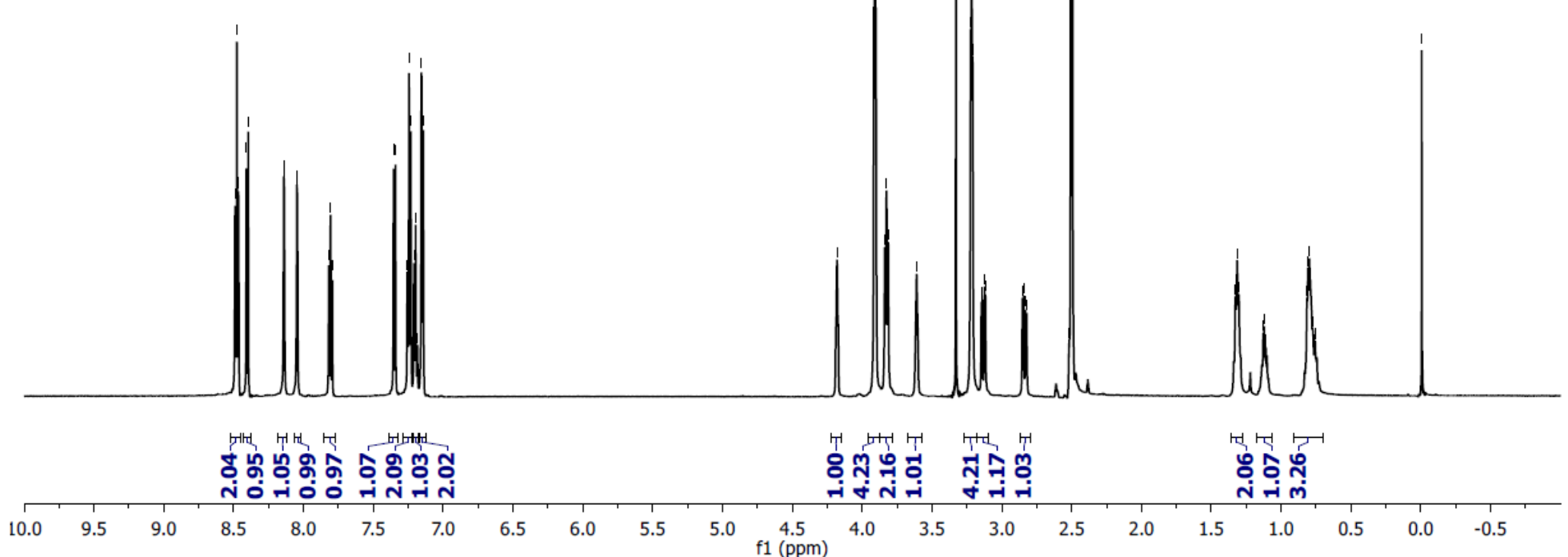

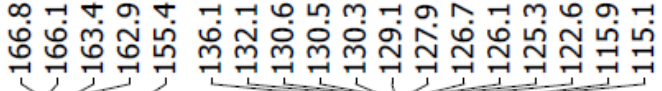

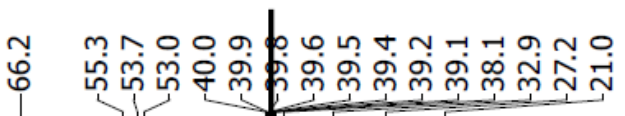

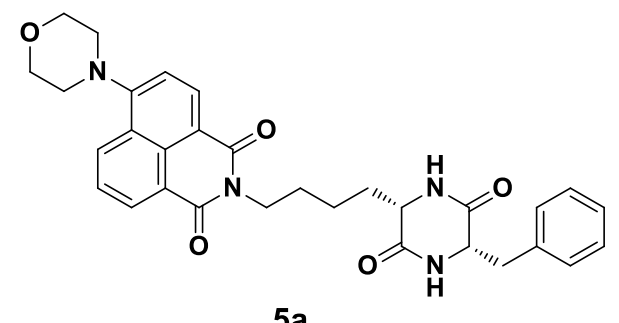

$5 a$

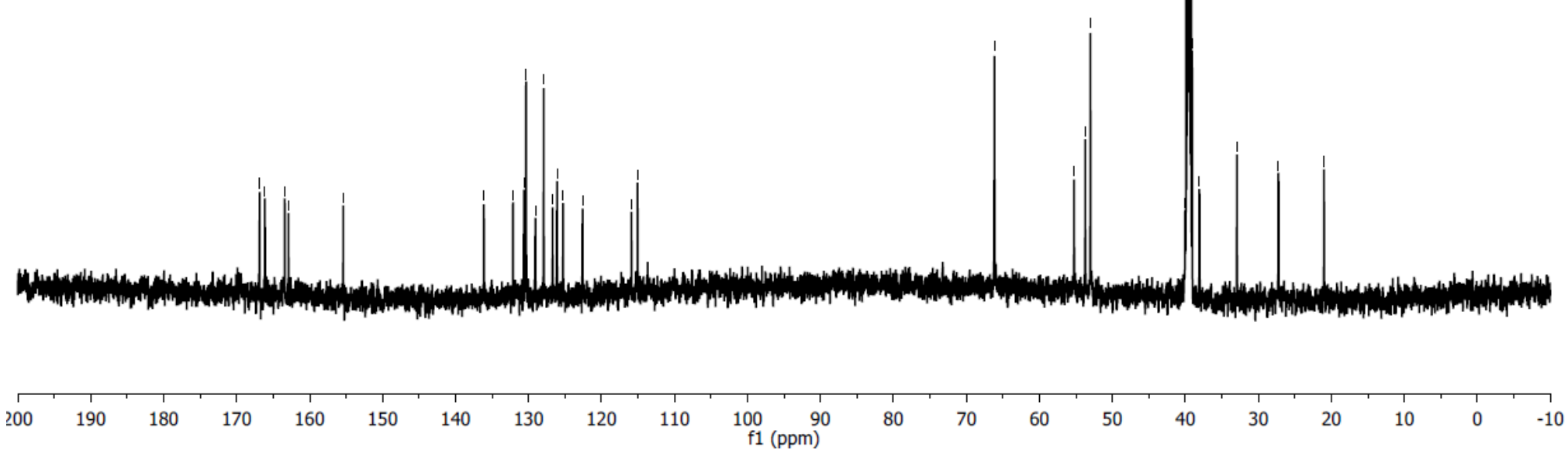




\section{0. ${ }^{1} \mathrm{H}$ and ${ }^{13} \mathrm{C}$ NMR spectra of $5 b$}

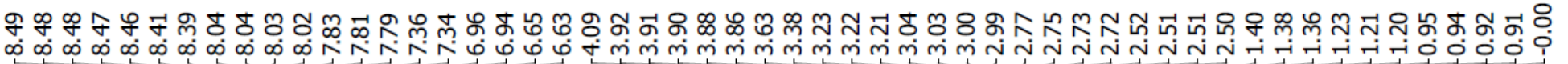<smiles>O=C1N[C@H](CCCCN2C(=O)c3cccc4c(N5CCOCC5)ccc(c34)C2=O)C(=O)N[C@H]1Cc1ccc(O)cc1</smiles>

$5 b$

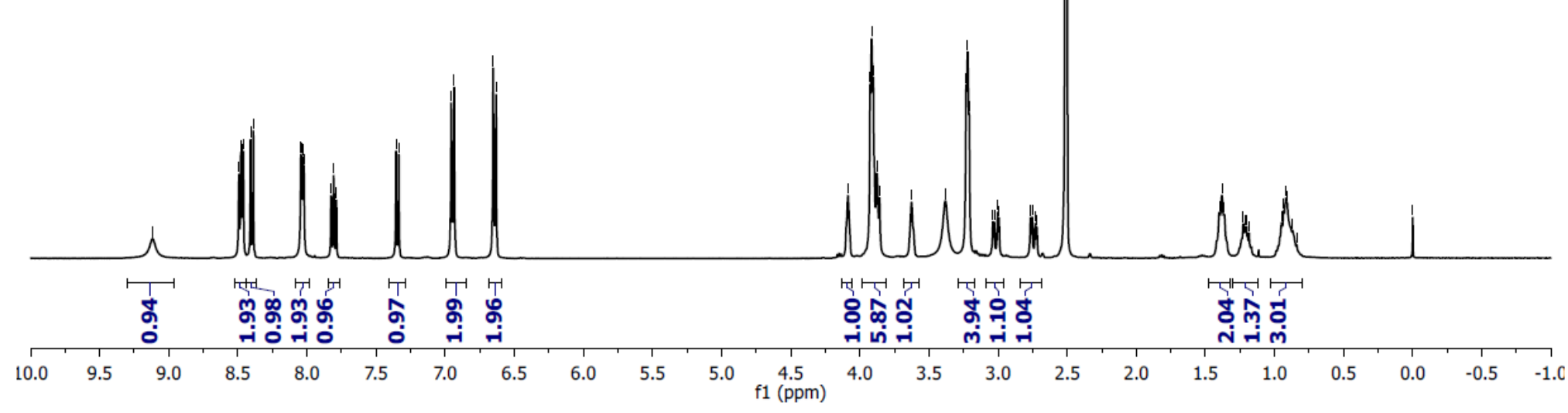

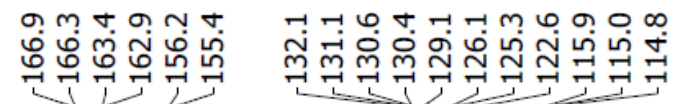
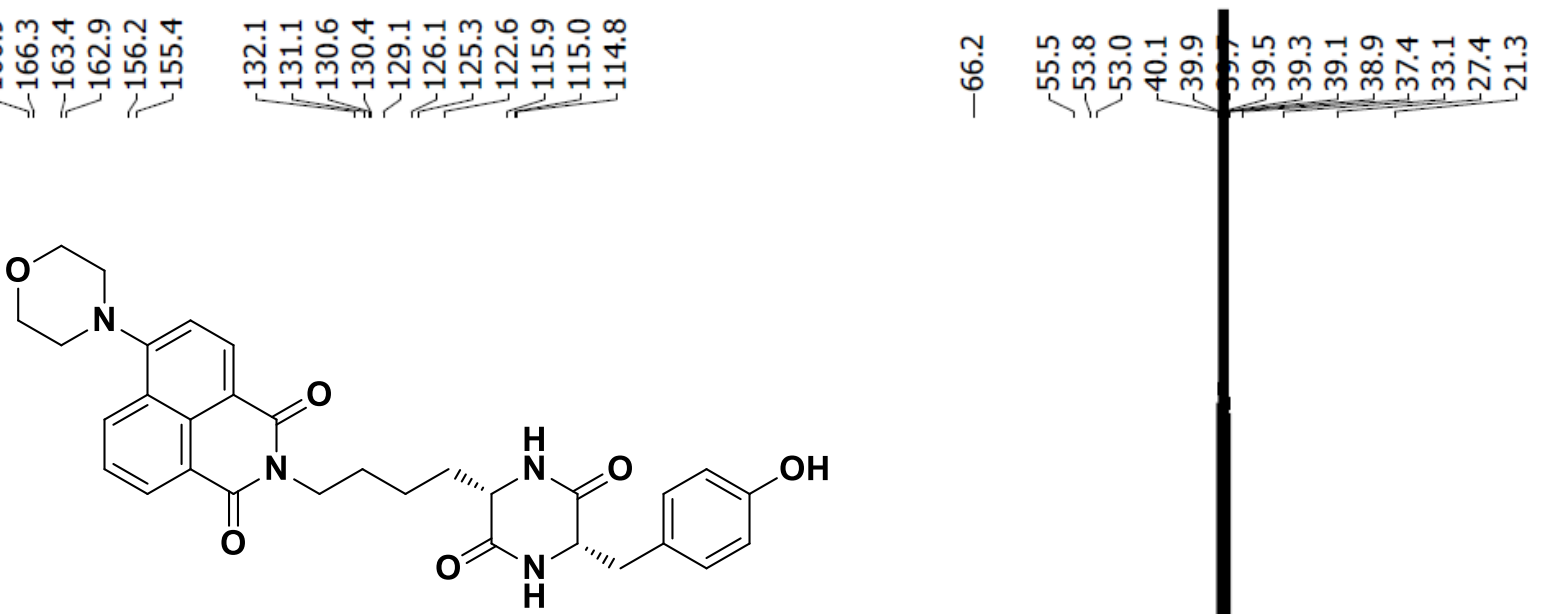

$5 b$

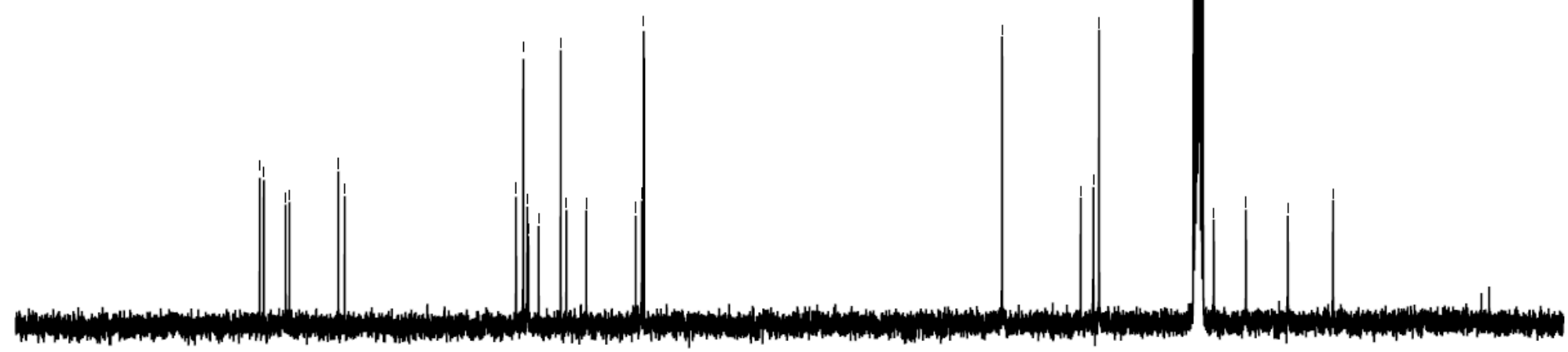




\section{1. ${ }^{1} \mathrm{H}$ and ${ }^{13} \mathrm{C}$ NMR spectra $5 \mathrm{c}$}

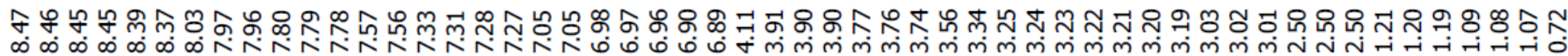
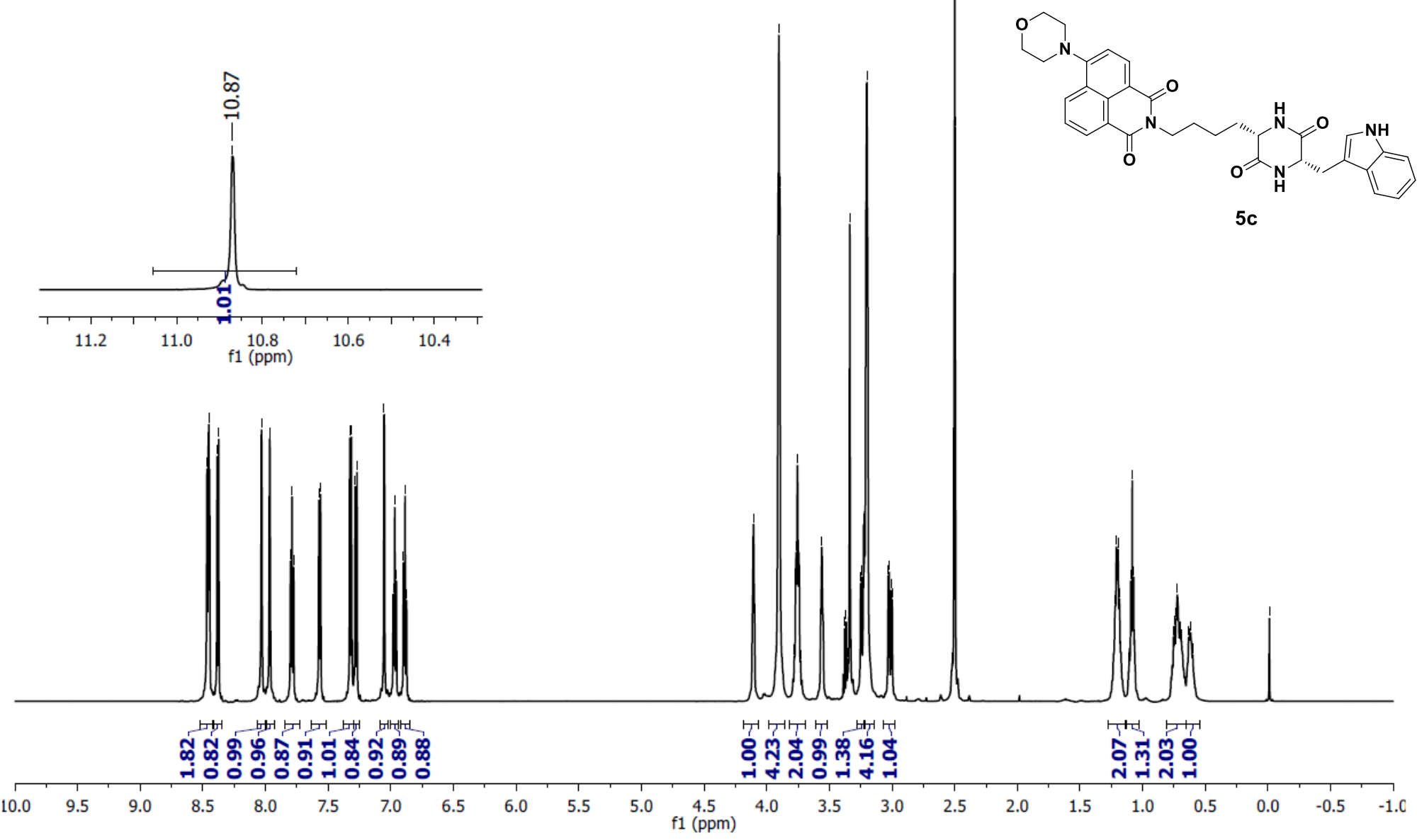

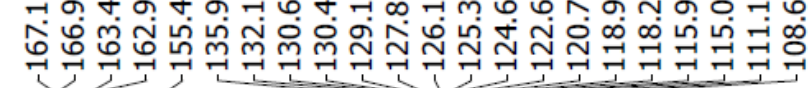
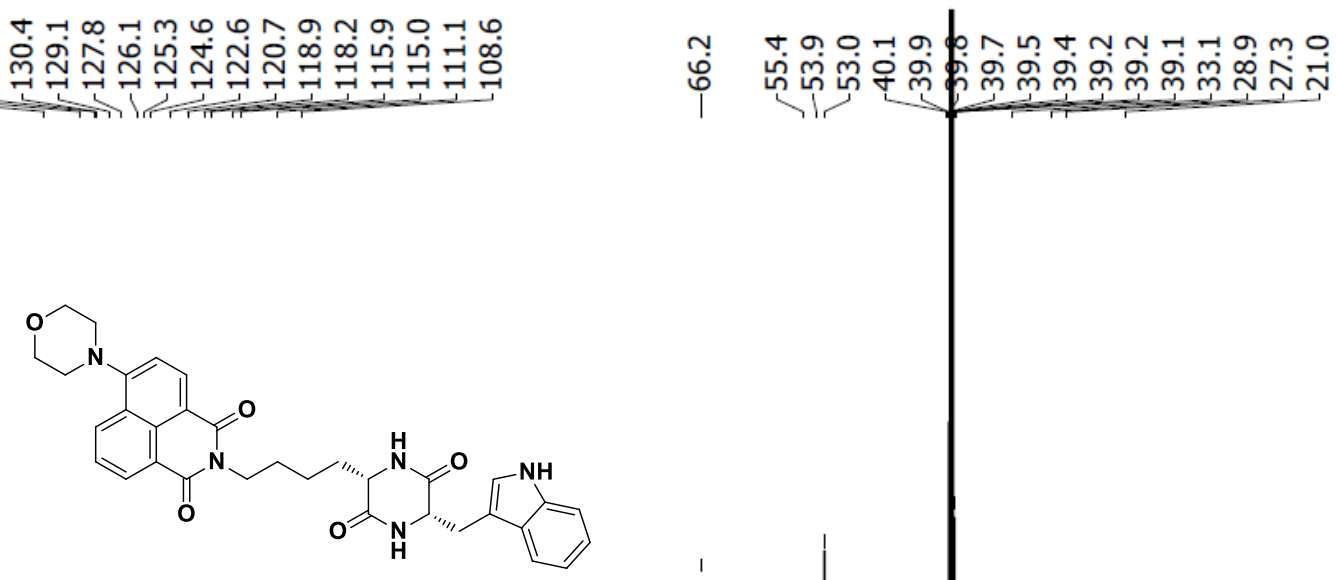

$5 c$ 


\section{2. ${ }^{1} \mathrm{H}$ and ${ }^{13} \mathrm{C}$ NMR spectra 6a}

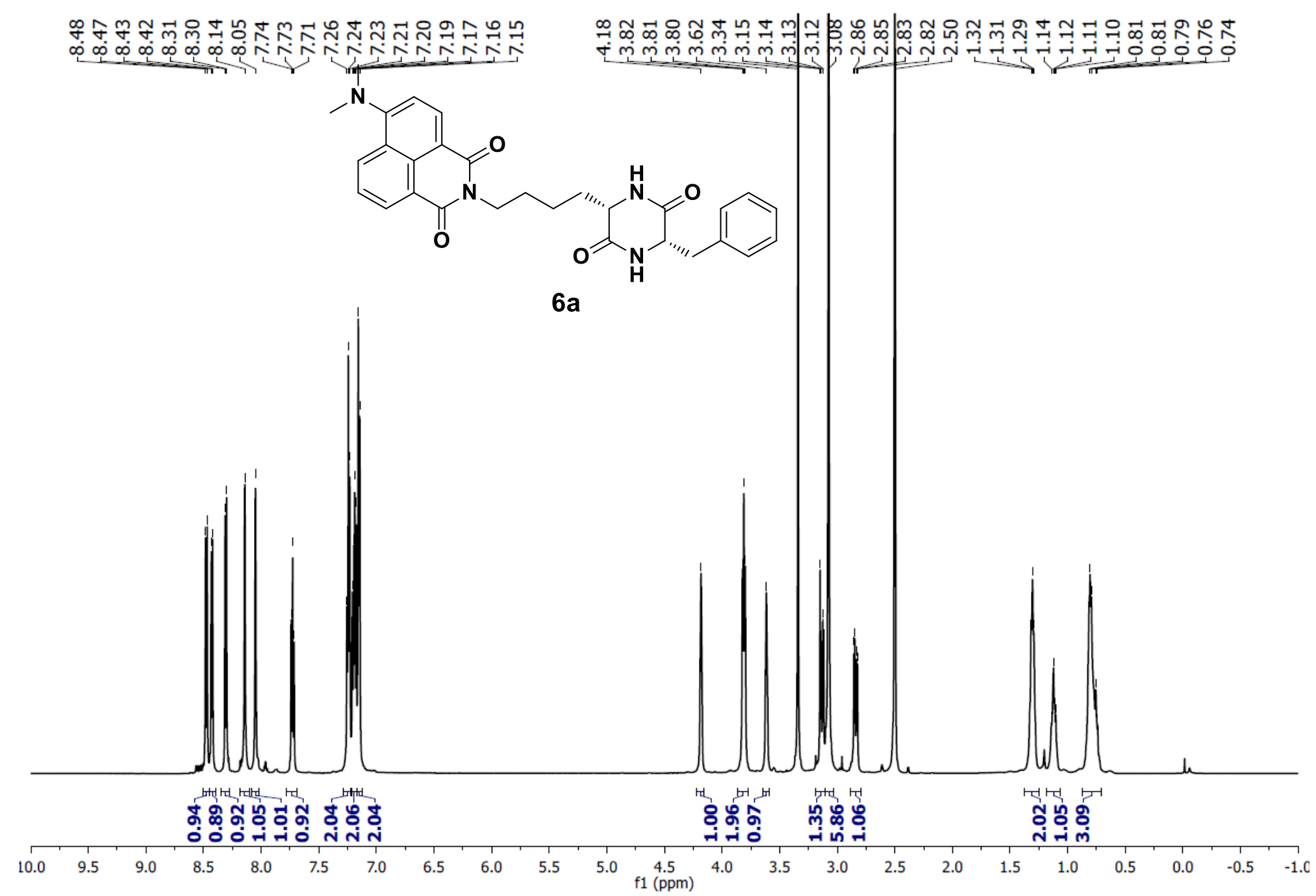

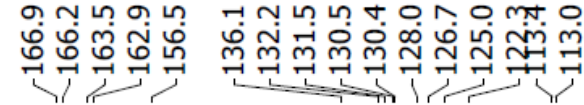

mุฒ

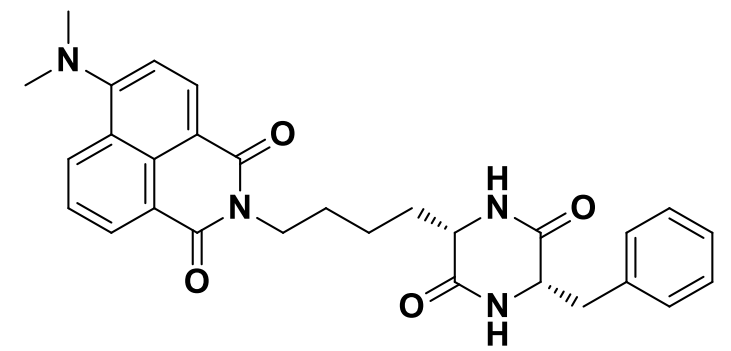

$6 a$

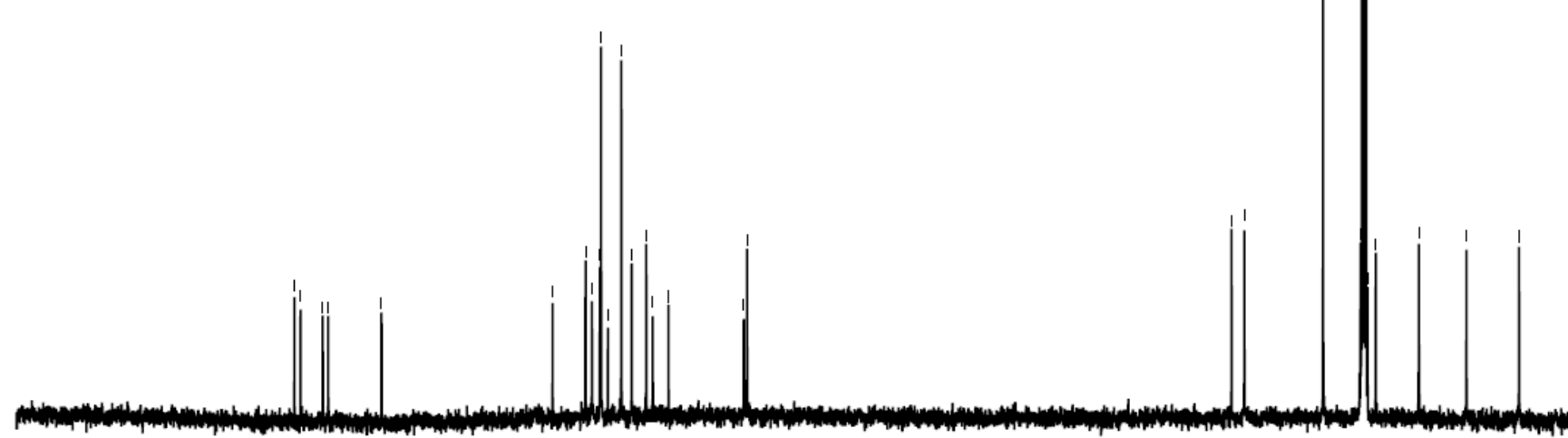

$\begin{array}{rlllllllllllllllllllll}200 & 190 & 180 & 170 & 160 & 150 & 140 & 130 & 120 & 110 & 100 & 90 & 80 & 70 & 60 & 50 & 40 & 30 & 20 & 10 & 0 & -10\end{array}$ 


\section{3. ${ }^{1} \mathrm{H}$ and ${ }^{13} \mathrm{C}$ NMR spectra $6 \mathrm{~b}$}

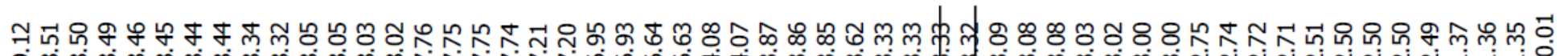

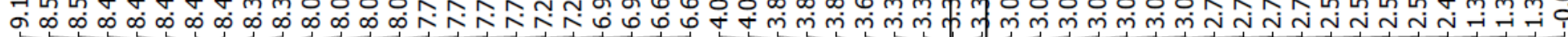<smiles>CN(C)c1ccc2c3c(cccc13)C(=O)N(CCCC[C@H]1NC(=O)[C@H](Cc3ccc(O)cc3)NC1=O)C2=O</smiles>

$6 b$

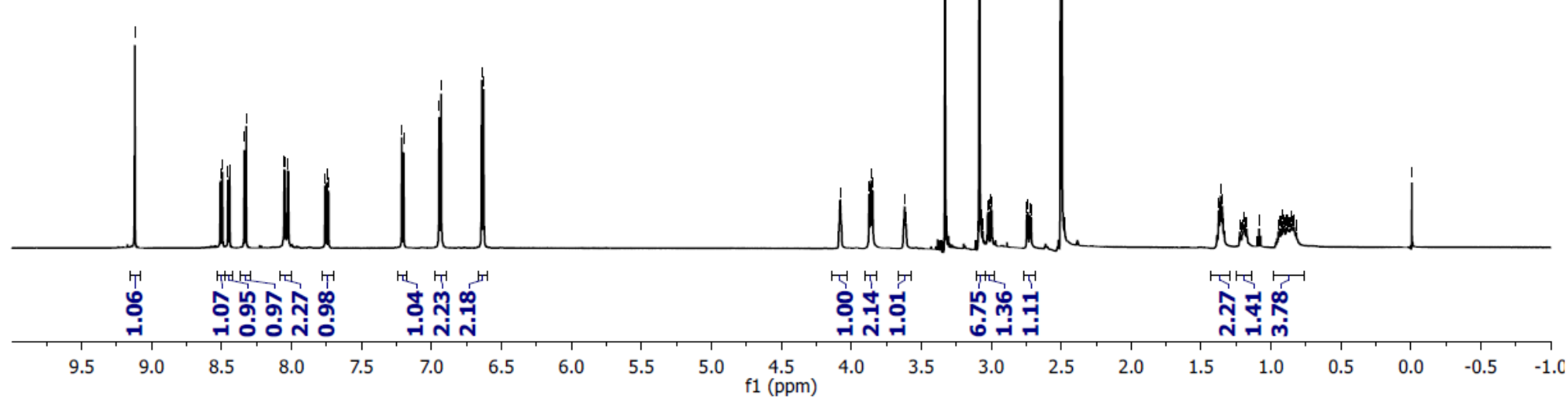

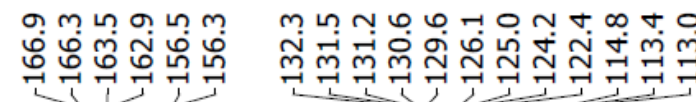<smiles>CN(C)c1ccc2c3c(cccc13)C(=O)N(CCCC[C@H]1NC(=O)[C@H](Cc3ccc(O)cc3)NC1=O)C2=O</smiles>

$6 b$

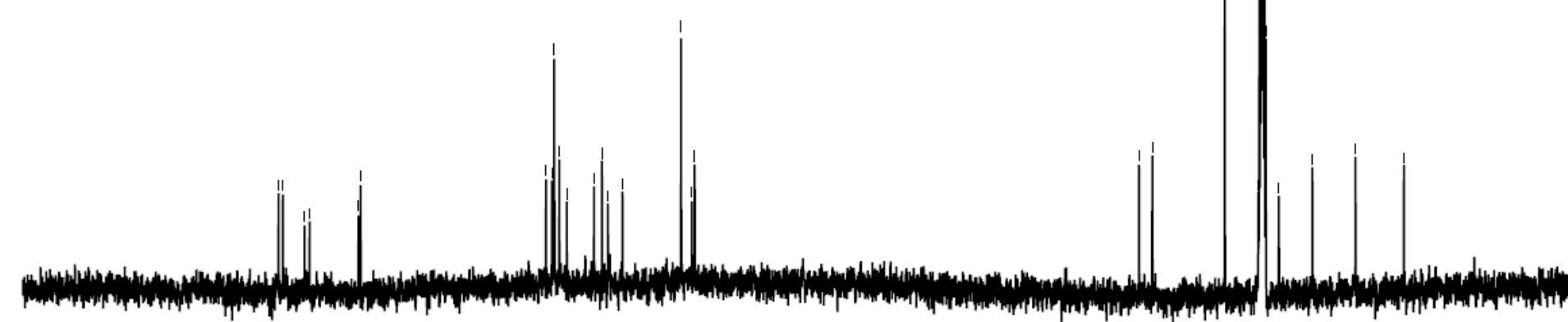

$\begin{array}{lllllllllll}200 & 190 & 180 & 170 & 160 & 150 & 140 & 130 & 120 & 110 & \begin{array}{c}100 \\ \mathrm{f} 1(\mathrm{ppm})\end{array}\end{array}$ 


\section{4. ${ }^{1} \mathrm{H}$ and ${ }^{13} \mathrm{C}$ NMR spectra $6 \mathrm{~b}$}

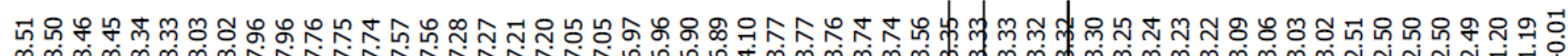
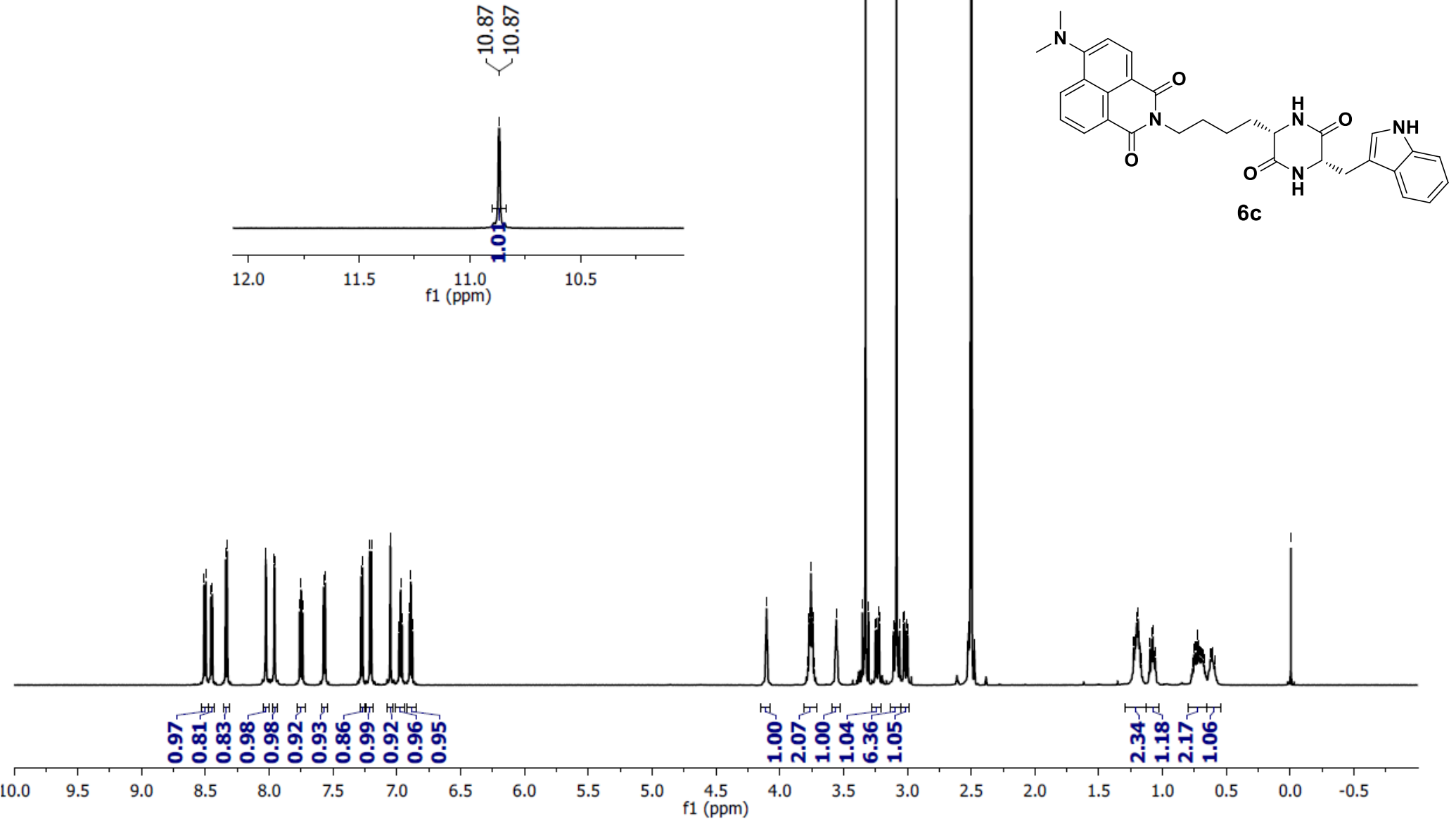

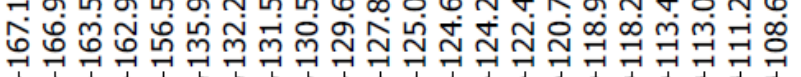

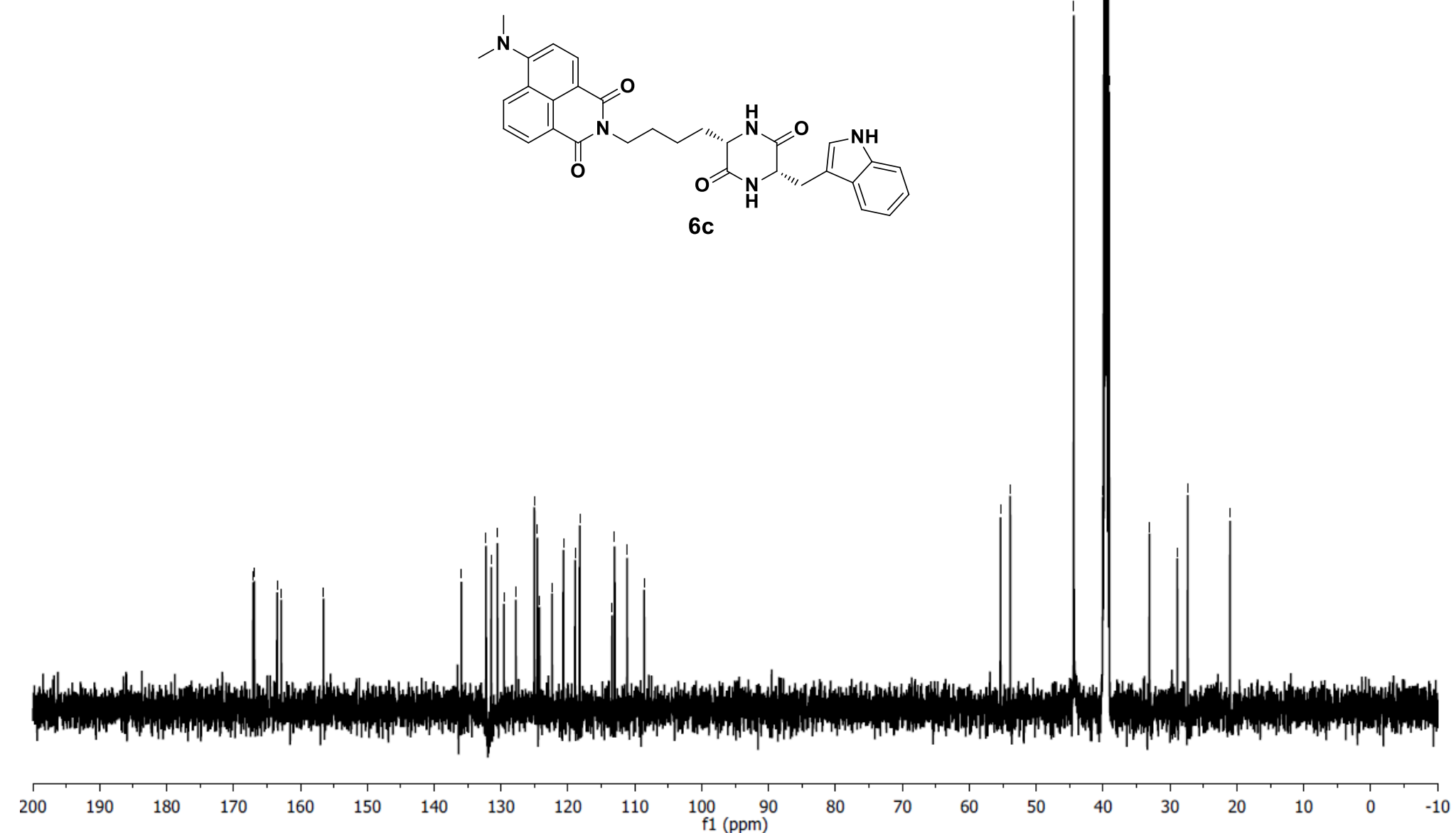

mุ 


\section{HRMS spectra}

User Spectra

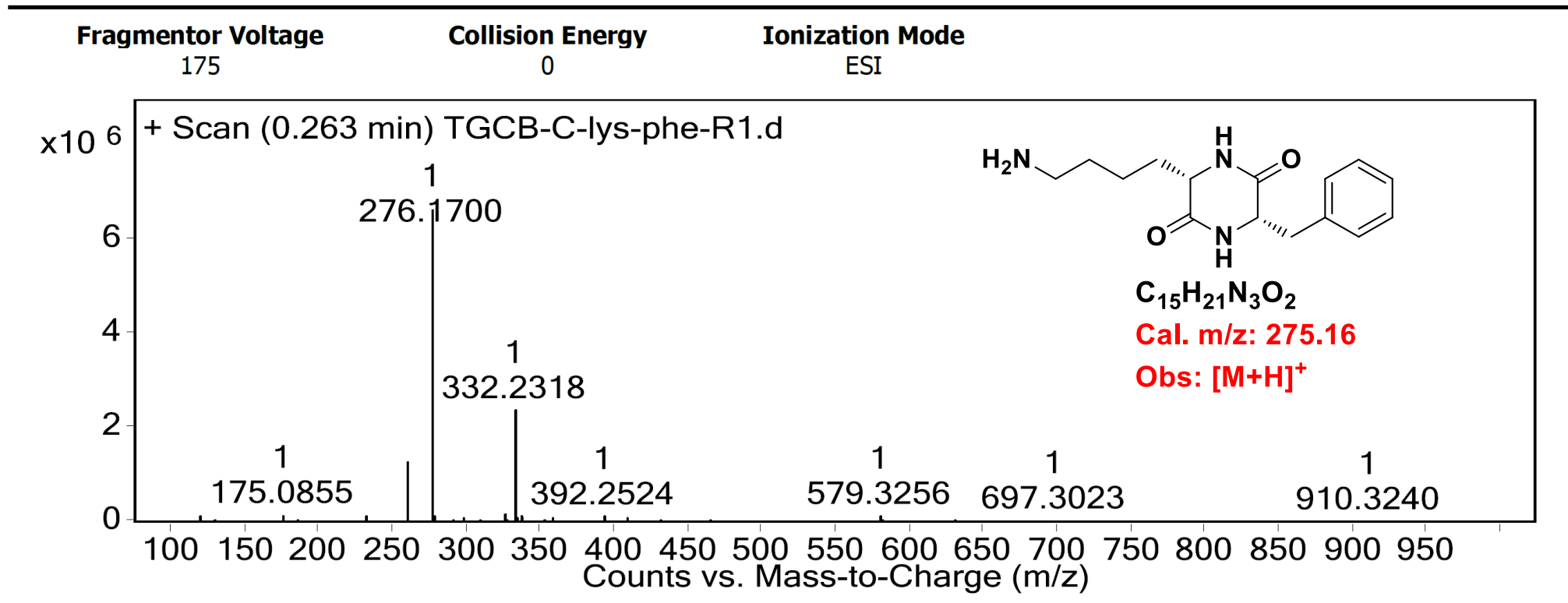

\section{User Spectra}

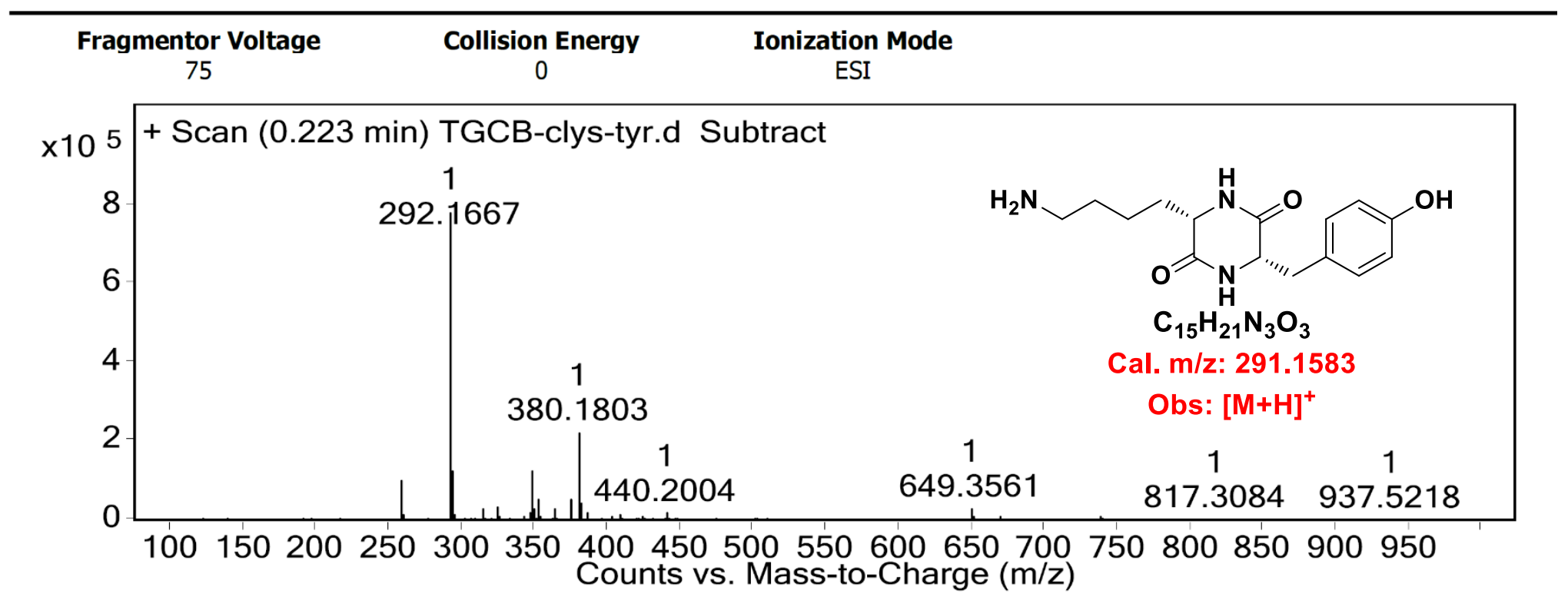

\section{User Spectra}

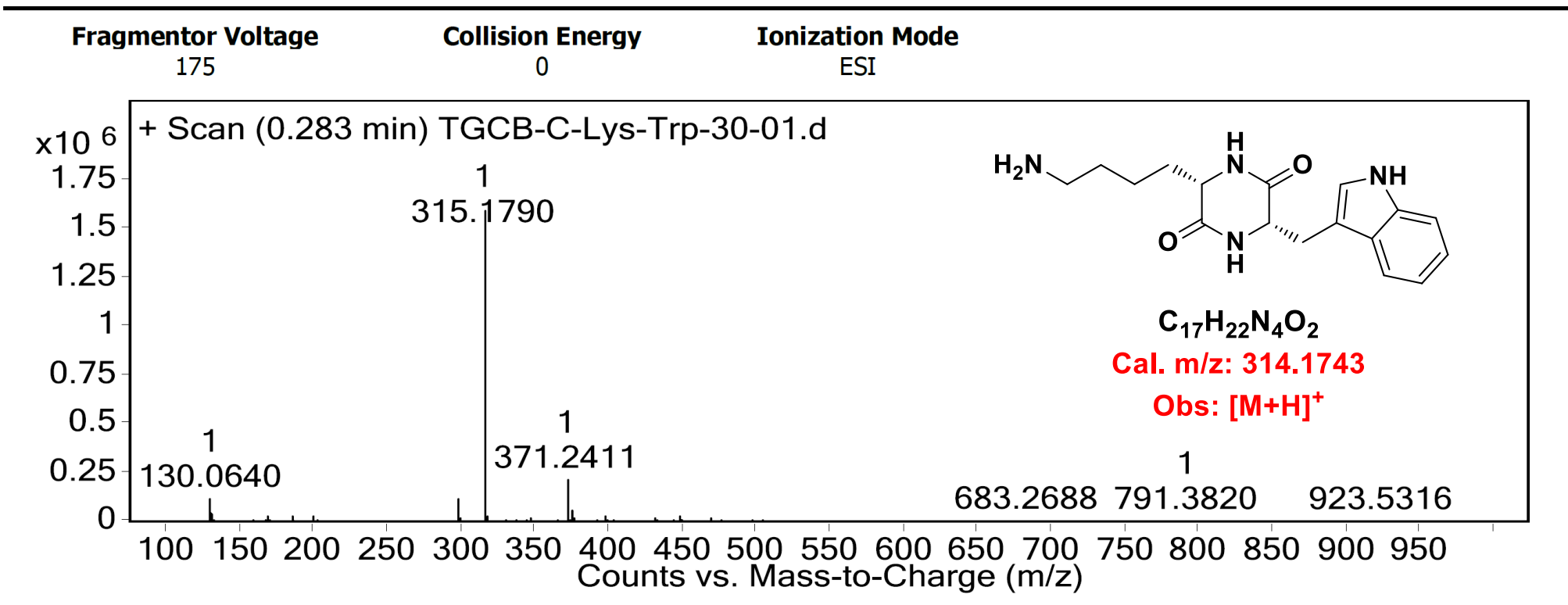




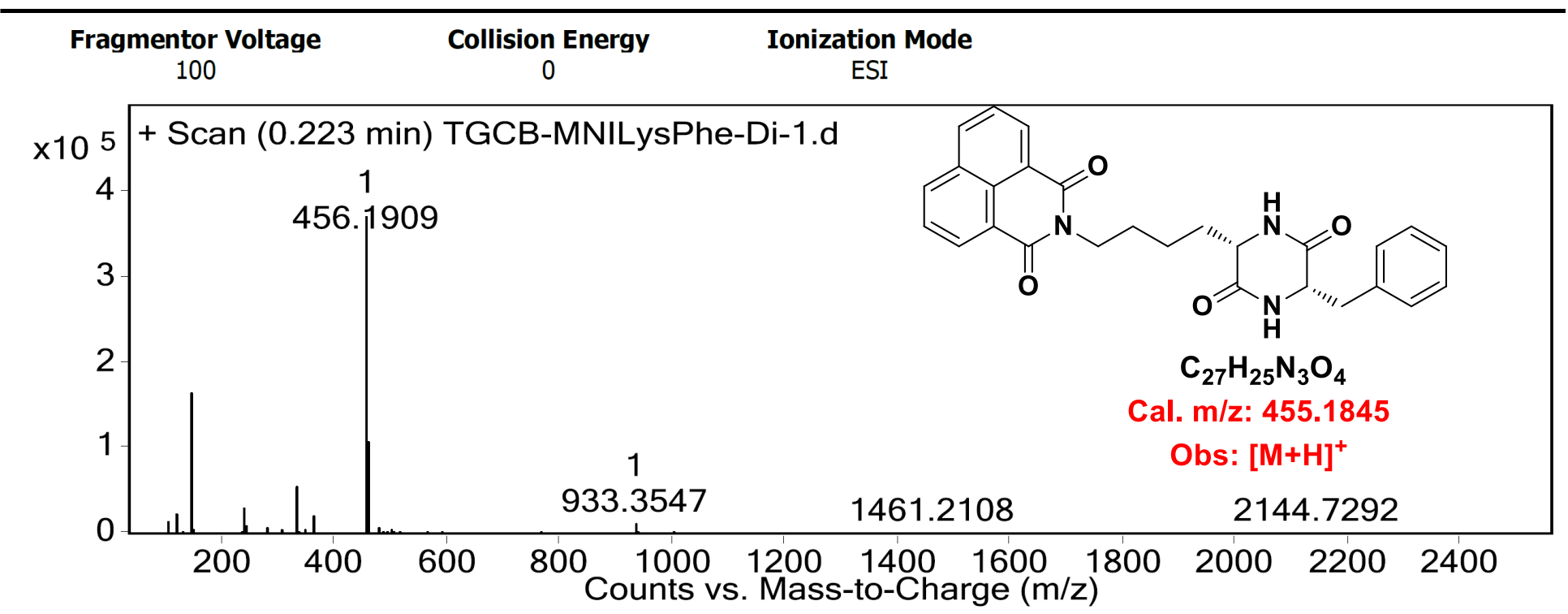

\section{User Spectra}

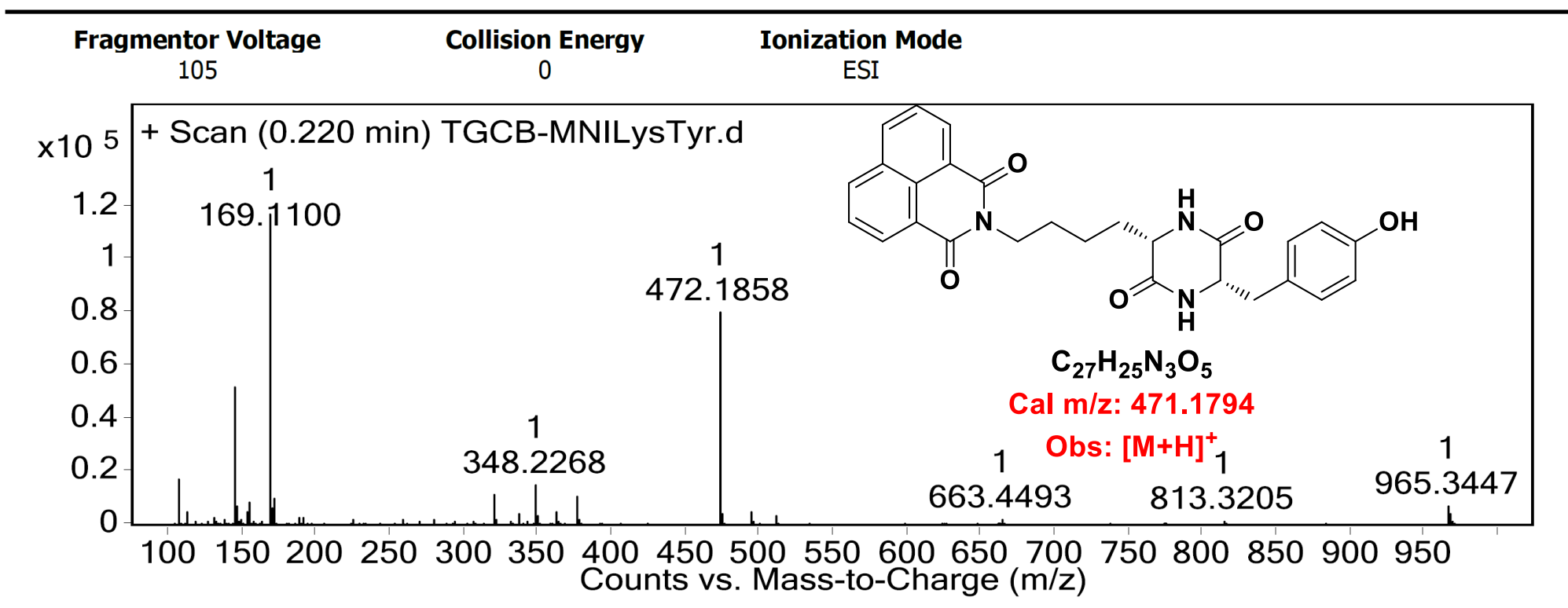

\section{User Spectra}

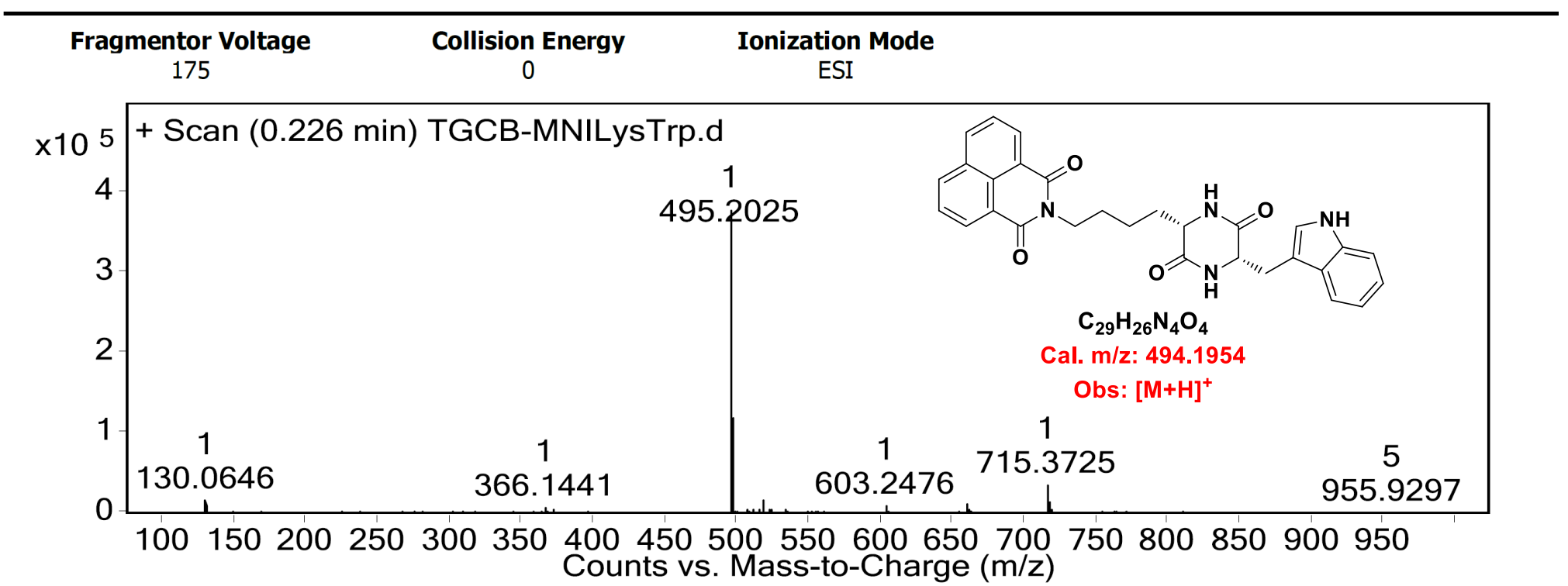




\section{User Spectra}

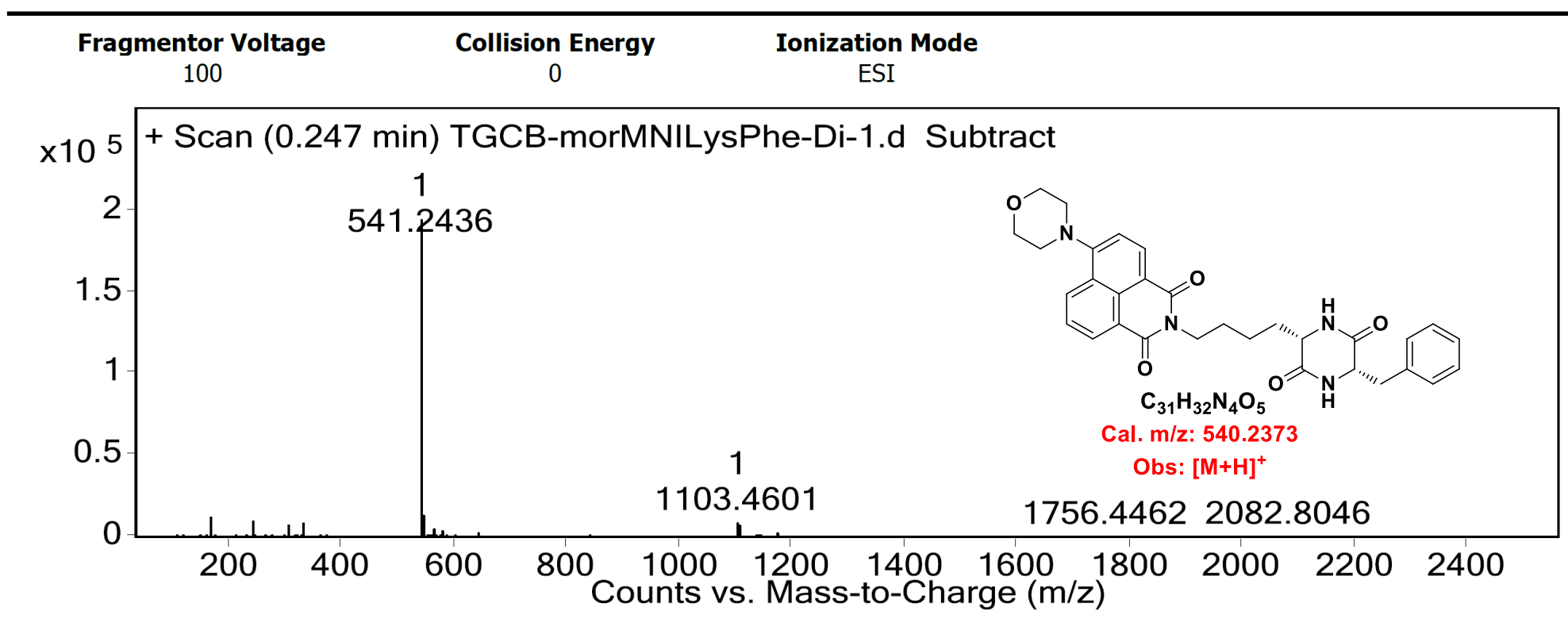

\section{User Spectra}

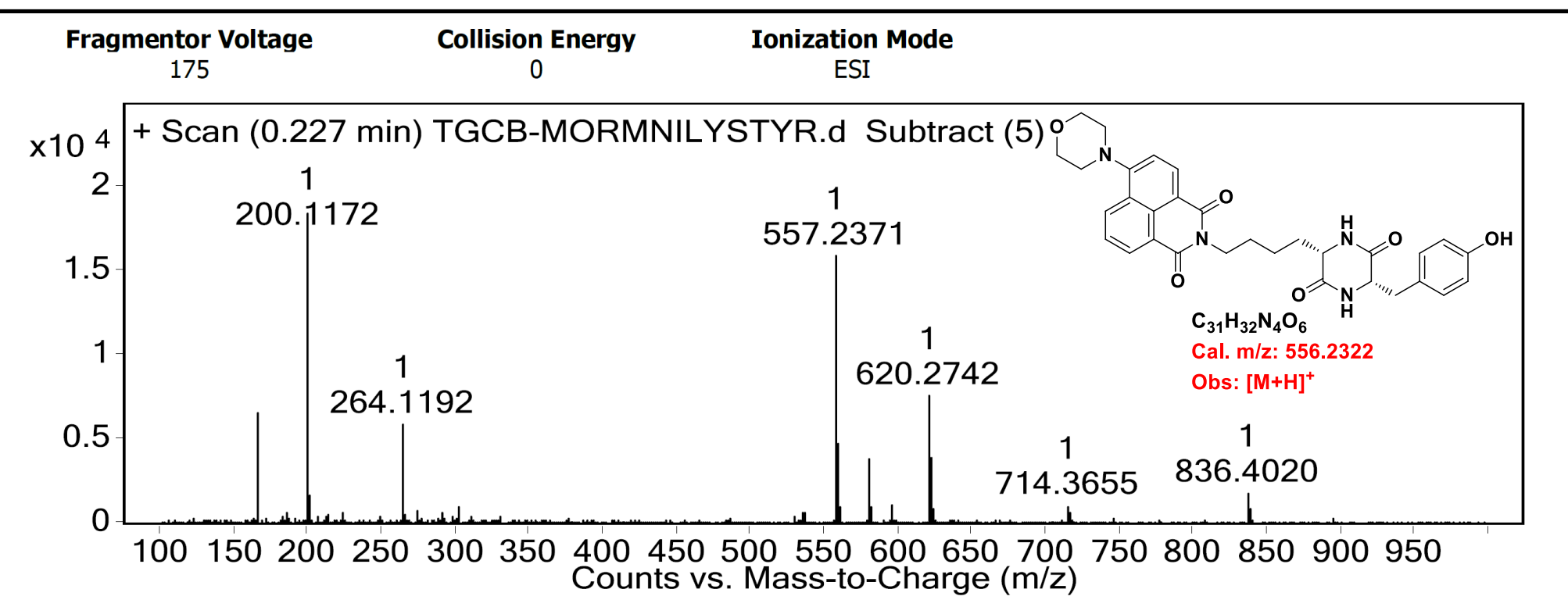

\section{User Spectra}

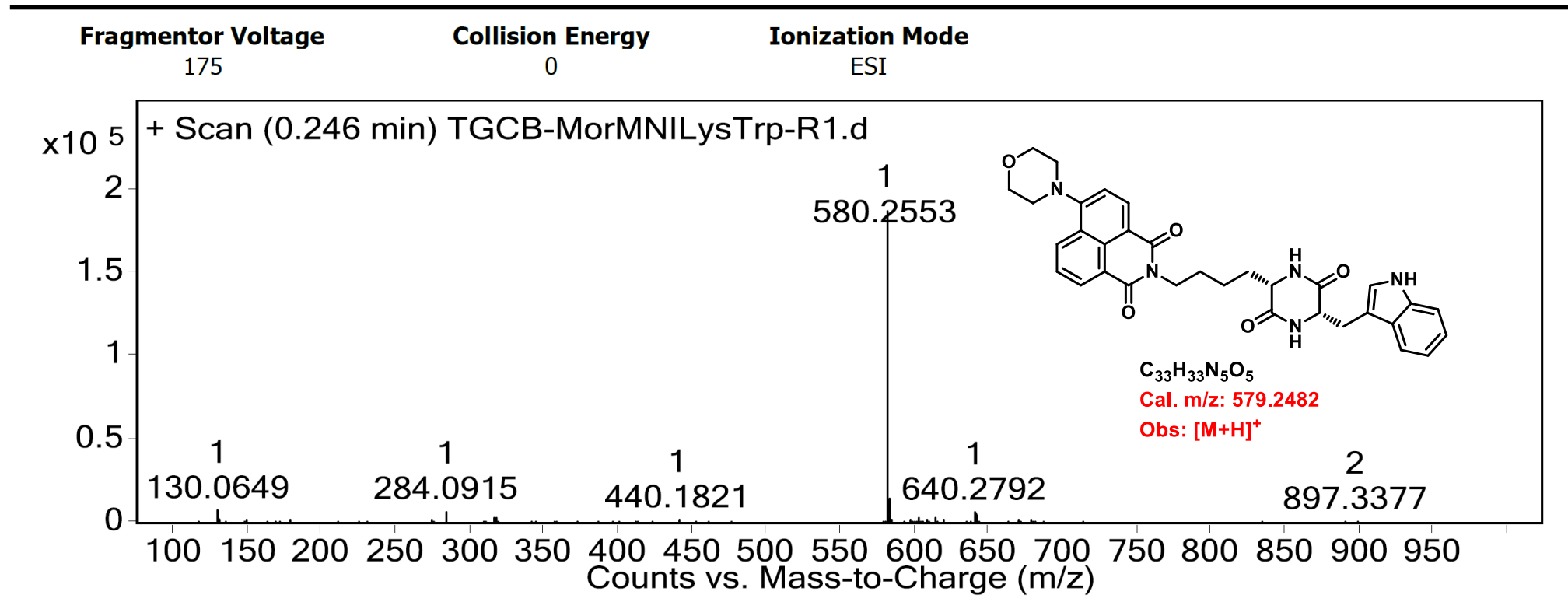




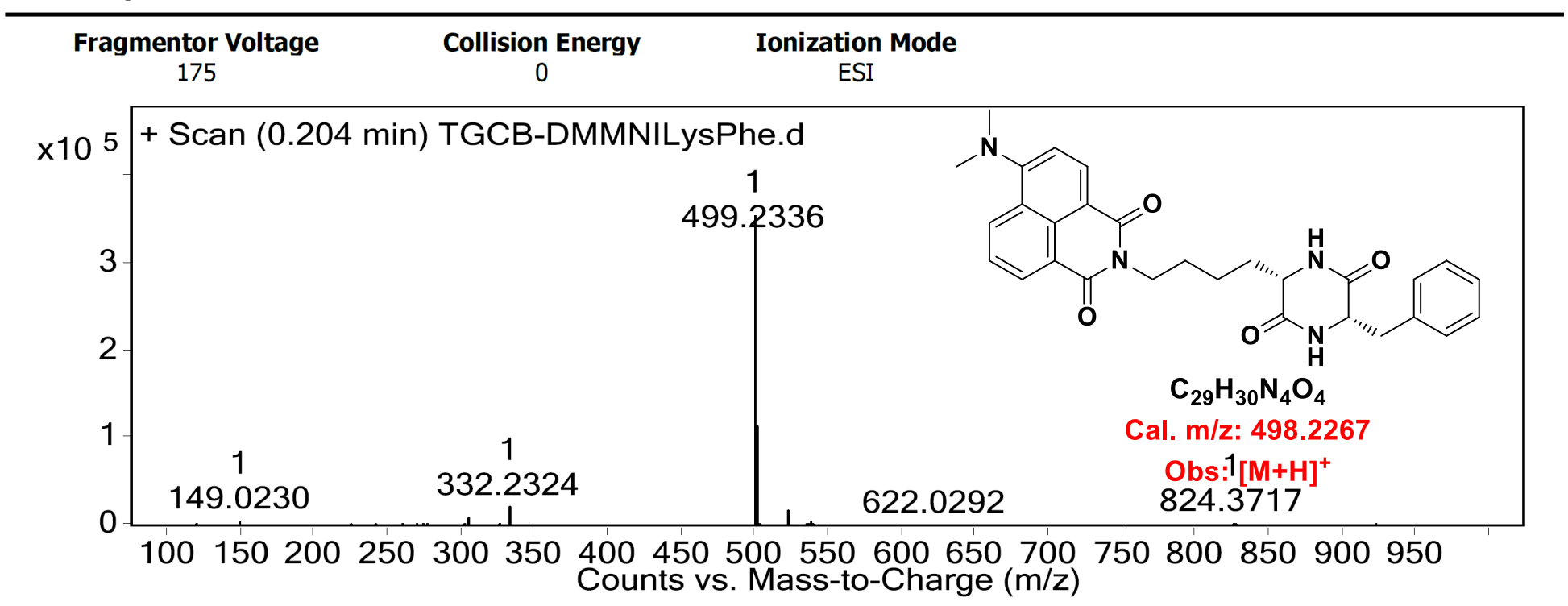

\section{User Spectra}

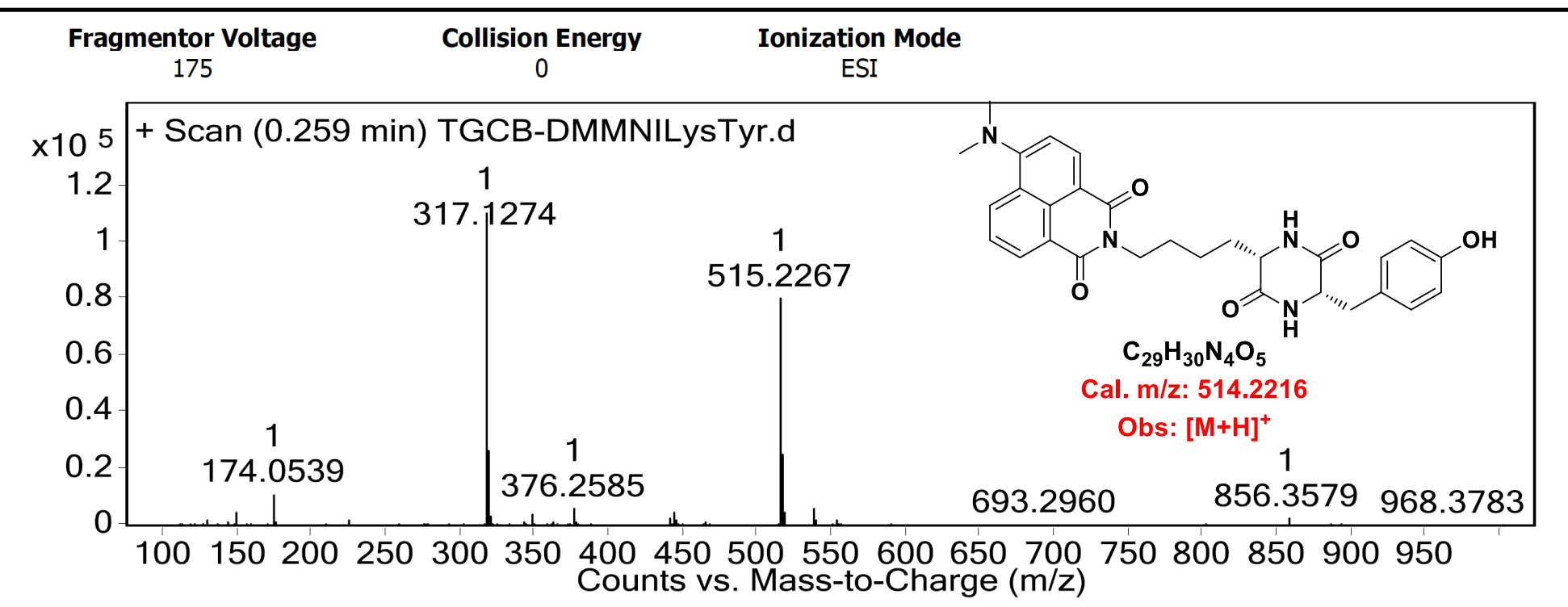

\section{User Spectra}

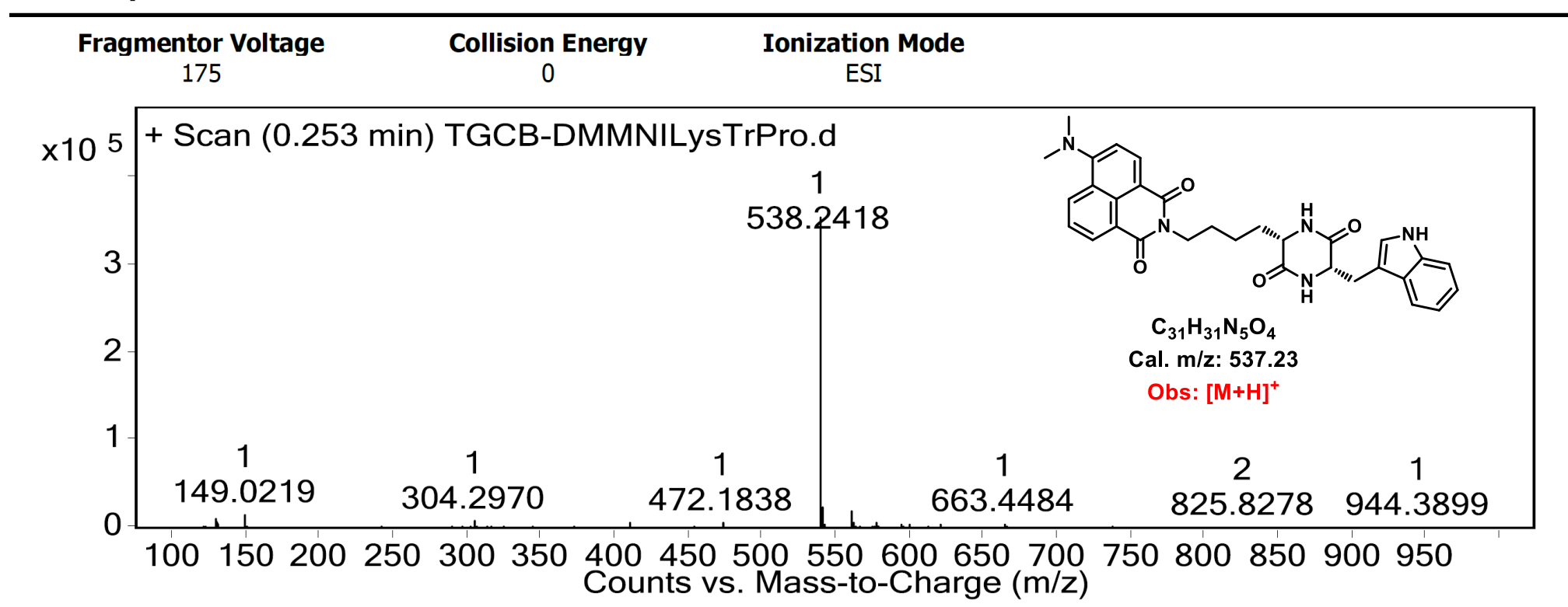

